\title{
Injection therapy for stress urinary incontinence in adult women
}

Citation for published version (APA):

Ter Meulen, PH. (2009). Injection therapy for stress urinary incontinence in adult women. [Doctoral Thesis, Maastricht University]. Maastricht University. https://doi.org/10.26481/dis.20090618pm

Document status and date:

Published: 01/01/2009

DOI:

10.26481/dis.20090618pm

Document Version:

Publisher's PDF, also known as Version of record

\section{Please check the document version of this publication:}

- A submitted manuscript is the version of the article upon submission and before peer-review. There can be important differences between the submitted version and the official published version of record.

People interested in the research are advised to contact the author for the final version of the publication, or visit the DOI to the publisher's website.

- The final author version and the galley proof are versions of the publication after peer review.

- The final published version features the final layout of the paper including the volume, issue and page numbers.

Link to publication

\footnotetext{
General rights rights.

- You may freely distribute the URL identifying the publication in the public portal. please follow below link for the End User Agreement:

www.umlib.nl/taverne-license

Take down policy

If you believe that this document breaches copyright please contact us at:

repository@maastrichtuniversity.nl

providing details and we will investigate your claim.
}

Copyright and moral rights for the publications made accessible in the public portal are retained by the authors and/or other copyright owners and it is a condition of accessing publications that users recognise and abide by the legal requirements associated with these

- Users may download and print one copy of any publication from the public portal for the purpose of private study or research.

- You may not further distribute the material or use it for any profit-making activity or commercial gain

If the publication is distributed under the terms of Article $25 \mathrm{fa}$ of the Dutch Copyright Act, indicated by the "Taverne" license above, 


\section{Injection Therapy for Stress Urinary Incontinence in Adult Women}

Philip Hendrik ter Meulen 
Philip Hendrik ter Meulen

Injection Therapy for Stress Urinary Incontinence in Adult Women

ISBN: 978-90-5681-355-0

NUR code: 876

Cover design by: Denkbeeld

Printed by: Océ Business Services, Maastricht

(C)2009, Philip Hendrik ter Meulen

No part of this thesis may be reproduced or transmitted in any form by print, photo print, microfilm or any other means without permission of the rightful claimant(s). This restriction concerns the entire publication or any part of it. 


\section{Injection Therapy for Stress Urinary Incontinence in Adult Women}

PROEFSCHRIFT

ter verkrijging van de graad van doctor aan de Universiteit Maastricht, op gezag van de Rector Magnificus, Prof.mr. G.P.M.F. Mols volgens het besluit van het College van Decanen,

in het openbaar te verdedigen op donderdag 18 juni 2009 om 16.00 uur

door

Philip Hendrik ter Meulen 


\section{Promotor}

Prof. Dr. Ph.E.V.A. van Kerrebroeck

\section{Co-promotor}

Dr. L.C.M. Berghmans

\section{Beoordelingscommissie}

Prof.dr.ir. L.H. Koole (voorzitter)

Prof.dr. C.G.M.I. Baeten

Prof.dr. R.A. de Bie

Dr. J.P.F.A. Heesakkers (UMC St. Radboud Nijmegen)

Prof.dr. J.G. Nijhuis 


\section{Contents}

Chapter 1 Introduction

Chapter 2 Injection therapy for stress urinary incontinence in adult women (Expert Rev Med Devices 2004;1(2):205-213)

Chapter 3 Efficacy and safety of a novel system (NASHA/Dx copolymer using the Implacer device) for treatment of stress urinary incontinence (Urology 2004;64:276-281)

Chapter 4 Treatment of stress urinary incontinence using a copolymer system: impact on quality of life (BJU Int 2004;94:1040-1043)

Chapter 5 NASHA/Dx gel (Zuidex ${ }^{\mathrm{TM}}$ ) for the treatment of stress urinary incontinence: results up to three year of follow-up (submitted)

Chapter 6 Systematic review: Efficacy of silicone microimplants (Macroplastique ${ }^{\circledR}$ ) therapy for stress urinary incontinence in adult women (Eur Urol $2003 ; 44: 573-582)$

Chapter 7 Effects of Macroplastique ${ }^{\circledR}$ Implantation System for stress urinary incontinence and urethral hypermobility in women (Int Urogynecol J 2009;20:177-183)

Chapter 8 Discussion and conclusions

Chapter 9 Summary

Chapter 10 Nederlandse samenvatting

Dankwoord

Curriculum Vitae 


\section{Chapter 1}

\section{Introduction}

Stress urinary incontinence (SUI) is a common and potentially debilitating problem. It can affect physical, social and physiological functioning and health perception, as well as in some cases sexual function, participation in employment and sleep $(1,2)$. The prevalence of SUI increases with age and tends to be higher in women, older people and an institutionalized population (3). In different older and more recent studies the prevalence varies considerably $(8-43 \%)$. This could be due to different definitions of SUI, design of the questionnaires, study population and selection criteria (4-8). Proportions of types of urinary incontinence (stress, urge and mixed) are difficult to estimate, and estimates vary considerably. Approximately half of all incontinent women are classified as stress incontinent (8). A recent study by Hannestad et al which included the entire age range demonstrates a decrease in prevalence of SUI from 40-49 year old age group through the 60-69 year old group (9). Another issue is the possible under-estimation of SUI due to underreporting and consequent under-diagnosis, as urinary incontinence is often considered to be an inevitable part of aging, and an embarrassing and untreatable condition $(10,11)$. In a recent survey (2004) performed in 4 European countries, it was reported that $60-76 \%$ of women had not consulted a physician for urinary incontinence (UI). About $50 \%$ of women with UI used pads and $2.1 \%$ have had a surgical procedure for their condition (12).

In 2002 the International Continence Society (ICS) reported definitions of symptoms, signs, urodynamic observations and conditions associated with lower urinary tract dysfunction and urodynamic studies (13). SUI as a symptom is the complaint of involuntary leakage on effort or exertion, or on sneezing or coughing. SUI as a sign is the observation of involuntary leakage from the urethra, synchronous with exertion/effort, or sneezing or coughing. The urodynamic observation of stress urinary incontinence is the involuntary leakage of urine 
when the intra-vesical pressure exceeds the urethral resistance as a result of increased intraabdominal pressure in the absence of a detrusor contraction (13).

A healthy, functioning striated sphincter, a well-vascularized urethral mucosa and submucosa, a properly aligned and functioning intrinsic urethral smooth muscle, and an intact vaginal wall support are necessary for the urethra to remain closed at rest and during increased abdominal pressure for preventing SUI. These factors are well characterized, but their functional inter-relationships are still not fully understood (14).

The pathophysiological concept of SUI is conventionally considered as a dichotomy, due to either urethral hypermobility (displacement, or prolapse of the vaginal wall) or intrinsic sphincter deficiency (ISD). Currently, there appears to be a shift away from this simple categorization to a continuum between both categories. This has arisen in part because of the development of the concept of Valsalva Leak Point Pressure (VLPP) and more recent analyses of long-term results of stress incontinence surgery. These results of correction of hypermobility have suggested that there may be more urethral weakness among patients with urethral hypermobility than had been previously considered (14).

Treatments for SUI include lifestyle modifications (losing weight, quitting smoking, regulating fluid intake), pelvic floor muscle training (PFMT), minimally invasive devices, pharmacotherapy, urethral injection and surgery (See flowchart from ICI 2005). Patient's and physician's preferences, co-existent problems, physical features of the patient affected and evidence of treatment often influence the choice of treatment. It seems logic that in the treatment algorithm of SUI, PFMT is first choice before further interventions for SUI (15). Several randomised controlled trials (RCTs) have demonstrated that PFMT is more effective than no treatment for SUI as described by Bø et al (16) and Hay-Smith and Dumoulin (17). Subjective cure/improvement rates of PFMT reported in RCTs vary between 56 and 70\% (16). Cure rates defined as $<2$ grams of leakage on different pad tests vary between 44 and 
$69 \%$ (16). Compared to surgery, PFMT has no known side effects, is relatively inexpensive, and women should be motivated to intensively perform PMFT as first line treatment (16). However, long-term success depends on compliance, adherence to therapy and how disciplined the woman is in continuing the exercises and on the availability of a skilled physiotherapist (18). If PFMT is not successful, the next option could be invasive therapy (See flowchart from ICI 2005). In general, surgery has been widely considered as the only effective treatment after conservative therapy (27). However, surgery is not suitable for all patients, and fear of complications may act as an obstacle (19). An alternative option is injection therapy with urethral bulking agents (UBA's) and is generally considered as a minimally invasive procedure for SUI (20-22). "Minimally invasive" is a relative term and can be viewed as minimally invasive from physician's or patient's perspective. Acceptance of injection therapy as the least invasive of all invasive procedures is progressing (20-22). Injection therapy is suggested to offer several potential advantages over other surgical procedures, including lower morbidity, shorter procedure time, shorter inpatient stay and more rapid recovery $(19,23)$. The procedure is most commonly based on day-case care and use of local or regional anesthesia.

In general, the outcome of treatment for SUI is often unsatisfactory. This reflects uncertainty about which of the available treatment options are the most appropriate and effective, which may in part be due to lack of standardization of diagnostic criteria and outcome parameters in studies investigating this issue $(24,25)$. The wide variety of surgical treatments for SUI indicates the lack of consensus as to which procedure is the best. Evidence based guidelines using the available literature have been published but were based on studies of moderate quality and type (26-29). Therefore, there is a growing need to justify the rationale for treatments, and to provide evidence that a treatment such as injection therapy does have effect on SUI and impact on patient's condition (26). 
In fact, the situation is similar for injection therapy with UBA's. Many UBA's have been developed, although the ideal one remains to be discovered $(19,30)$. Safety profile and durability of these agents remain a concern $(19,30)$. Different injection techniques of UBA's, endoscopic and non-endoscopic administration, have been used. Injection therapy can be offered for all types of SUI as will be discussed in chapter 2. UBA's were usually used for ISD related SUI, although there is good evidence that women with (concomitant) urethral hypermobility respond similarly (31).

The exact place of injection therapy in a treatment algorithm of SUI is still unknown. In a recent Cochrane systematic review (2007), the effectiveness of periurethral/transurethral injection therapy for urinary incontinence in women has been reviewed (32). The authors reported that paucity of published data made pooled statistical analysis inappropriate and prevented meta-analysis. However, data suggested subjective and objective short-term improvement of SUI in women. It was also noted that the transurethral route results in fewer complications compared with periurethral injection (less retention and urinary tract infection). No studies were found comparing injection therapy with pelvic floor muscle training. Two studies that compared injection therapy with surgical management (bladderneck suspension, Burch colposuspension, and pubovaginal sling) found statistically significant better objective outcome in the surgical group $(33,34)$. Although no statistical significant difference in subjective outcome was reported between these groups. The complications (complete retention, transient difficult voiding, and urinary infection) were statistically significant more frequent in the surgery group.

In recent years, several suburethral tapes have reduced drawbacks (impact on hospitalization and convalescence, harvesting fascial sling) of other surgical suspension techniques. These tapes seem to result in high cure rates (84-95\%) and remain stable over time, with a reported $85 \%$ of patients cured and $11 \%$ with significant improvements after 5 years (35-37). 
Although the adverse events of tapes are still substantial and can have a serious impact on quality of life, such as bladder perforation (0.5-14\%), voiding difficulties (1.4-15\%), vaginal erosion (0.7-33\%), urethral erosion (2.7-33\%), de novo urgency (7.2-25\%) (38). Voiding difficulties, such as weak stream and retention, can persist in the long term ( $3 \frac{1}{2}$ years; 39$)$. Also sexual impairment including dyspareunia and loss of libido can occur (40). Even seven deaths after the first 500000 TVT procedures have been reported (41).

The general public becomes more informed about medicine in general and their health in particular, which may mean that treatments known to have few or no side-effects are preferable to those for which unwanted side-effects have been recorded. The availability of multiple SUI treatment options with variable risk-benefit profiles underscores the need for detailed informed consent and discussions of woman's goals and expectations. In a survey (2003) patients with SUI indicated that most of them preferred lesser invasive treatment, even if they would have to accept a lesser chance of cure (42). In this perspective, a minor invasive procedure, such as injection therapy with UBA's, might be preferable compared to more invasive therapies as suburethral tape, colposuspension, and artificial urinary sphincterprothese.

Randomized clinical trials (RCT's) are needed to establish the place and efficacy of injection therapy with UBA's compared with other treatments of SUI in adult women. Most studies of injection therapy with UBA's were designed for ISD related SUI. If there was concurrent urethral hypermobility this could have been a reason for exclusion in such a study. Because the dichotomy mentioned above had changed into the direction of a continuum between ISD and urethral hypermobility, a RCT was designed to study the effect of UBA Macroplastique ${ }^{\circledR}$ in adult women with urodynamic stress urinary incontinence and urethral hypermobility after non-successful conservative treatment with measurement of VLPP as an indicator for ISD. 
The aim of this thesis is to evaluate efficacy, safety, and durability of UBA's using new techniques of transurethral injection as a minimally invasive procedure with quality of life aspects for SUI in adult women and to assess its place in a treatment algorithm of SUI.

Chapter 2 presents a general review of injection therapy with different UBA's for stress urinary incontinence in adult women.

Chapter 3 discusses the efficacy and safety data of non-animal stabilized hyaluronic acid/dextranomer (NASHA/Dx) copolymer used for transurethral injection with a new guiding instrument (the Implacer) for stress urinary incontinence in adult women. Chapter 4 describes the effect on quality of life of this novel product (non-animal stabilized hyaluronic acid/dextranomer [NASHA/Dx] copolymer), injected transurethral with a new guiding instrument (the Implacer) for stress urinary incontinence in adult women. Chapter 5 discusses the durability of this non-animal stabilized hyaluronic acid/dextranomer (NASHA/Dx) copolymer for treating stress urinary incontinence in adult women. Chapter 6 contains a systematic review about the efficacy of another UBA, silicone microimplants (Macroplastique ${ }^{\circledR}$ ) for stress urinary incontinence in adult women. Chapter 7 describes a randomised clinical trial of the Macroplastique $\AA^{\circledR}$ Implantation System, as a minimally invasive procedure in adult women with urodynamic stress urinary incontinence and urethral hypermobility after non-successful conservative treatment. A discussion and conclusions regarding injection therapy for stress urinary incontinence in adult women are presented in chapter 8 . 


\section{References}

1. Hagglund D, Walker-Engstrom ML, Larsson G, et al. Quality of life and seeking help in women with urinary incontinence. Acta Obstet Gynecol Scand 2001;80:1051

2. Simeonova Z, Milsom I, Kullendorff AM, et al. The prevalence of urinary incontinence and its influence on the quality of life in women from an urban Swedish population. Acta Obstet Gynecol Scand 1999;78:546-51.

3. Elving LB, Foldspang A, Lam GW, et al. Descriptive epidemiology of urinary incontinence in 3,100 women ages 30-59. Scand J Urol Nephrol Suppl 1989;125:3743.

4. Diokno AC, Brock DM, Brown MB, Herzog AR. Prevalence of urinary incontinence and other urological symptoms in the non-institutionalized elderly. J Urol 1986;136:1022-1025.

5. Dolan LM, Casson K, McDonald P, Ashe RG. Urinary incontinence in Northern Ireland: a prevalence study. BJU International 1999;83:760-766.

6. Hunskaar S, Burgio K, Diokno AC, Herzog AR, Hjamas K, Lapitan MC. Epidemiology and natural history of urinary incontinence in women. Urology 2003;62(Suppl 4A):16-23.

7. Kondo A, Kato K, Saito M et al. Prevalence of handwashing urinary incontinence in females in comparison with stress and urge incontinence. Neurol Urodyn 1990;9:330331.

8. Hunskaar S, Burgio K, Clark A, Lapitan MC, Nelson R, Sillén, Thom D. Epidemiology of urinary (UI), and faecal (FI) incontinence and pelvic organ prolapse (POP). In: Abrams P, Cardozo L, Khoury S, Wein A (Eds): Incontinence. Paris, France, Health Publication Ltd, 2005, 265-280. 
9. Hannestad YS, Rortveit G, Sandvik H, Hunskaar S. A community-based epidemiological survey of female urinary incontinence: the Norwegian EPINCONT study. Epidemiology of Incontinence in the County of Nord-Trøndelag. J Clin Epidemiol 2000;53(11):1150-7

10. Goldstein M, Hawthorne ME, Engeberg S, et al. Urinary incontinence. Why people do not seek help. J Gerontol Nurs 1992;18:15-20.

11. Haslam J. Urinary incontinence: why women do not ask for help. Nurs Times $2005 ; 101(47): 47-8$

12. Hunskaar S, Lose G, Sykes D, Voss S. The prevalence of urinary incontinence in women in four European countries. BJU International 2004;93:324-330.

13. Abrams P, Cardozo L, Fall M, Griffiths D, Rosier P, Ulmsten U, van Kerrebroeck P, Victor A, and Wein A . The standardisation of terminology of lower urinary tract function. Neurolog Urodyn 2002;21:167-78.

14. Mostwin J, Bourcier A, Haab F, Koelbl H, Rao S, Resnick N, Salvatore S, Sultan A, Yamaguchi O. Pathophysiology of urinary incontinence, fecal incontinence and pelvic organ prolapse. In: Abrams P, Cardozo L, Khoury S, Wein A (Eds): Incontinence. Paris, France, Health Publication Ltd, 2005, 436-443.

15. Wilson PD, Berghmans B, Hagen S, Hay-Smith J, Moore K, Nygaard I, Sinclair L, Yamanishi T, Wyman J, Dorey G. Adult conservative management. In: Abrams P, Cardozo L, Khoury S, Wein A (Eds): Incontinence. Paris, France, Health Publication Ltd, 2005,857-885.

16. Bø K. Is there still a place for physiotherapy in the treatment of female incontinence? EAU Update Series 2003; 1:145-153. 
17. Hay-Smith EJ, Desmoulins C. Pelvic floor muscle training versus no treatment, or inactive control treatments, for urinary incontinence in women. Cochrane Database Sits Rev 2006 Jan 25;(1):CD005654.

18. Alewijnse D. Urinary incontinence in women. Long term outcome of pelvic floor muscle exercise therapy. Maastricht: Health Research Institute for Prevention and Care/Department of Health Education and Health Promotion; 2002.

19. Chapple CR, Wein AJ, Brubaker L, Dmochowski R, Espuna Pons M, Haab F, Hill S. Stress incontinence injection therapy: what is best for our patients? Eur Urol $2005 ; 48: 552-65$.

20. Usman F, Henalla S. A single transurethral macroplastique injection as primary treatment for stress incontinence in women. J Obstet Gynecol 1998;18:56-60.

21. Stenzl A, Strasser H. Submucosal bladder neck injections for management of stress urinary incontinence. Braz J Urol 2000; 26:199-207.

22. Tamanini JT, D’Ancona CA, Netto NR. Macroplastique Implantation System for female stress urinary incontinence: long term follow-up. J Endourol 2006;20(12):826.

23. Shah J. Injectables and stress urinary incontinence. Urol News 1997;2:7-11.

24. Blaivas JG, Appell RA, Fantl JA, Leach G, McGuire EJ, Resnick NM et al. Definition and classification of urinary incontinence: recommendations of the Urodynamic Society. Neurol Urodyn 1997;16(3):149-51.

25. Blaivas JG, Appell RA, Fantl JA, Leach G, McGuire EJ, Resnick NM et al. Standards of efficacy for evaluation of treatment outcomes in urinary incontinence: recommendations of the Urodynamic Society. Neurol Urodyn 1997;16(3):145-147. 
26. Fantl JA, Newman DK. Urinary incontinence in adults: Acute and Chronic Management. 2 edition. Washington: Agency for Health Care Policy and Research, US Government Printing Office, 1996.

27. Leach GE, Dmochowski RR, Appell RA, Blaivas JG, Hadley HR, Luber KM et al. Female stress urinary incontinence clinical guidelines panel summary report on surgical management of female stress urinary incontinence. The American Urological Association. J Urol 1997;158:875-880.

28. NICE guidelines.

29. Berghmans LCM, Bernards ATM, Bluyssen AMWL, Grupping-Morel MHM, Hendriks HJM, de Jong-van Ierland MJEA, Raadgers MC. KNGF-richtlijn Stress Urine-Incontinentie. Ned T v Fysiotherapie (supplement) 2005;115(1).

30. Haverkorn RM, Gomelsky A. Bulking agents for stress urinary incontinence: are they still indicated? Current Bladder Dysfunction Reports 2008;3:26-31.

31. Herschorn S. Current role of injectable agents for female stress urinary incontinence. Can J Urol 2006;13 suppl 1:5-12.

32. Keegan PE, Atiemo K, Cody J, McClinton S, Pickard R. Periurethral injection therapy for urinary incontinence in women. Cochrane Database of Syst Rev. 2007 Jul 18;(3):CD003881.

33. Corcos J, Collet JP, Shapiro S, Herschorn S, Radomski SB, Schick E, Gajewski JB, Benedetti A, Macramallah E, and Hyams B. Multicenter randomized clinical trial comparing surgery and collagen injections for treatment of female stress urinary incontinence. J Urol 2005;65:898-904.

34. Maher CF, O’Reilly BA, Dwyer PL, Carey MP, Cornish A, Schluter P. Pubovaginal sling versus transurethral Macroplastique for stress urinary incontinence and intrinsic 
sphincter deficiency: a prospective randomised controlled trial. BJOG 2005;112:797801.

35. Meschia M, Pifarotti P, Bernasconi F, et al. Tension-free vaginal tape: analysis of outcomes and complications in 404 stress incontinent women. Int Urogynecol J Pelvic Floor Dysfunct 2001;12(Suppl 2):S24-7.

36. Olsson I, Kroon U. A three-year postoperative evaluation of tension-free vaginal tape. Gynecol Obstet Invest 1999;48:267-9.

37. Nilsson CG, Kuuva N, Falconer G, Rezapour M, Ulmsten U. Long-term results of the tension-free vaginal tape (TVT) procedure for surgical treatment of female stress urinary incontinence. Int Urogynecol J Pelvic Floor Dysfunct 2001;12(suppl 2):S5-8.

38. Costantini E, Lazzeri M, Porena M. Managing complications after midurethral sling for stress urinary incontinence. Eur Urol Update Series 5;2007:232-240.

39. Sander P, Sørensen F, Lose G. Does the tension-free vaginal tape procedure (TVT) affect the voiding function over time? Pressure-flow studies 1 year and $3(1 / 2)$ years after TVT. Neurourol Urodyn 2007;26:995-7.

40. Mazouni C, Karsenty G, Bretelle F, Bladou F, Gamerre M and Serment G. Urinary complications and sexual function after the tension-free vaginal tape procedure. Acta Obstet Gynecol Scand 2004;83:955-961.

41. Burkhard FC, Heesakkers J. The motion: tapes and not bulking agents/drugs are first line treatment of SUI. Eur Urol 2005;52:914-917.

42. Robinson D, Anders K, Cardozo L, et al. What do women want? Interpretation of the concept of cure. J Pelvic Surg Med 2003;9:273-7. 
Flowchart (management recommendation for SUI) from ICI 2005 (Abrams P, Artbani

W, Cardozo L, Wein A. Clinical Manual of Incontinence in Women. Based on the Reports of the $3^{\text {rd }}$ International Consultation on Incontinence 2005)

Initial treatment:

1. Assess oestrogen status and treat as appropriate, life style interventions, pelvic floor muscle training

2. Other physical therapies, devices

3. Dual serotonin and noradrenaline reuptake inhibitors (subject to local regulatory approval)

\section{If initial therapy fails:}

4. Surgery; injections, low tension slings, colposuspension, artificial urinary sphincterprothese 


\section{Chapter 2}

Injection therapy for stress urinary incontinence in adult women

Ph.H. ter Meulen and Ph.E.V.A. van Kerrebroeck

Department of Urology, University Hospital Maastricht, the Netherlands

Journal: Expert Rev Med Devices 2004;1(2):205-213. 


\begin{abstract}
Stress urinary incontinence (SUI) is prevalent in adult women and has a considerable impact on quality of life. However, it often remains undiagnosed and therefore untreated.

Noninvasive treatment is likely to be offered in mild cases and may entail pelvic floor muscle re-education, minimally invasive devices or pharmacotherapy. Surgical intervention is widely considered as the only effective option for more severe SUI, although it is not suitable for all patients. Injection therapy with urethral bulking agents represents an alternative minimally invasive procedure and can be used for all types of SUI. Many bulking agents have been developed, although the ideal remains to be discovered. The safety and durability of agents remain a concern. No differences in agents from an efficacy point of view have been found. For many years urethral injection could only be administered endoscopically. The recent development of devices for blind injection has increased the speed and convenience of urethral injection, removing the need for surgical facilities. The subjective cure rate after injection therapy is higher than the objective one. A focus on patient's wishes and expectations with respect to success and risks of a treatment for SUI is required. In addition, randomized clinical trials are mandatory to establish the place and efficacy of urethral bulking agents compared with conservative therapy (pelvic floor muscle re-education) in treating SUI in adult women.
\end{abstract}

Keywords: adult woman, injectable, urethral bulking agent, urinary stress incontinence.

\title{
Introduction
}

Stress urinary incontinence (SUI) is a common clinical problem in adult women and a significant cause of disability and dependence. The incidence of the condition increases with age (1). It can affect women of all ages and has a prevalence of $10-30 \%$ in girls and women 
between 15 and 64 years, and more than $50 \%$ of nursing home residents (2). SUI affects around a third of women of childbearing age (3). The prevalence of SUI in adult women is liable to be under-estimated due to under-reporting and consequent under-diagnosis, as urinary incontinence is often considered to be an inevitable part of aging and an embarrassing and untreatable condition (4). Another issue is that prevalence studies are hampered by a lack of agreed definition of SUI. Increasing age and childbirth are relative risk factors of SUI, while other pre-disposing factors include obesity, smoking, previous urogenital surgery and restricted mobility (5). In a histological post mortem study, an age-dependent reduction in the number of striated muscle cells in the rhabdosphincter due to apoptosis was noted (77). SUI affects the physical, psychological and social well-being of a patient, thus having a considerable impact on quality of life (6). The patient and physician should discuss the available options for treating SUI, and patients should be informed of the relative benefits and risks for each option. The treatment options for SUI are pelvic floor muscle re-education, minimally invasive devices, pharmacotherapy, urethral injection and surgery. The choice of treatment will depend on the patient's preference, condition, and urodynamic diagnosis and also the physician's experience and preference. Injection therapy with urethral bulking agents for SUI seems to be an attractive option. The procedure is generally considered by patients and surgeons as minimally invasive. This article will present the current status of injection therapy with urethral bulking agents for treating SUI in adult women.

\section{Clinical presentation of SUI}

SUI is defined as the symptom of involuntary loss of urine associated with physical exertion (such as coughing, sport, and changes in position). It is a symptom, not a condition, which may be caused by pathological, anatomical or physiological factors (7). The International Continence Society (ICS) defines 'urodynamic stress incontinence' as the involuntary 
leakage of urine, when the intravesical pressure exceeds the urethral resistance, as a result of increased intra-abdominal pressure in the absence of a detrusor contraction (7). Diagnosis based on this definition requires invasive urodynamic_evaluation in addition to history taking, physical examination, frequency/volume charts and urine analysis. Invasive urodynamic evaluation, in addition to clinical assessment, is required for accurate diagnosis although its usefulness in improving outcome remains uncertain (11). SUI may be classified into three specific types according to anatomic classification of Blaivas (Table $1 ; 8$ ), although this system requires video-urodynamics or cystoscopy and not all cases require such thorough investigation. Urethral hypermobility (Type 1 and 2) and intrinsic sphincter deficiency (ISD; Type 3) may (and often do) coexist in the same patient. The severity of incontinence may influence the type of treatment offered to patients. Pelvic floor muscle re-education should be considered as first-line therapy for mild SUI, while urethral injection or surgery are the likely candidates for patients with severe SUI (9). The extent to which urethral hypermobility and ISD contribute to the condition is another consideration in the treatment decision and has been identified as a key influence on the choice of surgical intervention (10). Although, there is still no evidence that such a distinction alters the outcome of treatment.

\section{Patient selection}

In general, optimal patient selection for injection therapy seem to be elderly women, patients with high operative risk, those who refuse open surgery, those following multiple previous pelvic surgery and radiotherapy, or those with SUI due to intrinsic sphincter deficiency (12). Injection therapy might also be a good option for those women who wish for pregnancy/delivery. Patients with SUI, caused by a combination of urethral hypermobility and intrinsic sphincter deficiency, with failure of urethral suspension, may also benefit from this procedure (12). Bladder neck hypermobility may decrease the success of injection 
therapy (13-16). However, some studies have reported a positive outcome of periurethral collagen injections in patients with SUI caused by urethral hypermobility $(17,18)$. In other

studies, no differences in success between SUI with and without urethral hypermobility could be found (19-21). Success seemed to be independent of age, parity, previous pelvic surgery, severity of incontinence, or concomitant a small or mild cystocele $(13,22-24)$. However, patients with no previous anti-incontinence surgery appear to have subjectively and objectively superior results in comparison with patients after previous anti-incontinence surgery (25). It is likely that pre-existent and de novo idiopathic detrusor overactivity are negative prognostic factors for success. Patients with gross pelvic organ prolapse are not suitable for injection therapy (26).

\section{Mechanism of action of injectables}

The basic principle of endoscopic injection of bulk-enhancing agents for treating SUI is the provision of an additional submucosal bulk in the area of the bladder neck (mid-urethra) in women. The mechanism of restoring continence after successful injection therapy remains unclear. Three possible mechanisms of action can be hypothesized:

1. A bulking agent will augment the urethral mucosa, improve coaptation and intrinsic sphincter function, resulting in an increase of urethral closing pressure and restoring urinary incontinence (27).

2. Radley and colleagues reported that firm nodules were realized 6 weeks after polydimethylsiloxane implantation submucosal in the proximal urethra (28). These findings suggest that the mechanism of action of polydimethylsiloxane is augmentation of pressure transmission to the proximal urethra by producing focal and firm expansion of periurethral tissue (28). In some studies an obstructive component with a decrease in maximum flow and 
an increase in maximum detrusor pressure has been reported $(17,29,30)$. Other authors have suggested that obstruction is not the mechanism of restoring continence $(12,14,31,32)$.

3. In successfully treated patients, injections result in a cephalad elongation of the urethra with a concomitant increase in pressure transmission ratio in the first quarter of urethral length. These changes are due to adequate injection at the bladder neck or proximal urethra preventing bladder neck opening during stress $(12,14,31,32)$. Therefore, exact placement of the injection material is important to achieve continence.

The choice of bulking agent is crucial to the safety and efficacy of urethral injection for SUI. The ideal agent should be nonimmunogenic, biocompatible, nontoxic and hypoallergic. Moreover, a bulking agent should be effective and demonstrate anatomical integrity, bonds to local tissues with minimal inflammation, retain its injected volume, not migrate to vital organs (particle diameter greater than $80 \mu \mathrm{m}$ ), should be easy to use and be cost effective (33).

\section{History of injectables}

For many years various injectables or urethral bulking agents have been used in treating SUI in adult women. In 1938, Murless produced the first report after injection of a sclerosing solution (sodium morrhuate) into the anterior wall of the vagina of 20 incontinent women, obtaining temporary scarring of the juxtaurethral tissue (34). In 1955, Quackels described 2 cases treated with paraffin injection into the perineum, restoring continence by compression of the membranous urethra (35). In 1963, Sachse described the use of the sclerosant Dondren into the urethra with some success (36). Local tissue damage and pulmonary complications, including pulmonary infarction and emboli, restricted continuation of their use. In the early 1970s, Berg (37) and Politano (38) first described the use of polytetrafluoroethylene (PTFE; Teflon $\left.{ }^{\circledR}\right)$ injections around the urethra. Evidence of urethral scarring due to fibrosis, 
granuloma formation at injection site, particle migration, carcinogenic potential has now stopped the clinical use of this product (39-45). Another agent, autologous fat, is attractive in terms of reduced immunogenicity. Fat cells are harvested from the abdominal wall by liposuction. One study compared periurethral injection of this agent with placebo injection of saline and no difference was found in subjective or objective outcome measures between the two groups (46). One death attributed to fat embolization, urethral lipoma, and connective tissue replacement has been reported after autologous fat injection (47-49). The poor efficacy and unsatisfactory safety profile of this injectable have resulted in its discontinuation of use as a urethral bulking agent (50).

\section{Current available injectables}

A list of currently available injectables, as discussed below, is provided in Table 2.

\section{Bovine collagen}

Bovine collagen (Contigen $\left.{ }^{\circledR}\right)$ is well established as bulking agent for urethral injection. No risk of granuloma formation or migration with this agent has been reported (27). However, allergic reaction occurs in approximately $4 \%$ of females. Therefore, preinjection skin testing must be performed 30 days prior to treatment (33). The initial success rate (cure/improved) of collagen injection therapy for ISD is $85-94 \%(33,51)$. However, the proportion of patients remaining continent declines considerably over time following collagen injection. The longterm (greater than 2 years) success rate is not as favorable $(26-65 \%)(33,52)$. Repeat injections are usually required in the majority of patients to achieve continued continence (19). This may be attributable to in vivo degradation of the implant, a phenomenon that has been noted in animal studies (53). The overall complication rate for collagen injection is $20 \%$; urinary tract infection $4 \%$, hematuria $5 \%$, transient urinary retention $1.9-8 \%$, de novo 
urgency $12.6 \%$, and delayed skin reaction associated with athralgia $0.9 \%(33,54)$. Cost effectiveness remains a concern due to the need for repeat injections (55).

\section{Silicone}

Silicone (Macroplastique ${ }^{\circledR}$ ) is a soft tissue-bulking agent and is comprised of soft, flexible, highly textured irregularly shaped implants of heat vulcanized polydimethylsiloxane (a solid silicone elastomer), suspended in a bioexcretable carrier gel. The particle sizes of polydimethylsiloxane varied between 120 and $264 \mu \mathrm{m}(56,57)$. The risk of biodegradation and migration of polydimethylsiloxane appear to be nonexistant (56). No evidence has been reported that silicone elastomers are associated with connective tissue disease (58). The agent must be injected with a high-pressure injection gun due to its viscous nature.

Recently, a systematic review has been preformed to assess the efficacy of silicone microimplants for treating SUI in adult women (59). Reported cure and success rates (cured and improved) using silicone microimplants for only intrinsic sphincter deficiency varied between 14 and $66.7 \%$, and 46 and $80 \%$, respectively. For intrinsic sphincter deficiency with urethral hypermobility, the cure and success rates varied between 0 and $21.4 \%$, and 0 and $58.9 \%$, respectively. Follow-up of the studies varied between 3 months and 3 years and showed decreased success rates in six studies $(13,15,22-24,60)$. None of the studies reported major complications during or after the procedure. Only minor and transient complications, including dysuria, frequency, hematuria, postoperative pain, and urinary retention requiring intermittent catheterisation, have been described. The included studies showed a poor methodological quality and, therefore, results should be interpreted with caution.

\section{Carbon-coated zirconium beads}

Carbon-coated zirconium beads in a gel containing $\beta$-glucan (Durasphere ${ }^{\circledR}$ ) is the most recent bulking agent to be approved by the US Food and Drug Administration (FDA) in 1999. The beads are nonantigenic and size ranges from 251 to $300 \mu \mathrm{m}(61)$. Although 
carbon-coated zirconium beads are reported as being nonmigratory (61), Pannek and colleagues observed migration into local and distant lymph nodes (62).

A recent study conducted in 355 women compared the safety and efficacy of carbon-coated zirconium beads with bovine collagen for the treatment of ISD (61). At 12 months after the first injection, $80.3 \%$ of women in the carbon-coated zirconium beads group had improvement in continence grade versus $69.1 \%$ in the bovine collagen group. However, no significant difference in subjective and objective outcome between the two groups was noted. Fewer carbon-coated zirconium beads were injected in order to obtain comparable clinical results. The adverse events reported for both groups were similar; the carbon-coated zirconium beads had an increased short-term risk of urgency and urinary retention.

\section{Calcium hydroxylapatite}

Calcium hydroxylapatite (Coaptite $\left.{ }^{\circledR}\right)$ is a synthetic version of material found naturally in bone and teeth. It is a nonantigenic bulking agent consisting of hydroxylapatite spheres in an aqueous gel composed of sodium carboxylmethylcellulose. Calcium hydroxylapatite is formulated to prevent distant migration (particle size 75-125 $\mu \mathrm{m}$ ) (63). Animal studies have shown this material to be biocompatible, nonencapsulating, and adhesive to in-growing collagen fibres with little inflammation. Plain film radiography or ultrasonography will identify calcium hydroxylapatite at the injection site (33).

In a pilot study, ten women with a history of SUI (ISD with limited urethral hypermobility) were treated with calcium hydroxylapatite particles as a bulking agent (63). Three women received one injection and seven received two injections. At 12 months after the last injection, seven women reported substantially improved continence and two used fewer pads. No adverse events were identified and migration was not reported.

\section{Dextranomer/hyaluronic acid $(\mathrm{Dx} / \mathrm{HA})$ copolymer}


Dextranomer/hyaluronic acid (Dx/HA) copolymer (Zuidex $\left.{ }^{\circledR}\right)$ comprises dextranomer microspheres $(80-250 \mu \mathrm{m})$ in a gel of nonanimal stabilized HA. Both constituents are biocompatible, biodegradable and nonimmunogenic, and carry no risk of migration (64-66). Dx/HA copolymer has been demonstrated to be stable, and has a high safety and efficacy profile $(65,67,68)$. A preliminary 3 -month clinical study to examine the efficacy and safety of Dx/HA copolymer for the treatment of SUI has been conducted in 20 women with ISD and/or hypermobility (65). After 3 months 17 of the 20 patients were cured or showed improvement and there was no decline in the 17 women followed for a further 3 months. One case of granuloma formation causing urinary obstruction in a woman has been reported 5 years after injection of Dx/HA copolymer (78).

\section{Ethylene vinyl alcohol copolymer}

Ethylene vinyl alcohol copolymer (Uryx $\left.{ }^{\circledR}\right)$ is dissolved in a dimethyl sulfoxide (DMSO) carrier. Upon contact with an aqueous_environment, such as the submucosal tissues of the urethra, the DMSO solvent diffuses away, resulting in precipitation of the copolymer, which forms a cohesive spongy mass, creating a bulking effect. A large-scale North American trial is in progress. At 12 months, $74 \%$ of 40 Uryx patients were dry compared with $40 \%$ of 23 collagen patients. Rates of postimplantation urgency and dysuria were the same across both groups (79).

\section{Experimental agents}

The search for urethral bulking agents that fulfill the ideal criteria continues. Currently, agents as silicone microballoons, alginate gels, autologous ear chondrocytes and autologous myoblasts are subjects in phase 1 and 2 studies (50). Autologous chondrocytes are isolated from ear cartilage, expanded in culture and formulated with calcium alginate to form an injectable gel. In a preliminary study, 32 women with ISD were treated with a single injection of autologous chondrocytes. Using both objective and subjective measures, $50 \%$ of the 
patients were dry at 12 months. Of 32 patients $(81.3 \%), 26$ were dry or improved at 3 months after the injection and maintained the effect at 12 months (80). In a study in male rats, muscle precursor cells from limb myofiber explants were isolated, and injected into the damaged sphincter of the same animal. Motor units were formed that contract under stimulation of sphincteric nerves and partial restoration of sphincteric function was noted (81).

\section{Injection techniques}

\section{Trans- and periurethral administration}

The endoscopic injection procedure can be performed under general, regional or local anaesthesia. During the transurethral procedure, under direct cystoscopic vision the needle is placed submucosally into the urethra at the 6,10 and 2 o'clock positions, 1.5 to $2.0 \mathrm{~cm}$ distal from the bladder neck. The material is slowly injected until a sufficient mucosal bleb is achieved. The procedure is completed if there is a total mucosal apposition together with occlusion of the urethral lumen. The injectable can also be administered periurethrally. This procedure is performed under cystoscopic control by inserting a spinal needle percutaneously adjacent to the urethra. After injecting, the cystoscope should not be advanced past injected areas and only small in and out catheters (8-12 Fr) should be inserted, as this may result in compression or extrusion of the bulking agent.

An important aspect of endoscopic administration is accurate positioning of the implant to achieve continence $(27,69)$. An endoscopic procedure seems to be superior to periurethral application or ultrasound-guided injection for treating incontinence (70). Radley and colleagues reported success to be associated with complete encirclement of the urethra by polydimethylsiloxane (25). If polydimethylsiloxane treatment failed, transvaginal or transurethral ultrasound could be performed to investigate correct placement of polydimethylsiloxane. 
Precise placement of the bulking agent is difficult because of the mobility of the urethra and folding of the inner epithelium. Care is required to ensure that the needle is not placed too close to the urethral lumen to avoid the risk of mucosal rupture and extravasation. In addition, the second and third injections must be positioned correctly with respect to the first injection, as there is a risk of puncturing the previous implant. The need for precision is complicated by impaired vision from the endoscope, owing to the need for a continual water flush.

Probably, these factors have contributed to the variability in published outcomes with urethral injection.

\section{Semi-automated devices}

To improve, simplify and standardize the transurethral implantation technique, and to minimize problems associated with endoscopic procedures, devices allowing blind administration of urethral injection have recently been developed specifically for use with silicone and Dx/HA copolymer. This procedure can be performed under local anesthesia in a consulting room without surgical facilities. The Macroplastique ${ }^{\circledR}$ Implantation System (MIS) was the first to administer blind urethral injection (Figure1). The device allows constant placement of the implants at predefined depths and angles at the 6,10 and 2 o'clock position of the mid-urethra within the same circumferential plane. In order to identify the site of implantation correctly, the ruler measuring-scale on the topside of the device is used. The site of the bladder neck is identified as the position where the water flow from the fluid drainage channel ceases while the tip of the device is slowly withdrawn from the fluid-filled bladder. The standard implantation position is defined by withdrawing the device from the urethra to the appropriate location of the mid-urethra, i.e., a 10-15 $\mathrm{mm}$ distance from the level of the bladder neck.

Henalla and colleagues reported a 3-month study of the safety and efficacy of the MIS in 40 women with SUI, which included assessment of patient and physician acceptability of the 
procedure (71). Operator acceptance of this procedure was excellent or acceptable in $95 \%$ after first treatment and $100 \%$ after retreatment. Urethral insertion was rated as acceptable in $92.5 \%$ of the procedures. In $89 \%$ of the implantation procedures, mild or moderate pain was experienced. An overall success rate of 53\% was reported 3 months after the first treatment, increasing to $74 \%$ after retreatment. Another study reported 12-month results of this system in 21 women with ISD (72). The study demonstrates a subjective rate of cure of $57.1 \%$ and cure/improvement of $76.2 \%$. Surgeon assessment revealed a decrease in cure and improvement from 90.5 to $66.7 \%$ after a 6-month period. Urodynamic testing (using Valsalva leak point pressure) demonstrated that eight patients (40\%) were dry and one (5\%) was improved.

The Implacer ${ }^{\circledR}$ device has been developed for blind administration of Dx/HA copolymer using four syringes and needles (Figure 2). This device is inserted to a depth that is predetermined according to urethral length, while the four needles are held parallel to the urethral channel. The needles are then released outwards, stretching the urethra and holding the mucosa in a fixed position. One by one, the syringes are retracted by $5-10 \mathrm{~mm}$, then advanced fully for submucosal injection of Dx/HA copolymer.

A recent study investigated the efficacy and safety of nonanimal stabilized hyaluronic acid/Dx copolymer using the Implacer ${ }^{\circledR}$ device in 42 women with SUI (urethral hypermobility or ISD). Significant reduction in median urine leakage was observed, from 36 $\mathrm{g}$ at baseline to $5.5 \mathrm{~g}$ at 3 months, sustained at 12 months. After 3 and 12 months, 32 (76\%) women demonstrated a degree of improvement in urine leakage (18 received a second injection). The mean number of incontinence episodes per day significantly decreased from 1.9 at baseline to 0.4 . The treatment was well tolerated and no complications were reported (73). 


\section{Expert Opinion}

SUI is a common condition among women following childbirth and post menopause. The range of treatment options, their outcomes and possible complications must be discussed with the patient before treatment commences. Treatment should be offered sequentially, beginning with the least invasive therapy. Surgery is often considered as the only effective option for women with SUI who do not respond to pelvic floor muscle re-education or pharmacotherapy. However, there are several drawbacks with surgery including the risk of complications and the lack of suitability for women likely to conceive in the future. Injectables are suggested to offer several potential advantages over surgical procedures, including lower morbidity, shorter procedure time, shorter inpatient stay and more rapid recovery (74). The procedure is most commonly based on day-case care and use of local or regional anaesthesia. Injection therapy can be used for all types of SUI. Future childbirth is unlikely to be considered as a contraindication. Safety profile and durability of bulking agents remain a concern. The ideal bulking agent has not yet developed. To simplify, improve, and standardize the endoscopic procedure, new devices for blind administration of bulking agents have been developed. These systems seem to have promising results for the patient and surgeon.

In the Cochrane Database of Systematic Reviews, a systematic review of the effectiveness of periurethral injection therapy for urinary incontinence in women has been reported (75). As only small number of studies has been identified (seven randomized trials, and five of the studies were abstracts) and the paucity of published data, statistical analysis was inappropriate and prevented meta-analysis. The data suggested subjective and objective short-term improvement of SUI in women and that the transurethral route results in fewer complications (less retention and urinary tract infection compared with paraurethral injection). No difference in subjective outcome was reported between injection therapy and 
surgery, although more patients were cured (using 24-hr pad test) after surgery. The complications were significantly more frequent and severe in the surgery group. No data are available comparing injection therapy with pelvic floor muscle training. Furthermore, no injection material is superior at present.

In two studies, the subjective success rate following injection therapy was higher than the objective one $(18,72)$. A recent survey of patients with SUI demonstrated that most patients prefer less invasive therapy, even if the chance of cure may be lower than with major procedure (76). Therefore, a focus on patient's wishes and expectations with respect to success and risks is required.

\section{Five-year view}

Continuous advancements in injectable agent materials and delivery techniques will evolve in the next 5 years. Experience continues to accrue in randomized clinical trials with urethral bulking agents for treating SUI in adult women.

Knowledge of the safety, efficacy and durability of the agent, delivery techniques, quantity and site of injection are being gained. Injection therapy for treating SUI in adult women may have a place between conservative therapy (pelvic floor muscle exercises) and surgery.

\section{Conclusion}

Injection therapy with urethral bulking agents would be a good option as treatment for SUI after failing conservative therapy. Randomized clinical trials (RCT) of urethral bulking agents compared with conservative treatment (pelvic floor muscle re-education) and placebo are required, with a long follow-up and health economic analysis to provide evidence of efficacy, cost-effectiveness, and risks. A randomized clinical trial to evaluate efficacy and 
acceptability by patient and physician using the MIS for the treatment of SUI in women compared with pelvic floor muscle exercises is scheduled for the near future.

\section{Key issues}

- $\quad$ Stress urinary incontinence (SUI) is prevalent in adult women and has a considerable impact on quality of life. However, it often remains undiagnosed and therefore untreated.

- Injection therapy with urethral bulking agents is a minimally invasive procedure and can be used for all types of SUI. Many bulking agents have been developed, although the ideal remains to be discovered.

- The subjective cure rate following injection therapy is higher than the objective one. A focus on patient's wishes and expectations with respect to success and risks of a treatment for SUI is required.

- $\quad$ Randomized clinical trials are mandatory to establish the place and efficacy of urethral bulking agents compared with conservative therapy in treating SUI in adult women.

\section{References}

1. Elving LB, Foldspang A, Lam GW, et al. Descriptive epidemiology of urinary incontinence in 3,100 women age 30-59. Scand J Urol Nephrol Suppl 1989;125:37-43. 2. Urinary incontinence-ACOG Technical Bulletin, No 213, October 1995 (Replaces No. 100, January 1987). Int J Obstet Gynecol 1996;52:75-86.

3. Wilson PD, Herbison RM, Herbison GP. Obstetric practice and the prevalence of urinary incontinence three months after delivery. Br J Obstet Gynecol 1996;103(2):154-61. 
4. Goldstein M, Hawthorne ME, Engeberg S, et al. Urinary incontinence. Why people do not seek help. J Gerontol Nurs 1992;18:15-20.

5. Keane DP, O'Sullivan S. Urinary incontinence: anatomy, physiology and pathophysiology. Baillieres Best Pract Res Clin Obstet Gynaecol 2000;14:207-26.

6. Hunskar S, Arnold EP, Burgio K, et al. Epidemiology and natural history of urinary incontinence. Int Urogynecol J 2000;11:301-19.

7. Abrams P, Cardozo L, Fal M, et al. The standardisation of terminology of lower urinary tract function: report from the Standardisation Sub-committee of the International Continence Society. Neurourol Urodyn 2002;21:167-78.

8. Blaivas JG, Olsson CA. Stress incontinence: classification and surgical approach. J Urol 1988;39:727-31.

9. Kobashi KC, Leach GE. Stress urinary incontinence. Curr Opin Urol 1999;9:285-90. 10. Leach GE, Dmochowski RR, Appell RA, et al. Female Stress Urinary Incontinence Clinical Guidelines Panel summary report on surgical management of female stress urinary incontinence. The American Urological Association. J Urol 1997;158:875-80.

11. Bent AE, McLennan MT. Surgical management of urinary incontinence. Obstet Gynecol Clin North Am 1998;25:883-906.

12. Benshushan A, Brezezinski A, Shoshani O, et al. Periurethral injection for the treatment of urinary incontinence. Obstet Gynecol Surv 1998;53(6):383-8.

13. Sheriff MKM, Foley S, Mcfarlane J, et al. Endoscopic correction of intractable stress incontinence with silicone micro-implants. Eur Urol 1997;32:284-8.

14. Barranger E, Fritel X, Kadoch, et al. Results of transurethral injection of silicone microimplants for women with intrinsic sphincter deficiency. J Urol 2000;164:1619-22. 
15. Gürdal M, Tekin A, Erdoğan K, et al. Endoscopic silicone injection for female stress urinary incontinence due to intrinsic sphincter deficiency: impact of coexisting urethral mobility on treatment outcome. Urology 2002;60:1016-9.

16. Herschorn S, Radomski SB, Steele DJ. Early experience with intraurethral collagen injections for urinary incontinence. J Urol 1992;148:1797-1800.

17. Monga AK, Robinson D, Stanton SL. Periurethral collagen injections for genuine stress incontinence: A 2-year follow-up. Br J Urol 1995;76:156-60.

18. Bent AE, Foote JE, Siegel S, et al. Collagen implant in treating stress urinary incontinence in women with urethral hypermobility. J Urol 2001;164(4):1354-7.

19. Herschorn S, Radomski SB. Collagen injections for genuine stress urinary incontinence: Patient selection and durability. Int Urogynecol 1997;8:18-24.

20. Steele AC, Kohli N, Karram MM. Periurethral collagen injection for stress incontinence with and without urethral hypermobility. Obstet Gynecol 2000;95:327-31.

21. Herschorn S, Steele DJ, Radomski S. Followup of intraurethral collagen for female stress urinary incontinence. J Urol 1996;156:1305-9.

22. Harriss DR, Iacovou JW, Lemberger RJ. Periurethral silicone microimplants (Macroplastique) for the treatment of genuine stress incontinence. Br J Urol 1996;78:722-8. 23. Usman F, Henalla S. A single transurethral macroplastique injection as primary treatment for stress incontinence in women. J Obstet Gynecol 1998;18:56-60.

24. Hidar S, Attyaoui F, de Leval J. Injection périurétrale de microparticules de silicone dans le traitement de l'incontinence urinaire par insuffisance sphinctérienne. Prog Urol 2000;10:219-23.

25. Radley SC, Chapple CR, Mitsogiannis IC, et al. Transurethral implantation of macroplastique for the treatment of female stress urinary incontinence secondary to urethral sphincter deficiency. Eur Urol 2001;39:383-9. 
26. Buckley J, Lingham K, Scott R. Early experience with a new injectable material for female stress incontinence. Abstract from the Institute of Urology and Nephrology, University College, London, UK, 1995, Jun; and the British Association of Urological Surgeons (BAUS) Annual Meeting, Brighton, UK, 1995, Jun.

27. Herschorn S. Current status of injectable agents for female stress urinary incontinence. Can J Urol 2001;8:1281-9.

28. Radley SC, Chapple CR, Lee JA. Transurethral implantation of silicone polymer for stress incontinence: evaluation of a porcine model and mechanism of action in vivo. BJU Int 2000;85:646-50.

29. Kieswater H, Fischer M, Wober L, et al. Endoscopic implantation of collagen (GAX) for the treatment of urinary incontinence. Br J Urol 1992;69:22-5.

30. O'Connell HE, McGuire EJ, Aboseif S, et al. Transurethral collagen therapy in women. J Urol 1995;154:1463-5.

31. Khullar V, Cardozo LD, Abbott D, et al. GAX collagen in the treatment of urinary incontinence in elderly women: a two year follow up. Br J Obst Gynaecol 1997;104:96-9. 32. Monga AK, Stanton SL. Urodynamics: prediction, outcome and analysis of mechanism for cure of stress incontinence by periurethral collagen. Br J Obstet Gynaecol 1997;104:158-62.

33. Dmochowski RR, Appell RA. Injectable agents in the treatment of stress urinary incontinence in women: where are we now? Urology 2000;56:32-40.

34. Murless BC. The injection treatment of stress incontinence. J Obstet Gynaecol Br Emp 1938;45:67-71.

35. Quackels R. Deux incontinences après adenomectomie gueries par injection de parrafine dans le perinee. Acta Urol Belg 1955;23:259-62. 
36. Sachse S. Treatment of urinary incontinence with sclerosing agent solutions: Indication, results, complications. Urol Int 1963;15:225-44.

37. Berg S. Polytef augmentation urethroplasty correction of surgically incurable incontinence by injection technique. Arch Surg 1973;107:379-81.

38. Politano AV. Periurethral polytetrafluoroethylene injection for urinary incontinence. $\mathrm{J}$ Urol 1982;127:439-42.

39. Mittleman RE, Marracchini JV. Pulmonary Teflon granuloma following periurethral Teflon injection for urinary incontinence. Arch Pathol Lab Med 1983;107:611-18.

40. Boykin W, Rodriquez FR, Brizzolara J, et al. Complete urinary obstruction following periurethral polytetrafluoroethylene injection for urinary incontinence. J Urol 1989:11991200.

41. Malizia AA, Reiman HM, Myers RP, et al. Migration and granulomatous reaction after periurethral injection of polytef (Teflon). JAMA 1984;251:3277-81.

42. Aaronson IA, Rames RA, Green WB, et al. Endoscopic treatment of reflux: migration of teflon to the lungs and brain. Eur Urol 1993;23:394-9.

43. Kiilholma PJ, Chancellor MB, Makinen J, et al. Complications of Teflon injection for stress urinary incontinence. Neurourol Urodyn 1993;12:131-7.

44. Hakky M, Kolbusz R, Reyes CV. Chondrosarcoma of the larynx. ENTJ 1989;68:60-2.

45. Lewy RB. Experience with vocal cord injection. Ann Otol 1976;85:440-50.

46. Lee PE, Kung RC, Drutz HP. Periurethral autologous fat injection as treatment for female urinary stress incontinence: a randomised double blind controlled trial. J Urol 2001;165:153-8.

47. Currie L, Drutz HP, Oxorn D. Adipose tissue and lipid drop embolism following periurethral injection of autologous fat: case report and review of the literature. Int Urogynecol J Pelvic Floor Dysfunct 1997;8:923-6. 
48. Palma PC, Riccetto CL, Netto Jr NR. Urethral pseudolipoma: a complication of periurethral lipo-injection for stress urinary incontinence in a women. J Urol $1996 ; 155(2): 646$.

49. Su TH, Hsu CY, Chen JC. Injection therapy for stress incontinence in women. Int Urogynecol J 1999;10:200-6.

50. Lightner DJ. Review of the available urethral bulking agents. Curr Opin Urol $2002 ; 12: 333-8$.

51. Cross CA, English SF, Cespedes RD, et al. A follow-up on transurethral collagen injection therapy for urinary incontinence. J Urol 1998;159:106-8.

52. Corcos J, Fournier C. Periurethral collagen injection for the treatment of female stress urinary incontinence: 4-year follow-up results. Urology 1999;54:815-8.

53. Canning DA, Peters CA, Gearhart JP, et al. Local tissue reaction to glutaraldehyde crosslinked bovine collagen in the rabbit bladder. J Urol 1998;139 (Suppl.):Abs. no.381.

54. Stothers L, Goldenberg SL, Leone EF. Complications of periurethral collagen injection for stress urinary incontinence. J Urol 1998;159:806-7.

55. Berman CJ, Kreder KJ. Comparative cost analysis of collagen injection and fascia lata sling cystourethropexy for the treatment of type 3 incontinence in women. J Urol 1997; 157:122-4.

56. Schulman CC. "Biocompatibility of Injected Materials in Urology" in Implanted and Injected Materials in Urology, Buzelin JM (Editor), ISIS Medical Media, Oxford, United Kingdom: 1995, Chapter 1 and 2.

57. Solomon LZ, Birch BR, Cooper AJ, et al. Nonhomologous bioinjectable materials in urology: 'size matters’?. BJU Int 2000;85:641-5. 
58. Tinkler JB, Campbell HJ, Senior JM, et al. Evidence for an association between the implantation of silicones and connective tissue disease. Medical Device Directorate (UK Department of Health) Report 1993; MDD/92/42:1-65.

59. ter Meulen $\mathrm{PhH}$, Berghmans LCM, van Kerrebroeck PhEVA. Systematic review: Efficacy of silicone microimplants (Macroplastique $\left.{ }^{\circledR}\right)$ Therapy for stress urinary incontinence in adult women. Eur Urol 2003;44:573-82.

60. Koelbl H, Saz V, Doerfler D, et al. Transurethral injection of silicone microimplants for intrinsic urethral sphincter deficiency. Obstet Gynecol 1998;92:332-6.

61. Lightner D, Calvosa C, Andersen R, et al. A new injectable bulking agent for treatment of stress urinary incontinence: results of a multicenter, randomised, controlled, double blind study of Durasphere. Urology 2001;58:12-15.

62. Pannek J, Brands FH, Senge T. Particle migration after transurethral injection carbon coated beads for stress urinary incontinence. J Urol 2001;166:1350-3.

63. Mayer R, Lightfoot M, Jung I. Preliminary evaluation of calcium hydroxylapatite as a transurethral bulking agent for stress urinary incontinence. Urology 2001;57:434-8.

64. Stenberg A, Larsson E, Lindholm A, et al. Injectable dextranomer-based implant: histopathology, volume changes and DNA-analysis. Scand J Urol Nephrol 1999;33:355-61. 65. Stenberg A, Larsson G, Johnson P, et al. DiHA Dextran Copolymer, a new biocompatible material for endoscopic treatment of stress incontinent women. Short term results. Acta Obstet Gynecol Scand 1999;78:436-442.

66. Stenberg AM, Sundin A, Larsson BS, et al. Lack of distant migration after injection of a 125iodine labeled dextranomer based implant into the rabbit bladder. J Urol 1997;158:1937-41. 
67. Lackgren G, Wahlin N, Skoldenberg E, et al. Long-term follow-up of children treated with dextranomer/hyaluronic acid copolymer for vesicoureteral reflux. J Urol 2001;166:188792.

68. Lackgren G, Wahlin N, Stenberg A. Endoscopic treatment of children with vesicoureteric reflux. Acta Paediatr Suppl 1999;88:62-71.

69. Dmochowski RR, Appell RA. Delivery of injectable agents for treatment of stress urinary incontinence in women: evolving techniques. Tech Urol 2001;7:110-17.

70. Gottfried HW, Maier S, Gschwend J, et al. Minimally invasive treatment of stress urinary incontinence by collagen administration. Comparison between endosonography controlled and transurethral submucous collagen injection. Urologe A 1996;35:6-10.

71. Henalla SM, Hall V, Duckett JRA, et al. A multicentre evaluation of a new surgical technique for urethral bulking in the treatment of genuine stress incontinence. Br J Obstet Gynecol 2000;107:1035-9.

72. Tamanini JTN, D'Ancona CAL, Tadini V et al. Macroplastique implantation system for the treatment of female stress urinary incontinence. J Urol 2003;169:2229-33.

73. Van Kerrebroeck P, ter Meulen F, Larson G et al. Efficacy and safety of a novel system (NASHA/Dx copolymer via the Implacer device) for the treatment of SUI. Urology in press.

74. Shah J. Injectables and stress urinary incontinence. Urol News 1997;2:7-11.

75. Pickard R, Reaper J, Wyness L, et al. Periurethral injection therapy for urinary incontinence in women. The Cochrane Database of Systematic Reviews, issue 1, 2003, Oxford.

76. Robinson D, Anders K, Cardozo L, et al. What do women want? Interpretation of the concept of cure. J Pelvic Surg Med 2003;9:273-7. 
77. Strasser H, Tiefenthaler M, Steinlechner M, et al. Age dependent apoptosis and loss of rhabdosphincter cells. J Urol 2000;164:1781-5.

78. Bedir S, Kilciler M, Ozgok Y, et al. Long-term complication due to dextranomer based implant: granuloma causing urinary obstruction. J Urol 2004;172:247-8.

79. Dmochowski RR, Appell RA. Advancements in minimally invasive treatments for female stress urinary incontinence: radiofrequency and bulking agents. Curr Urol Rep $2003 ; 4: 35-5$.

80. Bent AE, Tutrone RT, McLennan MT, et al. Treatment of intrinsic sphincter deficiency using autologous ear chondrocytes as a bulking agent. Neurol Urodyn 2001;20:157-65.

81. Yiou R, Yoo JJ, Atala A. Restoration of functional motor units in a rat model of sphincter injury by muscle precursor cell autografts. Transplantation 2003;76:1053-60.

Table 1. Classification of stress urinary incontinence (8).

\begin{tabular}{|l|l|}
\hline Classification of & Description of symptoms \\
\hline Type I & $\begin{array}{l}\text { Bladder neck and urethra open and descend during stress. Descent } \\
\text { less than } 2 \mathrm{~cm}, \text { no evidence of cystocele. }\end{array}$ \\
\hline Type IIA & Bladder neck and urethra open and descend during stress. Descent \\
& less than $2 \mathrm{~cm}$, evidence of cystocele. \\
\hline Type IIB & Bladder neck and urethra closed and below the symphysis pubis at \\
\hline Type III & Bladder neck and urethra open at rest, absence of detrusor contraction \\
\hline
\end{tabular}


Table 2. Technical information of current available injectables.

$\begin{array}{ccc}\text { Agent } & \text { Marketed name size Characteristic } & \text { Success (\%) } \\ (\mu \mathrm{m}) & \end{array}$

Allergic reaction

Refrigeration required

$\begin{array}{cccc}\text { Silicone } & \text { Macroplastique }{ }^{\circledR} & \text { Viscous } & \text { 120-264 } \\ & \text { Stable } & \text { 46-80 (3m-3yrs) }\end{array}$

Carbon beads Durasphere ${ }^{\circledR}$

$251-300$

Nonantigenic

$80.3(1 \mathrm{yr})$

Viscous

Migration

Calcium

Coaptite $\mathbb{R}$

75-125

Nonantigenic

Trials in progress

hydroxylapatite

Stable

Radiolucent

Dextranomer/ Zuidex ${ }^{\circledR}$

$80-250$

Significant elasticity

76 (1 yr.) copolymer

hyaluronic acid

High viscosity

Biodegradable

Nonimmunogenic

Granuloma formation

Ethylene vinyl Uryx ${ }^{\circledR}$

NA

Solidification

Trials in progress

alcohol copolymer

$\mathrm{NA}=$ not applicable, yr $(\mathrm{s})=$ year(s), m = months

Success: Improvement of stress urinary incontinence and dry. 
Figure 1. Macroplastique ${ }^{\circledR}$ implantation device for delivery of silicone. One needle is transferred between each of the three deployment sites to complete the urethral injection.

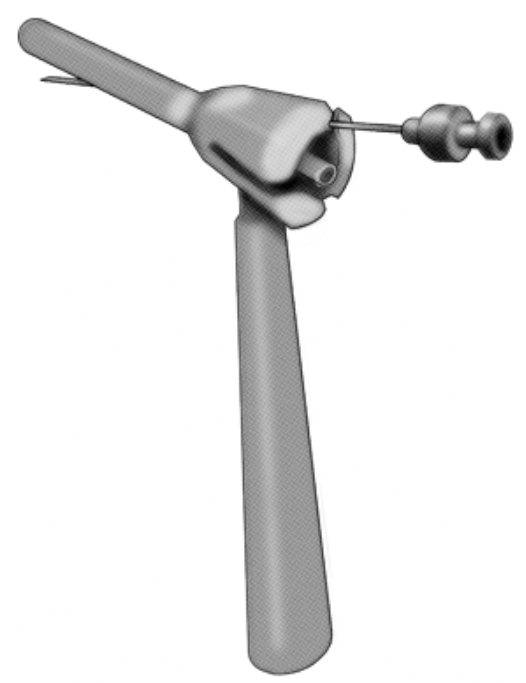

Figure 2. The Implacer ${ }^{\circledR}$ device for delivering dextranomer/hyaluronic acid copolymer; A) Ready for insertion into the urethra, B) Positioned within the urethra prior to injection from each of the four syringes.

A)

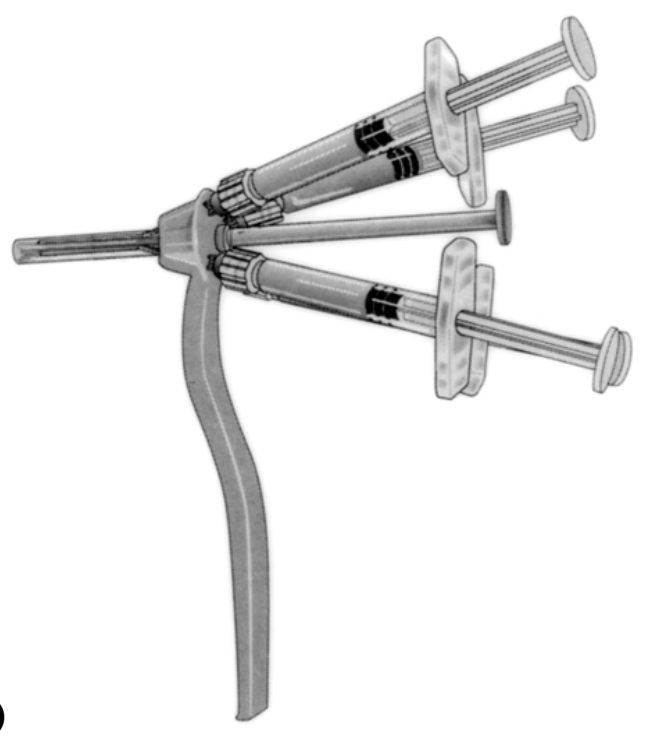

B)

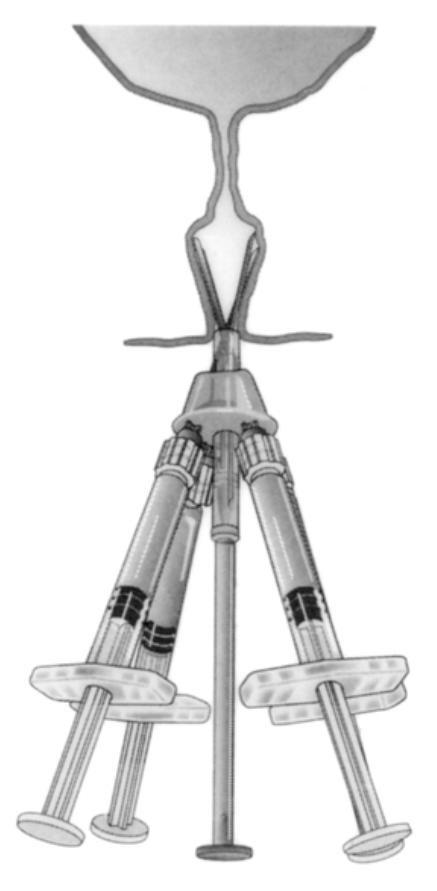




\section{Chapter 3}

\section{Efficacy and safety of a novel system (NASHA/Dx copolymer}

using the Implacer device) for treatment of stress urinary incontinence

Philip van Kerrebroeck ${ }^{\mathrm{a}}$, Flip ter Meulen ${ }^{\mathrm{a}}$, Gregor Larsson ${ }^{\mathrm{b}}$, Elisabeth Farrelly ${ }^{\mathrm{c}}$, Lena Edwall ${ }^{\mathrm{d}}$, and Aino Fianu-Jonasson ${ }^{\mathrm{d}}$

${ }^{a}$ Department of Urology, University Hospital Maastricht, the Netherlands

${ }^{b}$ Department of Obstetrics and Gynecology, Västerås Central Hospital, Västerås, Sweden

${ }^{\mathrm{c}}$ Department of Urology, Karolinska Hospital, Stockholm, Sweden

${ }^{\mathrm{d}}$ Department of Obstetrics and Gynecology, Huddinge University Hospital, Stockholm, Sweden

Journal: Urology 2004;64(2):276-281. 


\begin{abstract}
Objectives. To investigate the efficacy and safety of non-animal-stabilized hyaluronic acid/dextranomer (NASHA/Dx) copolymer for transurethral injection using a new guiding instrument (the Implacer) for stress urinary incontinence.
\end{abstract}

Methods. In an open, prospective, multicenter study, 42 invasive therapy-naive female patients with stress urinary incontinence were given $4 \times 1.0 \mathrm{ml}$ or $4 \times 0.7 \mathrm{ml}$ of NASHA/Dx copolymer using the Implacer. The efficacy parameters, measured at baseline, and 1, 3, 6, and 12 months after treatment, included cough-induced leak point pressure, urine leakage by provocation test, number of incontinence episodes in 24 hours, and patient perception of bladder condition, rated on a 6-point scale.

Results. The collected cough-induced leak point pressure data were not judged to be valid and reliable. Statistically significant reductions in median urine leakage were observed $(P$ $<0.0001$ ), from $36 \mathrm{~g}$ (range $0.0-300$ ) following 20 'jumping jacks' or vigorous coughs at baseline to $5.5 \mathrm{~g}$ (range $0.0-98)$ at 3 months and sustained at 12 months ( $7.0 \mathrm{~g}$, range $0.0-98)$. Of the 42 patients, $32(76 \%)$ demonstrated a degree of improvement in urine leakage at 3 and 12 months. The median number of incontinence episodes in 24 hours decreased significantly from 1.9 (range $0.0-24)$ at baseline to 0.4 (range $0.0-24)$ at 12 months $(P<0.0001)$. At both 3 and 12 months, 29 patients (69\%) had improved by at least one category on the 6-point patient perception scale. Treatment was well tolerated, and no complications were reported with use of the Implacer.

Conclusions. The results of this study indicate that a novel system (NASHA/Dx copolymer insertion using the Implacer) is an effective and well-tolerated treatment for invasive therapynaive patients with stress urinary incontinence, with improvement sustained for at least 12 months. These encouraging results warrant additional study. 
Key words: urinary incontinence, stress; female; urethral injection; non-animal-stabilized hyaluronic acid; NASHA/Dx copolymer.

Zuidex $^{\mathrm{TM}}$ and Implacer ${ }^{\mathrm{TM}}$ are trademarks of Q-Med AB, Uppsala, Sweden.

\section{Introduction}

Stress urinary incontinence (SUI), characterized by the involuntary leakage of urine, is a condition with a considerable impact on quality of life. Two etiologic mechanisms have been postulated: hypermobility and intrinsic sphincter deficiency (ISD), and the two mechanisms may co-exist in most patients. ${ }^{1}$

First-line treatment is usually noninvasive (eg, physiotherapy), with pharmacotherapy another option. Surgery has been widely considered the only effective next treatment, but it is not suitable for all, and fear of complications may act as an obstacle. Endoscopic urethral injection has gained limited acceptance, with the durability and safety of the injected material a concern. ${ }^{2}$ A clear need exists for the development of a new, effective approach for the treatment of SUI.

NASHA/Dx copolymer comprises dextranomer (Dx) microspheres (80 to $250 \mu \mathrm{m}$ ) in a carrier gel of non-animal stabilized hyaluronic acid (NASHA). The gel is a biocompatible,

biodegradable material free from animal products, which has no immunogenic properties, 3,4 and has been shown not to migrate to different organs after submucosal injection. ${ }^{5}$

NASHA/Dx copolymer is the only injectable agent approved by the U.S. Food and Drug Administration for endoscopic treatment of vesicoureteral reflux in children and has also gained European approval for the treatment of SUI.

A new guiding instrument - the Implacer - has been developed to facilitate reproducible and standardized transurethral injection of NASHA/Dx copolymer, without the need for surgical facilities or cystoscopic guidance. This device comprises a holder that is placed into, and 
fixates, the urethra (ie, distends the urethral circumference, thus smoothing out the longitudinal folds), allowing use of four syringes to inject implants at approximately the 2, 4, 8 , and 10 o'clock positions.

This study was undertaken to investigate a novel system, transurethral injection of NASHA/Dx copolymer using the Implacer, in invasive therapy-naive female patients with SUI.

\section{Materials and methods}

This was an open, prospective, multicenter study, conducted in accordance with the principles of the Declaration of Helsinki, and approved by appropriate independent ethics committees. All participants provided written informed consent. Study treatment comprised 4 x $1.0 \mathrm{ml}(\mathrm{n}=32)$ or 4 x $0.7 \mathrm{ml}(\mathrm{n}=10)$ injections of NASHA/Dx copolymer $(\mathrm{Q}-\mathrm{Med}$ AB, Uppsala, Sweden) administered via the Implacer (Zuidex system: four NASHA/Dx copolymer-filled syringes and the Implacer, Q-Med). The original protocol specified 4 x 1.0 $\mathrm{ml}$, but was amended to also investigate a lower treatment volume $(4 \times 0.7 \mathrm{ml})$. The inclusion criteria were women 18 years of age or older with SUI verified by demonstrable leakage on coughing or Valsalva maneuver; a history of SUI for at least 12 months; invasive therapy (ie, no previous surgical therapy for SUI); and failure with prior noninvasive treatment (eg, behaviour modification, pelvic floor exercises, drug therapy). The pathophysiology of SUI (ie, hypermobility and/or ISD) was not determined.

The exclusion criteria were a mean volume voided of less than $200 \mathrm{ml}$; post-void residual urine (PVRU) of greater than $100 \mathrm{ml}$; urge incontinence; detrusor overactivity; medication for SUI; recurrent urinary tract infection; and anticoagulant or immunosuppressive therapy. General and/or local anesthesia was administered, depending on investigator preference. The Implacer was assembled using four syringes containing NASHA/Dx copolymer with 50-mm 21-gauge needles attached (Fig. 1A). The four needles were covered by a cylinder sliding 
through the handle and inserted into the urethra (Fig. 1B). The cover was retracted to release the four needles outwards at the designated mid-urethral position (Fig. 1C). ${ }^{6}$ Sequentially, each needle was retracted 5-10 $\mathrm{mm}$, and pushed forward to penetrate the mucosa, thus allowing injection of the NASHA/Dx copolymer. Patients were required to void before leaving the clinic, and the PVRU volume was measured. Patients not responding to the initial treatment were offered one repeat treatment 1 to 2 months after the first procedure, using an identical method.

Follow-up visits were scheduled at 1, 3, 6, and 12 months, with treatment efficacy parameters assessed at baseline and each of these points. The primary endpoint was the change from baseline in cough-induced leak point pressure (CILPP). ${ }^{7}$ Secondary assessments included urine leakage by provocation test, measured by pad weight before and after 20 'jumping jacks' or vigorous coughs, and performed with $300 \mathrm{ml}$ saline in the bladder; and the number of incontinence episodes in 24 hours, assessed by a 1-week micturition chart. Given that these tests did not form part of the inclusion criteria, 1 patient did not show leakage at baseline by provocation test and 1 patient had no incontinence episodes in 24 hours. The patients' perception of their bladder condition was also assessed, with bother graded on a 6-point scale as no, some very minor, some minor, some, some severe, and many severe problems.

Safety assessments included adverse event (AE) monitoring and PVRU measurement at each visit, with maximum cystometric capacity and maximum urethral closure pressure (MUCP) assessed up to 6 months before the baseline visit, and at the 1,3, 6, and 12-months. Statistical analyses were performed using the Statistical Analysis System software, ${ }^{8}$ the intention-to-treat principle, and the last observation carried forward method. Sample size was determined based on $95 \%$ power, a statistical significance level of $5 \%$ and an increase in the CILPP of $30 \mathrm{~cm} \mathrm{H}_{2} 0$. However, the collected CILPP data were not judged to be valid and reliable, and a statistical analysis was performed using only descriptive statistics. Changes 
from baseline in urine leakage by provocation test and number of incontinence episodes in 24 hours were analysed by Wilcoxon signed rank test, with a two-tailed probability of 0.05 or less considered statistically significant. The data were not normally distributed, consequently the median values are given. The data for the patients' perception of their bladder condition were analyzed using descriptive statistics.

\section{Results}

A total of 49 individuals were screened, of whom 42 were recruited into the study. Of these, 32 received $4 \times 1.0 \mathrm{ml}$ and 10 received $4 \times 0.7 \mathrm{ml}$. Seven patients were not included in the study because consent was withdrawn $(n=2)$, of personal problems $(n=1)$, of a broken leg $(n=1)$, no leakage occurred at urodynamic investigation $(n=1)$, of social reasons $(n=1)$, and of personal reasons $(\mathrm{n}=1)$. The demographic variables and baseline incontinence parameters are presented in Table 1.

Between the baseline and 3-month follow-up visit, 1 patient was lost to follow-up and 1 patient withdrew consent; 4 patients were lost to follow-up between the 3 and 12-month visits.

Three patients (7\%) were withdrawn from further follow-up because of a lack of efficacy between the baseline and 3-month visits, as assessed by the patients' perception of treatment benefit (ie, whether the patient considered their incontinence problems improved since their last visit). Seven patients (17\%) were withdrawn between 3 and 12-month follow-up visits because of a lack of efficacy.

Given that the two dosage groups showed very similar efficacy results, we combined the data and considered as one group in the efficacy evaluation. The assessment of the CILPP showed that at 3 months, 13 (42\%) of 31 patients had no leakage, and, compared with baseline, 10 (32\%) had improved (increased CILPP), and 8 (26\%) had worsened (decreased CILPP). The corresponding values at 12 months were $14(64 \%), 4(18 \%)$, and $4(18 \%)$ of 22 patients. 
Statistically significant reductions in median urine leakage as measured by the provocation test were observed after treatment at 3 months and sustained at 6 and 12 months $(P<0.0001$ versus baseline; Fig. 2A). The number of patients demonstrating a degree of improvement in urine leakage at 3 and 12 months compared with baseline is shown in Table 2, with $32(76 \%)$ of 42 patients improved at both points. Statistically significant reductions in the median number of incontinence episodes in 24 hours were also observed, again sustained at 12 months $(P<0.0001$ versus baseline; Fig. 2B). At the 3-month follow-up visit, 29 (69\%) of 42 patients were improved by at least one category on the 6-point patient perception scale, with the same percentage improved at 12 months.

Eighteen patients underwent one repeat treatment because of an insufficient response, with a mean time between the first and second injections 48.9 days (range 24.0 to 65.0 ). At 3,6 , and 12 months, statistically significant reductions in the median urine leakage as measured by the provocation test and the median number of incontinence episodes in 24 hours was observed in both the re-treated patients and those not requiring re-treatment $(P<0.014$ versus baseline, for all 12 scenarios).

Treatment-related AEs, which were transient and as expected following urethral injection, were reported by 15 patients (36\%). For the $4 \times 1.0-\mathrm{ml}$ group, apart from 1 patient with a sterile abscess, all treatment-related AEs were urinary system disorders, with the most common urinary tract infection $(n=5)$, haematuria $(n=4)$, urethral disorder $(n=3)$, and decreased urinary flow $(n=3)$. Fewer AEs were observed in the 4 x 0.7-ml group (urinary tract infection in 1 and urinary retention in 1).

Almost all treatment-related AEs were of mild (70\%) or moderate $(26 \%)$. No complications were reported in relation to the use of the Implacer. Three treatment-related AEs involving a PVRU of greater than $100 \mathrm{ml}$ led to temporary catheterization. Catheterization was started on the day of treatment and lasted for a mean of 4 days (range 2 to 8 days). 
No statistically significant changes were observed in the MUCP or maximal cystometric capacity compared with baseline at any point. Although the reduction in absolute urine leakage tended to be greater in the 5 patients with an MUCP of $20 \mathrm{~cm} \mathrm{H}_{2} \mathrm{O}$ or less, no noticeable difference was observed in the relative reduction in leakage between these patients and those with greater MUCP values.

\section{Comment}

This is the first study investigating the treatment of SUI with NASHA/Dx copolymer administered via the Implacer. Valid and reliable results could not be obtained for the primary endpoint, the change from baseline in CILPP, because CILPP was not measured consistently among the centers, values proved difficult to verify, and a large number of values were missing. This did not invalidate the other efficacy results, which showed sustained efficacy over time. Sustained and statistically significant improvements in quality of life $(P$ $<0.005)$, as assessed by the King's Health Questionnaire were also observed. ${ }^{9}$

Sixty percent of patients received only one injection procedure. Urethral injection with other bulking agents often require multiple injections, particularly collagen where up to five injections (ie, four retreatments) have been used. ${ }^{10,11}$ Statistically significant and sustained improvement was observed even if repeat treatment was required.

Whether the presence of hypermobility or ISD influenced the treatment outcome was not directly assessed. Nevertheless, this issue is worth addressing given that it has been investigated in other studies. Injectable agents are restricted to patients with ISD in some countries, but the concept of ISD and hypermobility dichotomy has been questioned. The International Continence Society has stated that delineation into such categories may be simplistic and arbitrary. ${ }^{12}$ ISD may co-exist in many patients previously categorized as hypermobile, ${ }^{1}$ and increasing data show that injectable agents are also effective in patients with hypermobility. ${ }^{13,14}$ 
The treatment was well tolerated, with fewer AEs in the $4 \times 0.7-\mathrm{ml}$ than the $4 \times 1.0-\mathrm{ml}$ group. Patients receiving the lower volume were treated later in the study, at the same center. Therefore, the difference may be explained by a learning curve for the device or reporting variation, although the possibility the lower volume produces fewer AEs cannot be excluded. The Implacer offers a standardized and guided injection technique, allowing injection of NASHA/Dx copolymer at specific sites, without the need for surgical facilities. Although the implants are not visualized during administration, magnetic resonance imaging of patients in this study demonstrated that the implants were deposited into the desired periurethral location in the urethral submucosa in most cases. ${ }^{15}$

Histopathologic data have shown that NASHA/Dx copolymer induces only a mild inflammatory reaction in contrast to the foreign body reactions and potential granuloma formation observed with other bulking agents (particularly silicone and polytetrafluoroethylene). ${ }^{3,16}$ The lack of a negative effect of NASHA/Dx copolymer on the surrounding tissue means that subsequent surgical procedures are not affected. In 3 subjects in the present study who did not respond adequately, tension-free vaginal tape procedure was performed as normal, without complications. ${ }^{17}$ Dx microspheres have been shown to persist for more than 3 years after injection. ${ }^{16}$ Accordingly, sustained clinical efficacy for at least 5 years has been observed in children with vesicoureteral reflux, together with an absence of long-term AEs. ${ }^{18}$ Moreover, after a 6.5 -year follow-up period, $57 \%$ of patients were still cured or improved in a preliminary study of NASHA/Dx copolymer injected endoscopically in 20 patients. ${ }^{19,20}$ Longer-term results with NASHA/Dx copolymer via the Implacer are awaited.

The present results have implications for the management of SUI. Patients in who noninvasive treatment fails are generally offered surgery. However, in a recent study, a major operation was unacceptable to most women, and a clinic procedure with lower success and no 
long-term risk was preferred. ${ }^{21}$ Where surgery is not an option, NASHA/Dx copolymer appears to be of benefit, with the number of individuals receiving active treatment potentially increased.

\section{Conclusions}

The results of the present study indicate that a novel system, NASHA/Dx copolymer using the Implacer, is an effective and well-tolerated treatment for patients with SUI who have not undergone invasive therapy, with improvement sustained for at least 12 months. The lack of a requirement for surgical facilities and the established safety profile of NASHA/Dx copolymer further support the use of this new SUI treatment.

\section{References}

1. Koelbl H, Mostwin J, Boiteux JP, et al: Pathophysiology, in: Abrams P, Cardozo L, Khoury S, Wein A (Eds): Incontinence. Plymouth, United Kingdom, Health Publication Ltd, 2002,205-241.

2. Herschorn S: Current status of injectable agents for female stress urinary incontinence. Can J Urol 8:1281-1289, 2001.

3. Lackgren G, Wahlin N, and Stenberg A: Endoscopic treatment of children with vesico-ureteric reflux. Acta Paediatr Suppl 88:62-71, 1999.

4. Stenberg AM, Larsson E, Lindholm A, et al: Injectable dextranomer-based implant: histopathology, volume changes and DNA-analysis. Scand J Urol Nephrol 33:355$361,1999$.

5. Stenberg AM, Sundin A, Larsson BS, et al: Lack of distant migration after injection of a ${ }^{125}$ iodine labeled dextranomer based implant into the rabbit bladder. J Urol 158: 1937-1941,1997. 
6. Van Kerrebroeck P, ter Meulen F, Farrelly E, et al: Treatment of stress urinary incontinence: recent developments in the role of urethral injection. Urol Res 30:356362,2003

7. Siltberg H, Larsson G, and Victor A: Reproducibility of a new method to determine cough-induced leak-point pressure in women with stress urinary incontinence. Int Urogynecol J Pelvic Floor Dysfunct 7:13-19,1996.

8. SAS Institute Inc: SAS/STAT, version 8.2.

9. Farrelly E, Fianu-Jonasson A, Larsson G, and van Kerrebroeck P: Zuidex ${ }^{\circledR}$ treatment of SUI - impact on quality of life (King's Health Questionnaire). International Continence Society 33rd Annual Meeting, Florence, Italy, 5-9 October. Abstract 331, 2003.

10. Groutz A, Blaivas JG, Kesler SS, et al: Outcome results of transurethral collagen injection for female stress incontinence: assessment by urinary incontinence score. $\mathrm{J}$ Urol 164:2006-2009,2000.

11. Appell RA: Collagen injection therapy for urinary incontinence. Urol Clin North Am 21:177-182,1994.

12. Abrams P, Cardozo L, Fall M, et al: The standardization of terminology of lower urinary tract function: report from the Standardisation Sub-committee of the International Continence Society. Neurourol Urodyn 21:167-178,2002.

13. Lightner DJ: Review of the available urethral bulking agents. Curr Opin Urol 12:333338,2002 .

14. Bent AE, Foote J, Siegel S, et al: Collagen implant for treating stress urinary incontinence in women with urethral hypermobility. J Urol 166:1354-1357,2001.

15. Fianu-Jonasson A, Edwall L, and Kristoffersen Wiberg M: Magnetic resonance imaging to confirm the periurethral location of Zuidex ${ }^{\mathrm{TM}}$ deposits. International 
Continence Society 33rd Annual Meeting, Florence, Italy, 5-9 October. Abstract 356, 2003.

16. Stenberg A, Larsson E, and Lackgren G: Endoscopic treatment with dextranomerhyaluronic acid for vesicoureteral reflux: histological findings. J Urol 169:1109$1113,2003$.

17. Fianu-Jonasson A, and Edwall L: Stress urinary incontinence: feasibility of surgery after urethral injection. Acta Obstet Gynecol Scand 82:1060,2003.

18. Lackgren G, Wahlin N, Skoldenberg E, et al: Long-term followup of children treated with dextranomer/hyaluronic acid copolymer for vesicoureteral reflux. J Urol 166:1887-1892,2001.

19. Stenberg AM, Larsson G, Johnson P, et al: DiHA Dextran Copolymer, a new biocompatible material for endoscopic treatment of stress incontinent women. Short term results. Acta Obstet Gynecol Scand 78:436-442,1999.

20. Stenberg AM, Larsson G, and Johnson P: Urethral injection for stress urinary incontinence: long-term results with dextranomer/hyaluronic acid copolymer. Int Urogynecol J Pelvic Floor Dysfunct 14:335-338,2003.

21. Robinson D, Anders K, Cardozo L, et al: What women want - their interpretation of the concept of cure. International Continence Society 32nd Annual Meeting, Heidelberg, Germany, 27-30 August. Abstract 115, 2002. 
Table 1. Patient demographics and baseline characteristics

$4 \times 1.0 \mathrm{ml}$

$4 \times 0.7 \mathrm{ml}$

$(\mathbf{n}=32)$

$(\mathbf{n}=\mathbf{1 0})$

Demographic variables

Baseline characteristics

Mean age, years (range)

Mean body mass index, $\mathrm{kg} / \mathrm{m}^{2}$ (range)

Menopause, $\mathrm{n}(\%)$

Deliveries 0-2, n (\%)

Deliveries 3-4, n (\%)

Duration of symptoms $>5$ years, $n(\%)$

Severe problems (patient perception) *, n (\%)

Previous nondrug therapy for SUI, n (\%)

$52.9(35.2-70.1) \quad 52.3(30.5-77.9)$

$24.7(19.0-34.3) \quad 23.6(20.1-28.7)$

$17(53 \%)$

$5(50 \%)$

$22(69 \%) \quad 7(70 \%)$

$10(31 \%) \quad 3(30 \%)$

$24(75 \%) \quad 9(90 \%)$

$18(56 \%) \quad 4(40 \%)$

$32(100 \%) \quad 10(100 \%)$

Urine leakage by provocation test, g, median (range)

Number of incontinence episodes/24 hours, median (range)

$40(0-300)$

$30(16-70)$

$1.8(0.0-24.0) \quad 2.2(0.4-7.1)$

$43.3(9.0-86.0) \quad 47.2(35.0-64.0)$

Maximum urethral closure pressure, mean (range)

$501(170-960)$

* Patients' perception of bladder condition graded as some severe, or many severe, problems on a 6-point scale. 
Table 2. Patients demonstrating improvement or no improvement in urine leakage as measured by provocation test at 3 and 12 months compared with baseline $(n=42)$ *

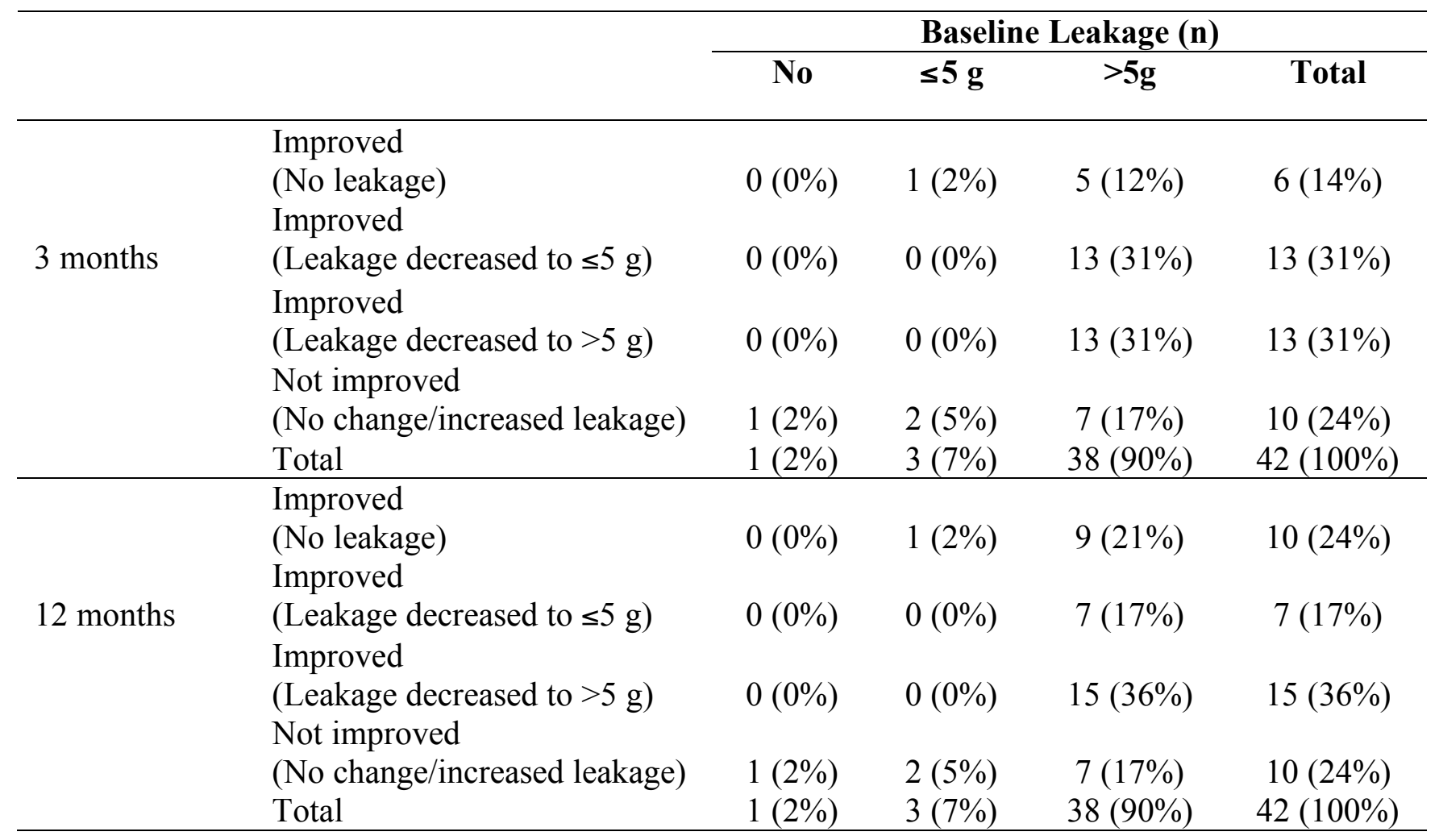

* Data presented using last observation carried forward method. 
Figure 1. Use of the Implacer (A-C).

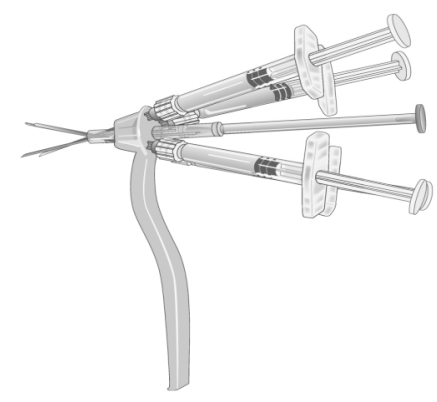

A Assembled Implacer
B Inserted into mid-urethra with needles covered
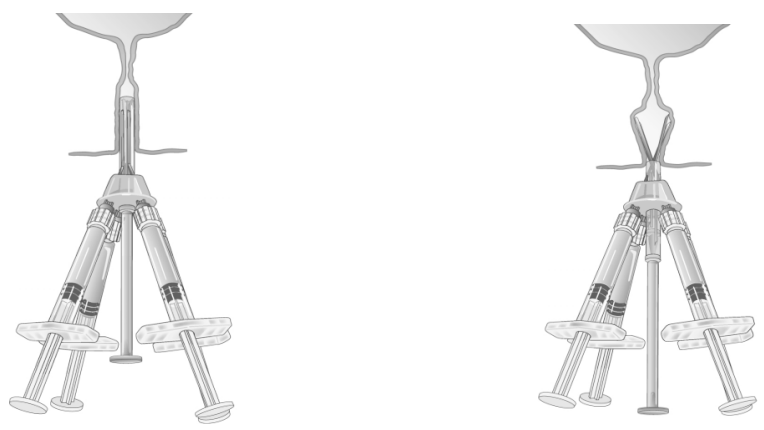

C Needle cover retracted;needle fixates the urethra 
Figure 2. Median urine leakage as measured by (A) provocation test ( $95 \%$ confidence interval at baseline and 3, 6, and 18 months: 22 to $59,2.0$ to $24,0.0$ to $18,2.0$ to 22 , respectively) and (B) median incontinence episodes in 24 hours after treatment $(95 \%$ confidence interval at baseline, 3,6 , and 18 months: 1.7 to $3.1,0.14$ to $1.0,0.29$ to $1.0,0.14$ to 0.71$)$ with NASHA/Dx copolymer using the Implacer $(n=42)$.

A

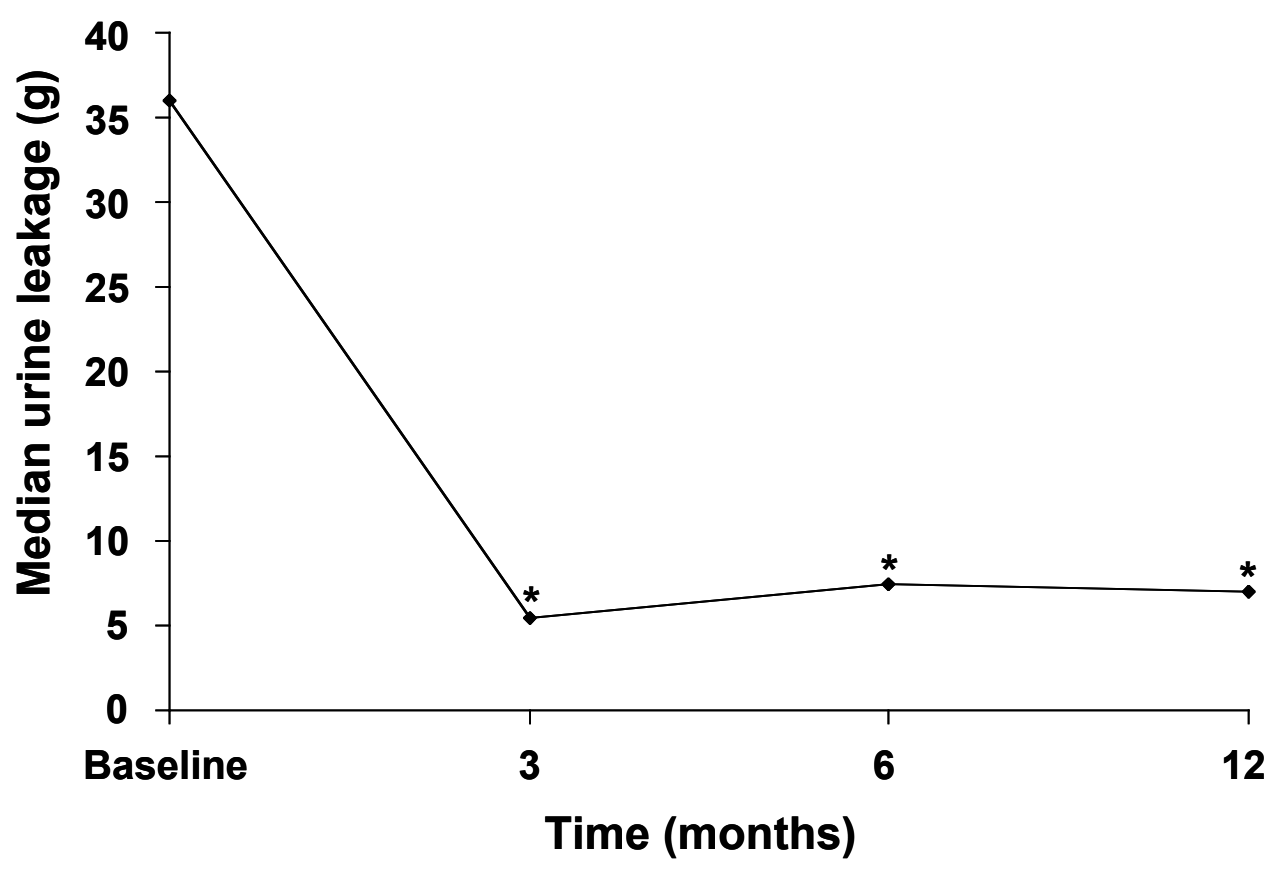

${ }^{*} P<0.0001$ vs baseline

B

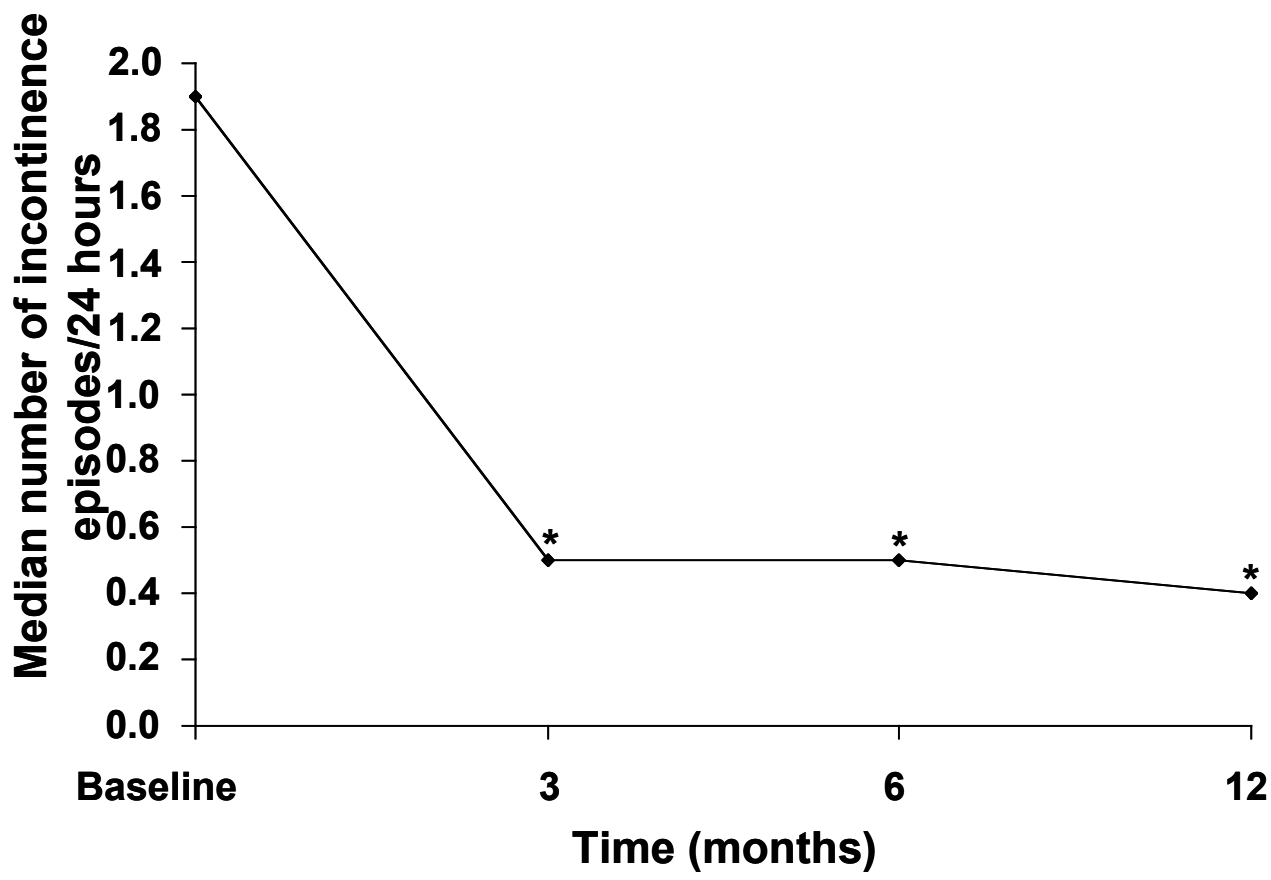




\section{Chapter 4}

\section{Treatment of stress urinary incontinence using a copolymer}

\section{system: impact on quality of life}

Philip van Kerrebroeck ${ }^{1}$, Flip ter Meulen ${ }^{1}$, Gregor Larsson ${ }^{2}$, Elisabeth Farrelly ${ }^{3}$, Lena Edwall ${ }^{4}$ and Aino Fianu-Jonasson ${ }^{4}$

${ }^{1}$ Department of Urology, University Hospital Maastricht, the Netherlands

${ }^{2}$ Department of Obstetrics and Gynecology, Västerås Central Hospital, Västerås,

Sweden

${ }^{3}$ Department of Urology, Karolinska Hospital, Stockholm, Sweden

${ }^{4}$ Department of Obstetrics and Gynecology, Huddinge University Hospital,

Stockholm, Sweden

Journal: BJU Int 2004;94:1040-1043. 


\section{Abstract}

Objective To investigate the effect on quality of life (QoL) of a novel system for stress urinary incontinence (SUI).

Patients and methods In an open, prospective, multicentre study, 42 women not previously treated by invasive therapy with urodynamically verified SUI received $4 \times 1.0 \mathrm{ml}$ or $4 \times 0.7 \mathrm{ml}$ of non-animal stabilized hyaluronic acid/dextranomer copolymer injected transurethrally into the urethra via the Implacer ${ }^{\mathrm{TM}}$ device (Zuidex ${ }^{\mathrm{TM}}$ system, Q-Med AB, Uppsala, Sweden). QoL was assessed using the King's Health Questionnaire. The patients' perception of treatment benefit and the number of incontinence episodes $/ 24 \mathrm{~h}$ were also investigated.

Results There were significant improvements over baseline in seven of 10 domains of the King's Health Questionnaire at 3 months, and these improvements were sustained at 1 year. For the change from baseline to 1 year, eight of 10 domains showed a significant positive correlation with the number of incontinence episodes/24 h. In terms of treatment benefit, most women perceived an improvement at 1, 3, 6 and 12 months. Of the 18 women requiring re-treatment, most perceiving an improvement at 3, 6 and 12 months.

Conclusions Treatment with the Zuidex system produced significant improvements over a year in both subjective QoL and objective incontinence measures, with a significant positive correlation observed between them.

Keywords stress urinary incontinence, quality of life, questionnaires, NASHA/dextranomer copolymer 


\section{Introduction}

Stress urinary incontinence (SUI), i.e. 'the complaint of involuntary leakage on effort or exertion, or on sneezing or coughing, ${ }^{1}$ is a common but often under-reported and under-treated condition, in which incidence rates increase with age. ${ }^{2}$ However, SUI is not just a problem in middle-aged or older women, as high prevalence rates have also been reported in younger women (20-45 years old). ${ }^{3}$ SUI can have a severe impact on quality of life (QoL), and women with this condition have a significantly lower QoL than continent women. ${ }^{4,5}$ The impact is multifactorial, affecting physical, social and psychological functioning and health perception, as well as in some cases sexual functioning, participation in employment, and sleep. Improving overall QoL should be the primary aim of all treatment for SUI. Current treatments include non-invasive therapy in the first instance (e.g. physiotherapy), sometimes supported by pharmacotherapy, with surgical therapy generally considered to be the next option in the many patients in whom these approaches fail. However, the majority of patients would choose not to have an operation for their incontinence, ${ }^{6}$ or it may be inappropriate. An alternative treatment option is endoscopic urethral injection, but this approach has gained limited acceptance because of concerns about both the safety and efficacy of previous bulking agents.

A commercial copolymer is available, consisting of dextranomer microspheres (80$250 \mu \mathrm{m}$ ) in a carrier gel of non-animal stabilised hyaluronic acid (Zuidex ${ }^{\mathrm{TM}}$, Q-Med $\mathrm{AB}$, Uppsala, Sweden). Injecting this copolymer via a guiding instrument (the ImplacerTM ${ }^{\mathrm{TM}} \mathrm{Q}-\mathrm{med} \mathrm{AB}$ ) is a minimally invasive treatment for SUI that can be administered as a hospital or an office procedure. Endoscopic injection of NASHA/Dx copolymer produced long-term efficacy ( $57 \%$ success rate; cure or improvement) in 20 SUI patients over a 6.5 -year follow-up, with no long-term safety 
concerns. ${ }^{7,8}$ These findings are notable, given the relative difficulty of achieving cure in the study population (elderly, median 74.5 years, and the failure of both previous and subsequent treatments for SUI). NASHA/Dx copolymer has been shown to be effective and well tolerated in the endoscopic treatment of VUR in children, with efficacy persisting for at least 5 years, and no associated long-term adverse events. ${ }^{9}$ The copolymer is the only injectable agent approved by the USA Food and Drug Agency for this indication; it is approved in European for the treatment of both VUR and SUI.

The Implacer is a new hand-held device that unfolds and fixates the urethra (i.e. distends the urethral circumference, thus smoothing the longitudinal folds), to ensure symmetrical placement of the NASHA/Dx copolymer gel at four evenly spaced locations around the urethra. Injection of the copolymer via the Implacer showed promising efficacy in a 12-month study and was well tolerated. There were significant reductions in urine leakage by the provocation test and in the number of incontinence episodes/24 h, and these were sustained for at least a year. ${ }^{10}$ Given the importance of improving QoL in the treatment of SUI, the effect of treatment on QoL was also investigated in the 12-month study, and the results are presented here.

\section{Patients and methods}

Women aged $\geq 18$ years (42, mean age 52.8 years, range $30.5-77.9)$ with SUI verified by leakage on coughing or a Valsalva manoeuvre, and with a history of SUI for at $\geq 1$ year, were treated in an open, prospective multicentre study. ${ }^{10}$ All the women had had no previous invasive therapy (i.e. no previous surgical therapy for SUI) and previous noninvasive treatment (e.g. behaviour modification, pelvic floor exercises, drug therapy) had failed. The study was conducted in accordance with the principles of the 
Declaration of Helsinki and approved by independent ethical committees, with informed consent obtained from all participants.

The patients were given 4 x $1.0 \mathrm{ml}$ (32 women) or 4 x $0.7 \mathrm{ml}$ (10 women) injections of NASHA/Dx copolymer using the Implacer (Zuidex ${ }^{\mathrm{TM}}$ system: four NASHA/Dx copolymer-filled syringes and the Implacer). After giving an appropriate anaesthetic and assembling of the Implacer, the four needles were covered with the Implacer tube and inserted into the urethra. The needle cover was retracted, allowing the four needles to move outwards at the mid-urethra. The four injections of copolymer were then given sequentially. Full information about the injection procedure is given elsewhere. ${ }^{10}$

The impact of treatment on QoL was assessed using the King's Health Questionnaire (KHQ), ${ }^{11}$ which patients completed at baseline, and at the 3- and 12-month follow-up visits. Translated and validated Swedish and Dutch versions were used, as the trial was conducted at centres in Sweden and The Netherlands.

Data was obtained from 32 questions relating to the following domains: general health perceptions (one question); urinary symptoms (one question); role limitations, physical limitations, social limitations, personal relationships, emotions, sleep/energy, severity measures (19 questions); and incontinence impact (11 questions). The answers were scored on a 4-point scale, and took $\approx 10$ minutes to complete. Summary scores in each domain range from 0 to 100 , a higher value indicating greater impairment. The patients' perception of treatment benefit was assessed at 1, 3,6 and 12 months after treatment. At the 1- and 3-month visits, patients were asked 'Do you consider yourself improved regarding your incontinence problems since your last visit?', with the response recorded as 'yes' or 'no'. At the 6- and 12-month visits, the same question was asked again and an answer of 'yes' or 'no' requested. If the answer 
was 'no' at the 1-month follow-up visit, one additional treatment could be administered 1-2 months after the first treatment, using the same method. If the answer was 'no' at the 3- or 6-month post-treatment visit, the patient was withdrawn because the treatment was ineffective and an alternative treatment prescribed.

The number of incontinence episodes/24 h, as assessed by a 1-week micturition chart, were measured at baseline and the 1, 3, 6 and 12-month follow-up visits.

Statistical analyses were based on the intention-to-treat and last observation carried forward principles. Median values are presented, as the data were not normally distributed. Changes from baseline in KHQ domain scores were analysed by Wilcoxon signed-rank test. Correlations between change from baseline to 12 months in KHQ domain scores and in the number of incontinence episodes/24 h were analysed using Spearman's correlation coefficient test (one-sided).

\section{Results}

As the efficacy outcomes and the patient demographics were very similar for the $4 \mathrm{x}$ $1.0 \mathrm{ml}$ and $4 \times 0.7 \mathrm{ml}$ groups, QoL variables were analysed for the total population only. At 3 months the median values of summary scores from seven of $10 \mathrm{KHQ}$ domains were significantly lower than the baseline scores (Fig. 1): incontinence impact, role limitations, physical limitations (all $p<0.0001$ ), social limitations $(p=0.0036)$, emotions, severity measures $(p<0.001)$ and urinary symptoms $(p=0.0019)$. Eight of 10 domains had no change in median scores between 3 and 12 months, while severity measures increased from 33 to 40 and urinary symptoms decreased from 7 to 6 . 
At 12 months the median scores were significantly lower than baseline for incontinence impact, role limitations, physical limitations, social limitations, emotions (all $\mathrm{p}<0.001)$, severity measures $(\mathrm{p}=0.0029)$, and urinary symptoms $(\mathrm{p}=0.0021)$. For the three remaining domains (personal relationships, sleep/energy and general health perceptions), the median scores were the same at baseline, and 3 and 12 months; for the first two of the three domains (personal relationships and sleep/energy) the median scores were zero at the three time.

The median number of incontinence episodes/ $24 \mathrm{~h}$ decreased significantly between baseline and 12 months $(\mathrm{p}<0.0001) .{ }^{10}$ In terms of the change from baseline to 12 months, eight of $10 \mathrm{KHQ}$ domains had a significant positive correlation with the number of incontinence episodes/24 h (Table 1), while two domains did not (general health perception and social limitations).

At 1, 3, 6 and 12 months, most patients perceived an improvement from the treatment (Fig. 2). The highest level of satisfaction was at 3 months (71\%), with a slight decrease in the percentage of patients perceiving an improvement over the 9 months. Eighteen patients (43\%) were re-treated because they had an insufficient response. Of these, $67 \%, 67 \%$ and $61 \%$ perceived an improvement at 3,6 and 12 months, respectively, compared with $75 \%, 63 \%$ and $58 \%$ of patients receiving only one injection.

\section{Discussion}

This study assessed the effect on QoL of a novel treatment system for SUI; the measurement of QoL is particularly important in the area of urinary incontinence, given that it is largely a symptom-defined condition. QoL assessment is recommended by several committees and by the ICS, ${ }^{12-14}$ with patient- rather than clinician-based 
questionnaires favoured ${ }^{14}$; both generic (e.g. the Short-Form Health Survey ${ }^{15}$ ) and disease-specific QoL questionnaires (e.g. the KHQ ${ }^{11}$ ) are used. Many recent studies investigating treatment options for SUI have assessed the impact on QoL. ${ }^{16-20}$ The KHQ has been classified as 'highly recommended' for both men and women, based on published data confirming its validity, reliability and responsiveness to change, ${ }^{14}$ and is simple to complete. In relation to the clinical significance of changes in domain scores, it is of relevance that there were significant correlations with common domains of the Short Form-36 questionnaire. ${ }^{11}$

The present findings show that injecting NASHA/Dx copolymer via the Implacer produced significant improvements in QoL throughout the 12-month study. Although there was no change in three domains (personal relationships, sleep/energy and general health perceptions), SUI does not generally affect sleep, and the results relating to personal relationships should be treated with caution, as values for this domain were missing in nine patients at all visits. For most KHQ domains the subjective improvement in QoL correlated with objective improvement (fewer incontinence episodes/24 h).

Importantly, the present data should be considered in context with patient preferences for the treatment of SUI. A recent survey of women with LUTS showed that most prefer less-invasive therapy, even if the chance of cure may be lower than with major procedures. ${ }^{6}$ The majority of women have realistic expectations of treatment outcome, with $43 \%$ hoping for a good improvement (reduced interference with daily life), and just $17 \%$ hoping for complete cure. Most women (65\%) considered occasional leakage on coughing or sneezing to be acceptable after treatment. Treatment with NASHA/Dx copolymer via the Implacer is consistent with these attitudes, and is therefore likely to be viewed positively by many patients. The convenience of this 
treatment (quick, office-based procedure with rapid resumption of normal routine) may also be an important consideration. Consistent with the improvement in QoL, there were high levels of patient-perceived treatment benefit. This was also evident in women who had been re-treated (i.e. two injections), with the level slightly higher at 6 and 12 months than in patients who had received one injection.

The small deterioration in the percentage of patients perceiving an improvement from 3 months onwards may be misleading, as the 3 -month value is enhanced by patients then having a re-treatment. Reductions in urine leakage and the number of incontinence episodes/24 h were sustained over the 1 -year period. ${ }^{10}$ Nevertheless, the follow-up of these patients will determine whether the decrease in perceived improvement will continue beyond a year, while further studies are awaited to determine whether this effect is real.

The typical management of SUI progresses from non-invasive therapy to surgical procedures, with clinical guidelines stating that, as a general rule, the first choice should be the least invasive treatment with the fewest potential complications appropriate for the patient. For example, US Agency for Health Care Policy and Research guidelines state that behavioural and pharmacologic therapies are usually reasonable first steps in management. ${ }^{21}$ NASHA/Dx copolymer offers a minimally invasive active treatment that has the potential to fill the present gap between these options. Possible benefits include increased speed and convenience of active treatment, and availability to many more women than is currently the case, with fewer patients needing to undergo surgery.

In conclusion, we describe a novel treatment for SUI that produces significant improvements over 12 months in both subjective QoL and objective incontinence measures, with a significant positive correlation observed between them. 
Acknowledgements. This study was supported by Q-Med AB, Uppsala, Sweden.

\section{References}

1. Abrams P, Cardozo L, Fall M, et al. The standardisation of terminology of lower urinary tract function: report from the Standardisation Sub-committee of the International Continence Society. Neurourol Urodyn 2002;21:167-78.

2. Elving LB, Foldspang A, Lam GW, et al. Descriptive epidemiology of urinary incontinence in 3,100 women age 30-59. Scand J Urol Nephrol Suppl 1989;125:3743.

3. van der Vaart CH, de Leeuw JR, Roovers JP, et al. The effect of urinary incontinence and overactive bladder symptoms on quality of life in young women. BJU Int 2002;90:544-9.

4. Hagglund D, Walker-Engstrom ML, Larsson G, et al. Quality of life and seeking help in women with urinary incontinence. Acta Obstet Gynecol Scand 2001;80:1051-5.

5. Simeonova Z, Milsom I, Kullendorff AM, et al. The prevalence of urinary incontinence and its influence on the quality of life in women from an urban Swedish population. Acta Obstet Gynecol Scand 1999;78:546-51.

6. Robinson D, Anders K, Cardozo L, et al. What do women want? Interpretation of the concept of cure. J Pelvic Surg Med 2003;9:273-7.

7. Stenberg AM, Larsson G, Johnson P. Urethral injection for stress urinary incontinence: long-term results with dextranomer/hyaluronic acid copolymer. Int Urogynecol J Pelvic Floor Dysfunct 2003;14:335-8; discussion 338. 
8. Stenberg AM, Larsson G, Johnson P, et al. DiHA Dextran Copolymer, a new biocompatible material for endoscopic treatment of stress incontinent women. Short term results. Acta Obstet Gynecol Scand 1999;78:436-42.

9. Lackgren G, Wahlin N, Skoldenberg E, et al. Long-term followup of children treated with dextranomer/hyaluronic acid copolymer for vesicoureteral reflux. J Urol 2001;166:887-92.

10. van Kerrebroeck P, ter Meulen F, Larsson G, et al. Efficacy and safety of a novel system (NASHA/Dx copolymer via the Implacer device) for the treatment of SUI. Urology 2004;64(2):276-281.

11. Kelleher CJ, Cardozo LD, Khullar V, et al. A new questionnaire to assess the quality of life of urinary incontinent women. Br J Obstet Gynaecol 1997;104:1374-9. 12. Mattiasson A, Djurhuus JC, Fonda D, et al. Standardization of outcome studies in patients with lower urinary tract dysfunction: a report on general principles from the Standardisation Committee of the International Continence Society. Neurourol Urodyn 1998;17:249-53.

13. Wall LL, Versi E, Norton P, et al. Evaluating the outcome of surgery for pelvic organ prolapse. Am J Obstet Gynecol 1998;178:877-9.

14. Donovan JL, Badia X, Corcos J, et al. Symptom and quality of life assessment. In: Abrams P, Cardozo L, Khoury S, Wein A, eds. Incontinence. 2nd edn. Plymouth: Health Publication Ltd, 2002:269-316.2002.

15. Ware JE, Jr., Sherbourne CD. The MOS 36-item short-form health survey (SF36). I. Conceptual framework and item selection. Med Care 1992;30:473-83.

16. Tamanini JT, D'Ancona CA, Tadini V, et al. Macroplastique implantation system for the treatment of female stress urinary incontinence. J Urol 2003;169:222933. 
17. van Kerrebroeck P, Abrams P, Lange R, et al. Duloxetine versus placebo in the treatment of European and Canadian women with stress urinary incontinence. BJOG 2004;111:249-57.

18. Goode PS, Burgio KL, Locher JL, et al. Effect of behavioral training with or without pelvic floor electrical stimulation on stress incontinence in women: a randomized controlled trial. JAMA 2003;290:345-52.

19. Perk H, Soyupek S, Serel TA, et al. Tension-free vaginal tape for surgical treatment of stress urinary incontinence: two years follow-up. Int J Urol 2003;10:1325.

20. Bidmead J, Cardozo L, McLellan A, et al. A comparison of the objective and subjective outcomes of colposuspension for stress incontinence in women. BJOG 2001;108:408-13.

21. AHCPR. Urinary Incontinence in Adults: Acute and Chronic Management. Clinical Practice Guideline Number 2 (1996 Update). AHCPR Publication 1996;No. 96-0682. 
TABLE 1. Spearman's correlation coefficients between change from baseline to 12 months in KHQ domain scores and in the number of incontinence episodes/24 h (All domains, 42 women, except personal relationships, 33, emotions, 41, and sleep/energy, 41).

\begin{tabular}{|l|c|c|}
\hline KHQ domain & $\begin{array}{c}\text { Correlation } \\
\text { coefficient }\end{array}$ & P \\
\hline General health perceptions & -0.12 & 0.8 \\
\hline Incontinence impact & 0.47 & $<0.001$ \\
\hline Role limitations & 0.37 & 0.005 \\
\hline Physical limitations & 0.40 & 0.002 \\
\hline Social limitations & 0.21 & 0.09 \\
\hline Personal relationships & 0.37 & 0.02 \\
\hline Emotions & 0.44 & 0.002 \\
\hline Sleep/energy & 0.29 & 0.03 \\
\hline Severity measures & 0.44 & $<0.001$ \\
\hline Urinary symptoms & 0.52 & $<0.001$ \\
\hline
\end{tabular}




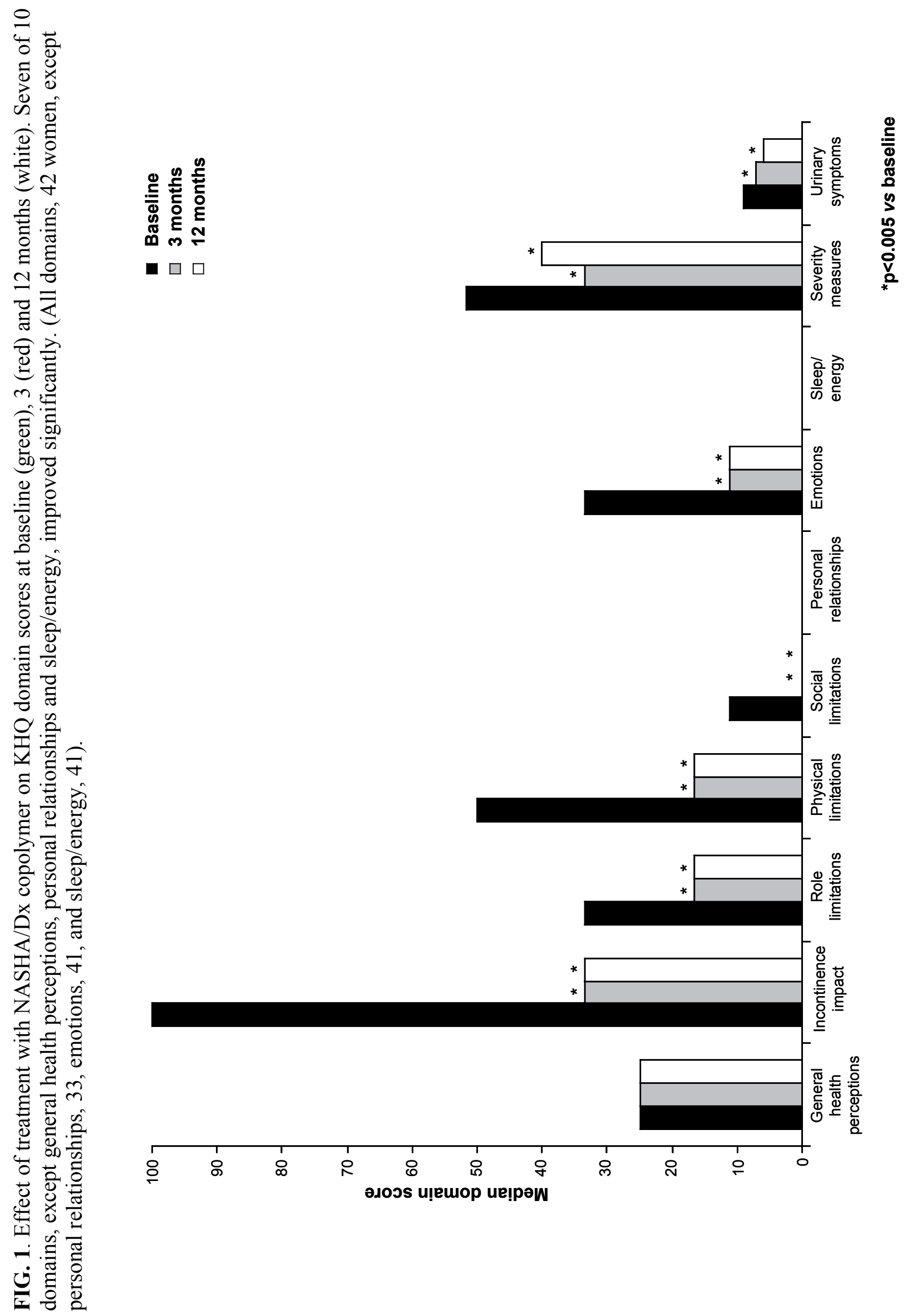


FIG. 2. The patients' perception of treatment benefit at 1, 3, 6 and 12 months (improved, red; not improved, white).

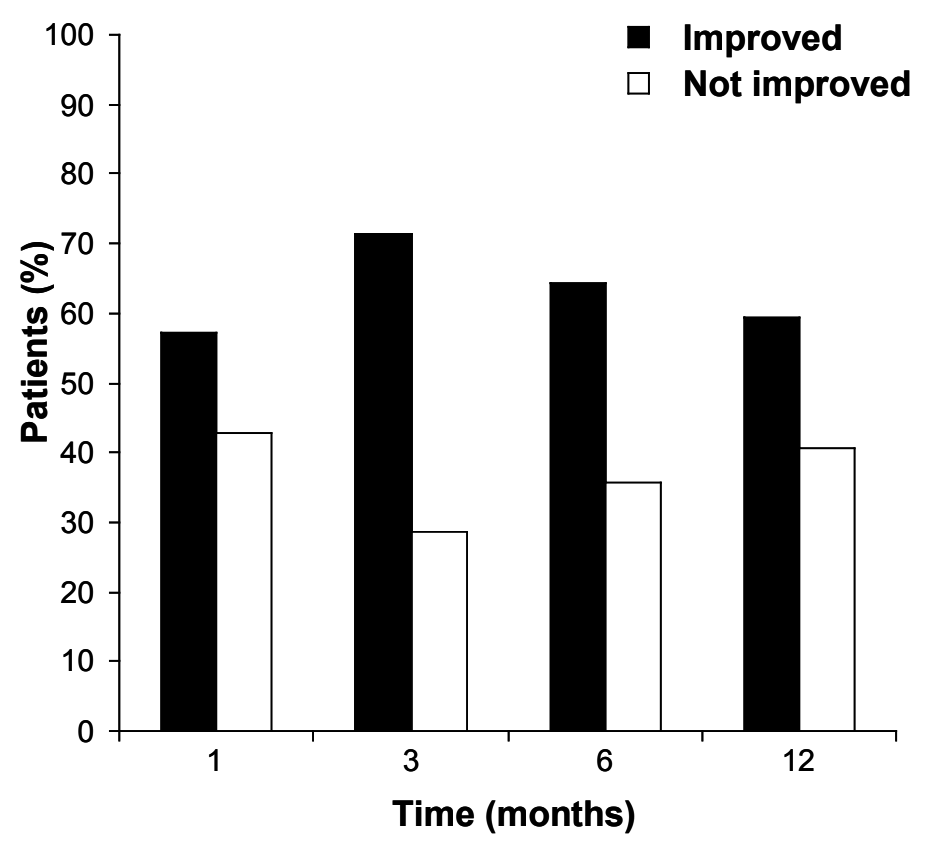




\section{Chapter 5}

\section{NASHA/Dx gel $\left(\right.$ Zuidex $\left.^{\text {TM }}\right)$ for the treatment of stress urinary}

\section{incontinence: results up to three year of follow-up}

Philip van Kerrebroeck ${ }^{a}$, Flip ter Meulen ${ }^{\text {a }}$, Gregor Larsson ${ }^{b}$, Elisabeth Farrelly ${ }^{\mathrm{c}}$, Lena Edwall $^{\mathrm{d}}$ and Aino Fianu-Jonasson ${ }^{\mathrm{d}}$

${ }^{a}$ Department of Urology, University Hospital Maastricht, the Netherlands

${ }^{\mathrm{b}}$ Department of Obstetrics and Gynecology, Västerås Central Hospital, Västerås, Sweden

${ }^{\mathrm{c}}$ Department of Urology, Karolinska Hospital, Stockholm, Sweden

${ }^{\mathrm{d}}$ Department of Obstetrics and Gynecology, Huddinge University Hospital, Stockholm,

Sweden

Submitted 


\begin{abstract}
Objectives To investigate the long-term efficacy, safety, and impact on quality of life (QoL) of stabilized non-animal hyaluronic acid/dextranomer (NASHA/Dx) gel (Zuidex $\left.{ }^{\mathrm{TM}}\right)-$ for the treatment of stress urinary incontinence (SUI).

Methods This was an open, multicenter, prospective study of NASHA/Dx gel, in 42 female patients aged $\geq 18$ years, with SUI of undetermined pathophysiology (hypermobility and/or intrinsic sphincter deficiency). Patients were followed for up to 36 months. Efficacy parameters included urine leakage by provocation test, number of incontinence episodes/24 hours and patients' perception of bladder condition. QoL was assessed using the King's Health Questionnaire (KHQ).
\end{abstract}

Results Seventeen patients completed the provocation test at 36 months: all were treatment responders ( $\geq 50 \%$ reduction in provocation test leakage) and nine were dry. For the intention-to-treat population (ITT), provocation test responder rate at 36 months was $41-66 \%$ (depending on statistical method used to substitute for missing values). At 36 months, significant reductions versus baseline were observed for the ITT population in both urine leakage by provocation test (6-14 vs. $37 \mathrm{~g})$ and number of incontinence episodes/24 hours (0.6-1 vs. 1.9 episodes/day). Significant improvements were noted in six of the ten KHQ domain scores sustained to 36 months. At their last clinic visit, 26 patients (62\%) reported improved perception of bladder condition. The majority of reported treatment-related adverse events was mild-to-moderate in severity and occurred within 12 months.

Conclusions For patients remaining in this study, significant improvements in incontinence symptoms were observed up to 3 years post-treatment.

Abbreviations: SUI, stress urinary incontinence; NASHA/Dx, stabilized non-animal hyaluronic acid/dextranomer; QoL, quality of life; KHQ, King's Health Questionnaire 


\section{Introduction}

Stress urinary incontinence (SUI; involuntary leakage of urine upon exertion such as jumping, coughing or sneezing ${ }^{1}$ ) accounts for $\geq 50 \%$ of urinary incontinence cases reported by women. ${ }^{2}$ Stabilized non-animal hyaluronic acid/dextranomer (NASHA/Dx) gel is a biocompatible and biodegradable material that, when injected into the urethra, augments the tissue helping to restore urinary continence. ${ }^{3}$ NASHA/Dx gel administered using the Implacer $^{\mathrm{TM}}$ device is approved in Europe and currently under investigation in the USA for SUI. ${ }^{4,5}$ The Implacer is a novel, hand-held guiding instrument that provides a standardized transurethral injection method. The procedure does not require an endoscope or surgical facilities.

The efficacy of NASHA/Dx gel for SUI was investigated in two open-label, multicenter, prospective studies. ${ }^{4,6}$ Statistically significant reductions in urine leakage were observed in both studies at 3 and 12 months post-treatment ( $<<0.0001$ vs baseline, intention-to-treat [ITT] population). Using the King's Health Questionnaire (KHQ), ${ }^{7}$ both studies also showed that NASHA/Dx gel treatment produced significant improvements in quality of life (QoL). ${ }^{6,8}$ Longer-term efficacy was demonstrated in a single cohort of elderly patients (using endoscopic urethral injection of NASHA/Dx gel, before introduction of the Implacer device), the majority of whom had failed previous SUI treatments. ${ }^{9}$ Of 16 patients followed up for 6-7 years post-treatment, nine $(56 \%)$ demonstrated a sustained response to treatment throughout follow-up.

The present study was performed to assess the response in terms of urinary leakage and QoL up to 36 months post-treatment.

\section{Materials and methods}

This was an extension of an open, multicenter, prospective study of NASHA/Dx gel (Zuidex ${ }^{\mathrm{TM}}$; Q-Med, Uppsala, Sweden) for the treatment of SUI in females. ${ }^{4}$ The study was 
approved by independent ethics committees and performed in accordance with the principles of the Declaration of Helsinki. A separate written consent form was signed by patients at 12 months, for continuation with the study longer term.

All patients were invasive-therapy naïve, aged $\geq 18$ years, had a history of SUI for $\geq 12$ months and had failed previous non-invasive treatments for SUI (e.g. pharmacotherapy, pelvic floor exercises, behavior modification). The presence of SUI was verified by demonstrable leakage on coughing or Valsalva maneuver. The pathophysiology of SUI (hypermobility and/or intrinsic sphincter deficiency) was not determined. Patients were excluded if they had a postvoid residual urine (PVRU) volume $>100 \mathrm{ml}$ or a mean volume voided $<200 \mathrm{ml}$, urge incontinence, detrusor overactivity, recurrent urinary tract infection, were receiving medication for SUI, or were undergoing anticoagulant or immunosuppressive therapy. NASHA/Dx gel was administered using the Implacer device, under either general or local anesthetic. If following initial treatment the patient was not completely dry or improved to her satisfaction, one further treatment was offered after 1-2 months. The timing of subsequent follow-up visits ( $\geq 3$ months) was taken from the last treatment received.

Clinic visits for the initial study were scheduled at months 1, 3, 6 and 12. Patients that completed the 12-month follow-up were eligible to attend at 24 and 36 months. At all visits, the following assessments were made: urine leakage by provocation test (primary variable; short-term pad test using a standardized exercise routine with $300 \mathrm{ml}$ saline in the bladder); number of incontinence episodes/24 hours (recorded in a patient diary); and patients' perception of bladder condition (validated in patients with overactive bladder and recommended by the European Medicine Evaluation Association as a measure for urinary incontinence; graded as: no, some very minor, some minor, some, some severe, and many severe problems). ${ }^{4,10,11}$ A positive response to treatment was defined as a reduction in urine 
leakage by provocation test of $\geq 50 \%$ from baseline. The KHQ was completed at months 3,12 , 24 and $36 .^{7}$

Statistical analyses were performed on the results from all patients attending each study visit, and for the ITT population (i.e. all patients enrolled) at the final visit (36 months). Two analyses were performed on the ITT population: last observation carried forward (LOCF), and baseline value carried forward (BCF) techniques to substitute missing values. Intra-patient changes from baseline in urine leakage by provocation test, number of incontinence episodes/24 hours and median change from baseline in KHQ domain scores were analyzed by Wilcoxon's signed rank test (two-tailed significance level of 0.05). Patients' perception of bladder condition was analyzed using descriptive statistics.

\section{Results}

Forty-two patients were recruited at baseline (ITT population, Table I). Eighteen patients $(43 \%)$ received a second treatment.

Of 42 patients enrolled, 5 were lost to follow-up, 1 withdrew consent and 10 were withdrawn due to lack of efficacy during the first 12 months. ${ }^{4}$ Six patients were excluded at 12 months: re-treatment (1); treatment with tension-free vaginal tape (3); a move abroad (1); and site not participating in the extended period of the study (1). A further 2 patients were lost to followup between 24 and 36 months: lack of efficacy and withdrew consent. Therefore, a total of 18 patients remained at 36 months; one of whom was excluded from the provocation test assessments due to a negative result $(0 \mathrm{~g})$ recorded at baseline (false inclusion).

Table II outlines results for patients attending each study visit up to 36 months. Of the seventeen patients who completed the final provocation test assessment all were treatment responders and $16(94 \%)$ were classified as treatment responders at both the 3 month and 36 month assessments. Nine patients attending at 36 months (53\%) were dry: two (12\%) were 
dry at both 3 and 36 months. For the ITT population at 36 months $(n=41)$, provocation test positive response rate was $41-66 \%$ (BCF and LOCF analyses, respectively) and $22-32 \%$ of patients were dry (no leakage $(0 \mathrm{~g})$ on provocation test). At each study visit, the majority of patients reported perceived improvements in bladder condition (intra-timepoint range 69$83 \%)$.

At 36 months, median urine leakage by provocation test in the ITT population decreased from $37 \mathrm{~g}$ at baseline to $6-14 \mathrm{~g}(\mathrm{p}<0.0001)$, and the median number of incontinence episodes $/ 24$ hours decreased from 1.9 at baseline to $0.6-1(\mathrm{p} \leq 0.0003)$. At all post-treatment visits, significant reductions versus baseline were observed in urine leakage by provocation test and number of incontinence episodes/24 hours ( $\mathrm{p}<0.0001$ vs baseline; Figs. 1 and 2).

The KHQ domain scores for incontinence impact, role limitations, physical limitations, social limitations, emotions and urinary symptoms were significantly reduced from baseline to 36 months in both ITT analyses (Table III). Similar outcomes were evident in results from patients attending each visit. Improvements in these domains were apparent at 3, 12 and 36 months, with no evidence of deterioration during the follow-up period. A reduction in the score for the severity measures domain was also observed, but this did not reach significance at 36 months.

The median domain scores for personal relationships and sleep/energy were zero at baseline (indicating no impairment) and did not increase at 3, 12 or 36 months. No significant change from baseline was observed in the general health perception domain score, either in the ITT analyses (36 months) or for the patients attending each visit.

Treatment-related adverse events were reported in 36\% (15/42) of patients. The majority (96\%) were mild-to-moderate, and all occurred within 12 months. ${ }^{4}$ All, except one sterile abscess, were urinary system disorders, the most common being urinary tract infection $(n=6)$, hematuria $(n=4)$, urethral disorder $(n=3)$ and decreased urine flow $(n=3)$. 


\section{Discussion}

In this, the longest follow-up study of NASHA/Dx gel using the Implacer to date, improvements in incontinence symptoms were sustained for at least 36 months.

A short-term pad test (provocation test) was chosen as the primary variable as it offers a standardized method of measuring incontinence severity (same bladder volume and exercise routine at each visit).

To give a non-biased representation of the long-term response to treatment, two statistical analyses were applied to the ITT population. The first assumed all drop-outs were nonresponders, and substituted missing values with the value observed at baseline (baseline carried forward, BCF). The BCF analysis represents the "worst case", as a proportion of dropouts may have achieved a long-term response, but discontinued the study for reasons unrelated to treatment (e.g. a move abroad). The second analysis assumed that the value obtained at the final visit attended is maintained for all subsequent timepoints (last observation carried forward, LOCF). The LOCF analysis may represent a "best case", as for some patients, treatment effect may not have continued after drop-out. The LOCF analysis is a widely accepted method for substituting missing values in a dataset, used in previous studies of SUI treatments. ${ }^{4,12}$ Treatment outcome can be expected to lie somewhere between the BCF and LOCF values.

For both ITT analyses, significant improvements in incontinence symptoms were observed at 36 months (41-66\% were treatment responders). For patients not responding to treatment, case reports have demonstrated that injection of NASHA/Dx gel does not affect later surgery for SUI if required. ${ }^{13}$

The positive impact of NASHA/Dx gel treatment on QoL was also sustained to 36 months. The greatest improvement was observed for those domains showing most impairment before treatment: incontinence impact, role limitations and physical limitations. 
Direct comparisons of NASHA/Dx gel with other injectable materials are hampered by a lack of comparative studies. Nevertheless, available data suggest no clear difference in response rates between NASHA/Dx gel, collagen, calcium hydroxyapatite, carbon coated zirconium beads and silicone (3/4 patients cured or improved). ${ }^{14-17}$

Comparing the long-term response of NASHA/Dx gel with other agents is also difficult due to lack of data and differences in study design (patient selection, assessments, definition of response). The results presented here are in agreement with a recent study of silicone $\left(\right.$ Macroplastique $^{\circledR}$ ) that demonstrated favourable long-term results (no significant difference in Stamey grading and objective cure rate between 6 and 60 months post-treatment). ${ }^{18}$ In contrast, a decline in effect over time has been observed with collagen, in particular, and carbon coated zirconium beads. ${ }^{14,17}$ The probability of remaining dry following collagen injection decreased from $71 \%$ to $46 \%$ at $1-3$ years post-treatment in one study. ${ }^{19}$ In a later comparative study, efficacy rates decreased from $63 \%$ at baseline, to $21 \%$ and $9 \%$ at 36 months for carbon-coated zirconium beads and collagen, respectively. ${ }^{20}$ The current observations with NASAH/Dx gel are of importance, therefore, given that NASHA/Dx gel, like collagen, is a biodegradable material.

NASHA/Dx gel was well tolerated. The most frequent adverse events were of a type common to all substances following urethral injection (e.g. hematuria, and decreased urine flow). ${ }^{14}$ One patient in the original 12-month follow-up developed a pseudocyst - a rare potential complication following urethral injection, also reported in studies of alternative injectable agents including collagen and carbon coated zirconium beads. ${ }^{14,21}$ Investigations of NASHA/Dx gel for SUI have revealed a low overall incidence of pseudocysts $\left(2-10 \%{ }^{6,22}\right)$ and cases can be easily resolved with simple fluid aspiration, performed as an outpatient procedure. ${ }^{5}$ 


\section{Conclusions}

Injection of NASHA/Dx gel is well tolerated and improvements in incontinence symptoms are sustained in many patients for at least 36 months. These findings are encouraging and suggest that the Zuidex system (NASHA/Dx gel administered using the Implacer) is an appropriate treatment option for SUI where non-invasive methods have failed.

\section{References}

1. Abrams P, Cardozo L, Fall M, Griffiths D, Rosier P, Ulmsten U, van Kerrebroeck P, Victor A and Wein A: The standardisation of terminology of lower urinary tract function: report from the Standardisation Sub-committee of the International Continence Society. Am J Obstet Gynecol. 187: 116-26, 2002.

2. Minassian VA, Drutz HP and Al-Badr A: Urinary incontinence as a worldwide problem. Int J Gynaecol Obstet. 82: 327-38, 2003.

\section{Stenberg A, Larsson G, Johnson P, Heimer G and Ulmsten U: DiHA Dextran}

Copolymer, a new biocompatible material for endoscopic treatment of stress incontinent women. Short term results. Acta Obstet Gynecol Scand. 78: 436-42, 1999.

4. van Kerrebroeck P, ter Meulen F, Larsson G, Farrelly E, Edwall L and Fianu-Jonasson A: Efficacy and safety of a novel system (NASHA/Dx copolymer via the Implacer device) for the treatment of SUI. Urology. 64: 276-81, 2004.

5. Petrou SP, Pak RW and Lightner DJ: Simple aspiration technique to address voiding dysfunction associated with transurethral injection of dextranomer/hyaluronic acid copolymer. Urology. 68: 186-8, 2006.

6. Chapple C, Haab F, Cervigni M, Dannecker C, Fianu-Jonasson A and Sultan AH: An open, multicentre study of NASHA/Dx gel $\left(\right.$ Zuidex $\left.^{\mathrm{TM}}\right)$ for the treatment of stress urinary incontinence. Eur Urol. 48: 488-94, 2005. 
7. Kelleher CJ, Cardozo LD, Khullar V and Salvatore S: A new questionnaire to assess the quality of life of urinary incontinent women. Br J Obstet Gynaecol. 104: 1374-9, 1997. 8. van Kerrebroeck P, ter Meulen F, Larsson G, Farrelly E and Fianu-Jonasson A: Treatment of stress urinary incontinence using a novel system (NASHA/Dx copolymer via the Implacer device) - impact on quality of life. BJU Int. 94: 1040-3, 2004.

9. Stenberg AM, Larsson G and Johnson P: Urethral injection for stress urinary incontinence: long-term results with dextranomer/hyaluronic acid copolymer. Int Urogynecol J Pelvic Floor Dysfunct. 14: 335-8; discussion 338, 2003.

10. Coyne KS, Matza LS, Kopp Z and Abrams P: The validation of the patient perception of bladder condition (PPBC): a single-item global measure for patients with overactive bladder. Eur Urol. 49: 1079-86, 2006.

11. Khullar V, Hill S, Laval KU, Schiotz HA, Jonas U and Versi E: Treatment of urgepredominant mixed urinary incontinence with tolterodine extended release: a randomized, placebo-controlled trial. Urology. 64: 269-74, 2004.

12. Van Kerrebroeck P: Duloxetine: an innovative approach for treating stress urinary incontinence. BJU Int. 94 Suppl 1: 31-7, 2004.

13. Fianu-Jonasson A and Edwall L: Stress urinary incontinence: feasibility of surgery after urethral injection. Acta Obstet Gynecol Scand. 82: 1060, 2003.

14. Chapple CR, Wein AJ, Brubaker L, Dmochowski R, Pons ME, Haab F and Hill S: Stress incontinence injection therapy: what is best for our patients? Eur Urol. 48: 552-65, 2005.

15. ter Meulen $\mathrm{H}$ and van Kerrebroeck E: Injection therapy for stress urinary incontinence in adult women. Expert Rev Med Devices. 1: 205-13, 2004.

16. Lightner D, Calvosa C, Andersen R, Klimberg I, Brito CG, Snyder J, Gleason D, Killion D, Macdonald J, Khan AU et al:: A new injectable bulking agent for treatment of 
stress urinary incontinence: results of a multicenter, randomized, controlled, double-blind study of Durasphere. Urology. 58: 12-5, 2001.

17. Costa P, Junemann KP and Lightner DJ: Advancing the treatment of stress urinary incontinence. BJU Int. 97: 911-5, 2006.

18. Tamanini JT, D'Ancona CA and Netto NR: Macroplastique implantation system for female stress urinary incontinence: long-term follow-up. J Endourol. 20: 1082-6, 2006.

19. Herschorn S, Steele DJ and Radomski SB: Followup of intraurethral collagen for female stress urinary incontinence. J Urol. 156: 1305-9, 1996.

20. Chrouser KL, Fick F, Goel A, Itano NB, Sweat SD and Lightner DJ: Carbon coated zirconium beads in beta-glucan gel and bovine glutaraldehyde cross-linked collagen injections for intrinsic sphincter deficiency: continence and satisfaction after extended followup. J Urol. 171: 1152-5, 2004.

21. Madjar S, Sharma AK, Waltzer WC, Frischer Z and Secrest CL: Periurethral mass formations following bulking agent injection for the treatment of urinary incontinence. J Urol. 175: 1408-10, 2006.

22. Hagemeier T, Blau U, Gauruder-Burmester A and Tunn R: [Paraurethral abscess developing after mid-urethral Zuidex-injection in women with stress urinary incontinence -management of complications and retrospective comparison with bladder neck located injection technique]. Zentralbl Gynakol. 128: 68-70, 2006. 
Figure 1. Median urine leakage by provocation test following treatment with NASHA/DX gel. Left-hand bars show results for the intention-to-treat population $(n=41)$, using the baseline carried forward and last observation carried forward methods, respectively, for substituting missing values at 36 months. Right-hand bars show results for patients attending each study visit.

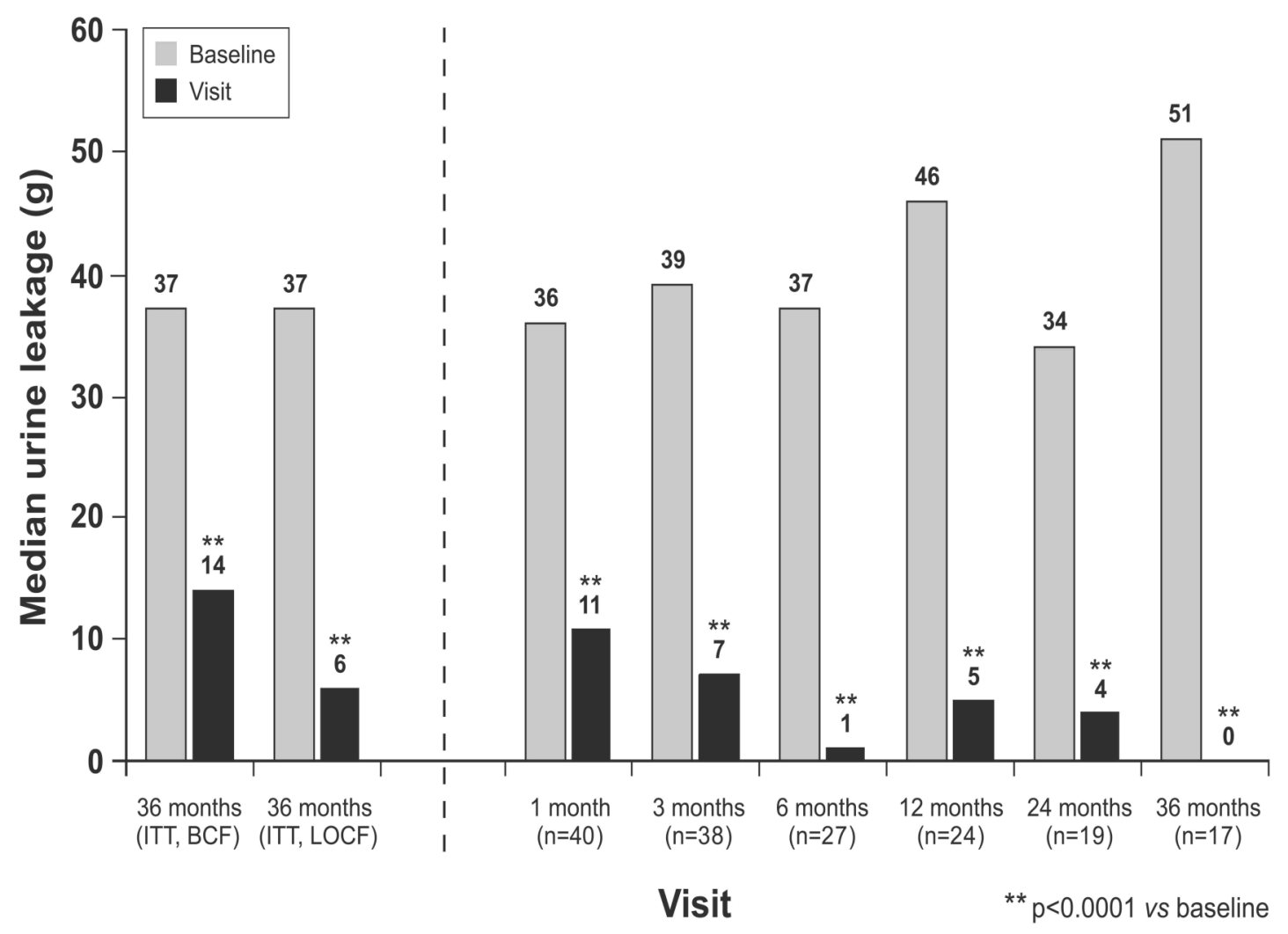

ITT: intention to treat. BCF: baseline carried forward. LOCF: last observation carried forward. 
Figure 2. Median number of incontinence episodes/24 hours following treatment with

NASHA/DX gel. Left-hand bars show results for the intention-to-treat population $(n=42)$

using the baseline carried forward and last observation carried forward methods, respectively, for substituting missing values at 36 months. Right-hand bars show results for patients attending each study visit.

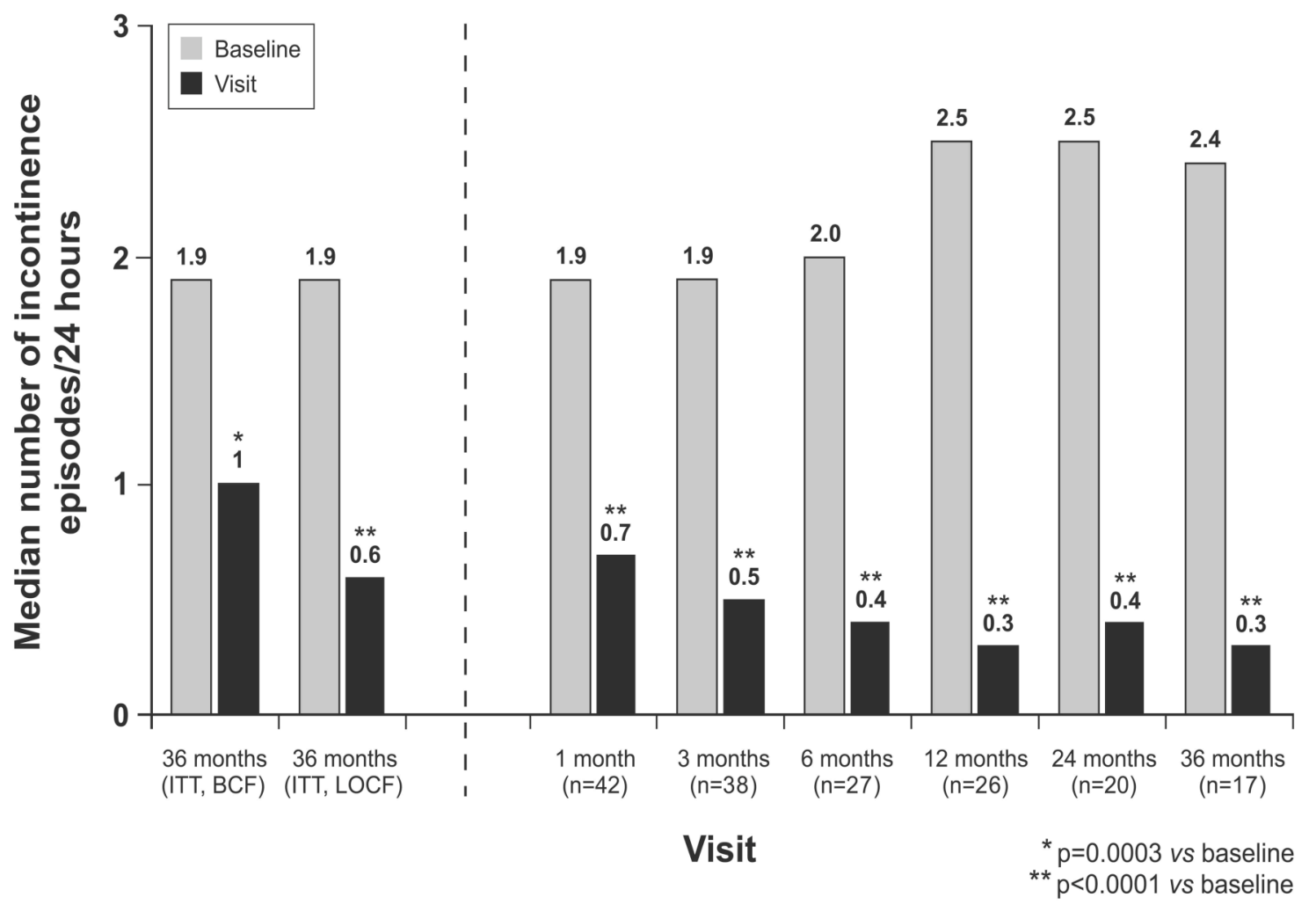

ITT: intention to treat. BCF: baseline carried forward. LOCF: last observation carried forward. 
Table 1. Baseline characteristics of the ITT study population $(n=42)$

\begin{tabular}{ll}
\hline Mean age, years (range) & $53(78-30)$ \\
Mean body mass index, $\mathrm{kg} / \mathrm{m}^{2}$ (range) & $24.4(34.3-19.0)$ \\
Menopause, $\mathrm{n}(\%)$ & $22(52 \%)$ \\
Deliveries 0-2, $\mathrm{n}(\%)$ & $29(69 \%)$ \\
Deliveries 3-4, $\mathrm{n}(\%)$ & $13(31 \%)$ \\
Duration of symptoms $>5$ years & $33(79 \%)$ \\
Severe problems (patient perception)* & $22(52 \%)$ \\
Previous non-drug therapy for SUI & $42(100 \%)$ \\
Urine leakage by provocation test, g (median [range]) & $35.5(300-0)$ \\
Number of incontinence episodes/24 hours (median [range]) & $1.9(24-0)$ \\
Maximum urethral closure pressure, cm H ${ }_{2} 0$ (mean [range]) & $44(86-9)$ \\
Maximum cystometric capacity, ml (mean [range]) & $473(960-170)$
\end{tabular}

*A report of 'some severe' or 'many severe' problems on the six-point patients' perception of bladder condition scale.

Table II. Treatment responders*, patients dry (no leakage) and patients showing an improvement of at least one category on the patients' perception of bladder condition scale

\begin{tabular}{|l|l|l|l|l|l|l|l|l|}
\hline & \multicolumn{2}{|l|}{$\begin{array}{l}\text { 36-month efficacy } \\
\text { (ITT population) }\end{array}$} & \multicolumn{6}{|c|}{$\begin{array}{l}\text { Observed efficacy at each study visit attended } \\
\text { (month) }\end{array}$} \\
\hline Assessment & $\begin{array}{l}\text { BCF } \\
\text { analysis }\end{array}$ & $\begin{array}{l}\text { LOCF } \\
\text { analysis }\end{array}$ & 1 & 3 & 6 & 12 & 24 & 36 \\
\hline $\begin{array}{l}\text { Provocation test } \\
\text { responder rate* }\end{array}$ & $\begin{array}{l}17 / 41^{\S} \\
(41 \%)\end{array}$ & $\begin{array}{l}27 / 41^{\S} \\
(66 \%)\end{array}$ & $\begin{array}{l}24 / 40 \\
(60 \%)\end{array}$ & $\begin{array}{l}25 / 38 \\
(66 \%)\end{array}$ & $\begin{array}{l}25 / 27 \\
(93 \%)\end{array}$ & $\begin{array}{l}20 / 24 \\
(83 \%)\end{array}$ & $\begin{array}{l}16 / 19 \\
(84 \%)\end{array}$ & $\begin{array}{l}17 / 17 \\
(100 \%)\end{array}$ \\
\hline $\begin{array}{l}\text { Patients dry } \\
\text { (no leakage (0 g) } \\
\text { on provocation } \\
\text { test) }\end{array}$ & $\begin{array}{l}9 / 41^{\S} \\
(22 \%)\end{array}$ & $\begin{array}{l}13 / 41^{\S} \\
(32 \%)\end{array}$ & $\begin{array}{l}8 / 40 \\
(20 \%)\end{array}$ & $\begin{array}{l}5 / 38 \\
(13 \%)\end{array}$ & $\begin{array}{l}13 / 27 \\
(48 \%)\end{array}$ & $\begin{array}{l}6 / 24 \\
(25 \%)\end{array}$ & $\begin{array}{l}6 / 19 \\
(32 \%)\end{array}$ & $\begin{array}{l}9 / 17 \\
(53 \%)\end{array}$ \\
\hline $\begin{array}{l}\text { Patients reporting } \\
\text { improved } \\
\text { perception of } \\
\text { bladder condition }\end{array}$ & $\begin{array}{l}15 / 42 \\
(36 \%)\end{array}$ & $\begin{array}{l}26 / 42 \\
(62 \%)\end{array}$ & $\begin{array}{l}30 / 42 \\
(71 \%)\end{array}$ & $\begin{array}{l}27 / 39 \\
(69 \%)\end{array}$ & $\begin{array}{l}22 / 27 \\
(81 \%)\end{array}$ & $\begin{array}{l}20 / 25 \\
(80 \%)\end{array}$ & $\begin{array}{l}15 / 20 \\
(75 \%)\end{array}$ & $\begin{array}{l}15 / 18 \\
(83 \%)\end{array}$ \\
\hline
\end{tabular}

*A response is defined as a $\geq 50 \%$ reduction from baseline in urine leakage by provocation test.

${ }^{\S}$ One patient was excluded from provocation test assessment due to false inclusion.

ITT: intention to treat. BCF: baseline carried forward. LOCF: last observation carried forward 
Table III. Effect of treatment with NASHA/Dx gel on King's Health Questionnaire domain scores

\begin{tabular}{|c|c|c|c|c|c|}
\hline \multirow[b]{2}{*}{ Domain } & \multicolumn{2}{|c|}{$\begin{array}{l}\text { Median change from baseline in } \\
\text { domain score at } 36 \text { months } \\
\text { (ITT population) }\end{array}$} & \multicolumn{3}{|c|}{$\begin{array}{c}\text { Median change from baseline in } \\
\text { domain score at each study visit } \\
\text { attended }\end{array}$} \\
\hline & $\begin{array}{l}\text { BCF analysis } \\
\text { (n) }\end{array}$ & $\begin{array}{l}\text { LOCF analysis } \\
\text { (n) }\end{array}$ & $\begin{array}{l}3 \text { months } \\
\text { (n) }\end{array}$ & $\begin{array}{l}12 \text { months } \\
\text { (n) }\end{array}$ & $\begin{array}{l}36 \text { months } \\
\text { (n) }\end{array}$ \\
\hline $\begin{array}{l}\text { General } \\
\text { health } \\
\text { perception }\end{array}$ & $\begin{array}{l}0(42) \\
p=0.29\end{array}$ & $\begin{array}{l}0(42) \\
\mathrm{p}=0.21\end{array}$ & $\begin{array}{l}0(39) \\
p=0.68\end{array}$ & $\begin{array}{l}0(25) \\
p=1.0\end{array}$ & $\begin{array}{l}0(17) \\
p=0.29\end{array}$ \\
\hline $\begin{array}{l}\text { Incontinence } \\
\text { impact }\end{array}$ & $\begin{array}{l}0(42) \\
p=0.0006\end{array}$ & $\begin{array}{l}-33(42) \\
p<0.0001\end{array}$ & $\begin{array}{l}-33(39) \\
p<0.0001\end{array}$ & $\begin{array}{l}-33(24) \\
p<0.0001\end{array}$ & $\begin{array}{l}-33(17) \\
p=0.0006\end{array}$ \\
\hline $\begin{array}{l}\text { Role } \\
\text { limitations }\end{array}$ & $\begin{array}{l}0(41) \\
p=0.0004\end{array}$ & $\begin{array}{l}-17(41) \\
p<0.0001\end{array}$ & $\begin{array}{l}-17(38) \\
\mathrm{p}<0.0001\end{array}$ & $\begin{array}{l}-17(24) \\
p=0.0002\end{array}$ & $\begin{array}{l}-33(16) \\
p=0.0004\end{array}$ \\
\hline $\begin{array}{l}\text { Physical } \\
\text { limitations }\end{array}$ & $\begin{array}{l}0(42) \\
p=0.0001\end{array}$ & $\begin{array}{l}-17(42) \\
\mathrm{p}<0.0001\end{array}$ & $\begin{array}{l}-33(39) \\
p<0.0001\end{array}$ & $\begin{array}{l}-33(25) \\
p<0.0001\end{array}$ & $\begin{array}{l}-33(17) \\
p=0.0001\end{array}$ \\
\hline $\begin{array}{l}\text { Social } \\
\text { limitations }\end{array}$ & $\begin{array}{l}0(41) \\
p=0.01\end{array}$ & $\begin{array}{l}-11(41) \\
p=0.0006\end{array}$ & $\begin{array}{l}-11(38) \\
p=0.004\end{array}$ & $\begin{array}{l}-11(24) \\
p=0.0004\end{array}$ & $\begin{array}{l}-11(16) \\
p=0.01\end{array}$ \\
\hline $\begin{array}{l}\text { Personal } \\
\text { relationships }\end{array}$ & $\begin{array}{l}0(31) \\
p=1.0\end{array}$ & $\begin{array}{l}0(31) \\
p=0.11\end{array}$ & \begin{tabular}{|l|}
$0(29)$ \\
$p=0.23$ \\
\end{tabular} & $\begin{array}{l}0(16) \\
p=0.55\end{array}$ & $\begin{array}{l}0(8) \\
p=1.0\end{array}$ \\
\hline Emotions & $\begin{array}{l}0(41) \\
p=0.005\end{array}$ & $\begin{array}{l}-11(41) \\
p=0.006\end{array}$ & $\begin{array}{l}-11(38) \\
p<0.0001\end{array}$ & $\begin{array}{l}-11(25) \\
p=0.006\end{array}$ & $\begin{array}{l}-11(16) \\
p=0.005\end{array}$ \\
\hline Sleep/energy & $\begin{array}{l}0(41) \\
p=0.53\end{array}$ & $\begin{array}{l}0(41) \\
p=0.03\end{array}$ & $\begin{array}{l}0(38) \\
p=0.009\end{array}$ & $\begin{array}{l}0(25) \\
p=0.01\end{array}$ & $\begin{array}{l}0(17) \\
p=0.53\end{array}$ \\
\hline $\begin{array}{l}\text { Severity } \\
\text { measures }\end{array}$ & $\begin{array}{l}0(42) \\
p=0.13\end{array}$ & $\begin{array}{l}-7(42) \\
p=0.03\end{array}$ & $\begin{array}{l}-10(38) \\
p=0.0005 \\
\end{array}$ & $\begin{array}{l}-13(25) \\
p=0.01\end{array}$ & $\begin{array}{l}-7(17) \\
p=0.13\end{array}$ \\
\hline $\begin{array}{l}\text { Urinary } \\
\text { symptoms }\end{array}$ & $\begin{array}{l}0(42) \\
p=0.002\end{array}$ & $\begin{array}{l}-1.0(42) \\
p=0.005\end{array}$ & $\begin{array}{l}-2(37) \\
p=0.002\end{array}$ & $\begin{array}{l}-4(24) \\
p=0.006\end{array}$ & $\begin{array}{l}-2(17) \\
p=0.002\end{array}$ \\
\hline
\end{tabular}

ITT: intention to treat. BCF: baseline carried forward. LOCF: last observation carried forward 


\section{Chapter 6}

Systematic review: Efficacy of silicone microimplants

(Macroplastique $\left.{ }^{\circledR}\right)$ therapy for stress urinary incontinence in adult women

Ph.H. ter Meulen (MD), L.C.M. Berghmans (PhD, MSc, RPt), Ph.E.V.A van Kerrebroeck $(\mathrm{PhD}, \mathrm{MD})$

Department of Urology, University Hospital Maastricht, Maastricht, the Netherlands

Journal: Eur Urol 2003:44:573-582. 


\begin{abstract}
Objective: To assess the efficacy of silicone microimplants (Macroplastique ${ }^{\circledR}$; polydimethylsiloxane) therapy for stress urinary incontinence in adult women, using a systematic review of identified studies.
\end{abstract}

Materials and methods: A computer-aided and manual search for published studies investigating silicone microimplants therapy for stress urinary incontinence in adult women. The methodological quality of the included studies was assessed using criteria based on generally accepted principles of interventional research.

Results: Only two RCTs, only published as an abstract, were found. Eleven pre-experimental or observational studies were identified. Overall, the methodological quality was low. The main methodological shortcomings of the studies were no random allocation procedure, lack of prestratification on prognostic determinants, no blinding, small sample sizes, and lack of proper analysis and presentation of results. There was variability in the indication for implantation, implantation procedure, rate and volume of silicone microimplants. The use of different outcome measures in most of the trials made comparison between studies difficult. Conclusions: Because of the low methodological quality of included studies, results should be interpreted with caution and no firm conclusions about the efficacy of silicone microimplants were possible. Randomized clinical trials, using valid and reliable subjective and objective measurements, are necessary to establish the efficacy of silicone microimplants therapy in treating stress urinary incontinence in adult women.

Key words: Macroplastique; silicone microimplants; injectable; urethral bulking agent; polydimethylsiloxane; stress urinary incontinence; adult; woman. 


\section{Introduction}

Urinary incontinence is a common but often neglected condition. The prevalence of urinary incontinence increases with age; $10-25 \%$ of women under age $65,15-30 \%$ of women in the community, and more than $50 \%$ of nursing home residents are affected by this condition (1). Stress urinary incontinence is a major contributor to urinary incontinence with an estimated prevalence of $21-46 \%(2,3)$. It is characterized by the involuntary leakage of urine, when the intra-vesical pressure exceeds the urethral resistance as a result of increased intra-abdominal pressure in the absence of a detrusor contraction (4). The treatment of an incontinent patient should be offered sequentially, beginning with the least invasive therapy. Treatment options are physiotherapy, minimally invasive devices, pharmacotherapy, urethral injections and surgery.

The basic principle of endoscopic injection of bulk-enhancing agents for treating stress urinary incontinence is the provision of an additional submucosal bulk. The bulking agent is usually implanted submucosally in the area of the bladder neck (mid-urethra) in women and at the external sphincter in men, and acts as a bulking agent which augments the urethral mucosa, improves coaptation and intrinsic sphincter function, resulting in an increase of urethral closing pressure and restoring urinary incontinence.

For many years various injectables or urethral bulking agents have been used in treating female stress urinary incontinence. In 1938, Murless produced the first report after injection of a sclerosing solution (sodium morrhuate) into the anterior wall of the vagina of 20 incontinent women, obtaining temporary scarring of the juxtaurethral tissues (5). In 1955, Quackels described 2 cases treated with paraffin injection into the perineum with restoring continence by compression of the membranous urethra (6). In 1963, Sachse described the use of the sclerosant Dondren into the urethra with some success (7). Local tissue damage and pulmonary complications, including pulmonary infarction and emboli, restricted continuation 
of their use. In the early seventies, Berg (8) and Politano (9) first described the use of polytetrafluoroethylene (PTFE : Teflon) injections around the urethra. In 1989, glutaraldehyde cross-linked collagen and autologous fat were first described by Shortliffe (10) and Gonzales de Garibay (11), respectively. The efficacy and disadvantage(s)/side-effect(s) of these injectables or urethral bulking agents are presented in Table 1 (12-35).

Ideally, a bulking agent should be non-immunogenic, biocompatible, non-toxic, and hypoallergenic. Moreover, a bulking agent should be effective and demonstrate anatomical integrity, bonds to local tissues with minimal inflammation, keeps its injected volume, does not migrate to vital organs, should be easy to use and be cost-effective.

The injectable agent, Macroplastique ${ }^{\circledR}$ (Uroplasty BV, Geleen, the Netherlands), is described as a solid silicone elastomer with favorable biocompatibility and bulking properties and meets, according to the manufacturer (36), the criteria mentioned above. In this report, we performed a systematic review to assess both this statement and its efficacy, and to evaluate procedures and possible side-effect(s) of silicone microimplants for the treatment of stress urinary incontinence in adult women.

\section{Macroplastique ${ }^{\circledR}$, the material}

Macroplastique ${ }^{\circledR}$ is a soft tissue bulking agent and is comprised of soft, flexible, highlytextured irregularly-shaped implants of heat vulcanized polydimethylsiloxane (a solid silicone elastomer) suspended in a bio-excretable carrier gel. The carrier gel is a pharmaceutical grade, water-soluble, low molecular weight polyvinylpyrrolidone (PVP or povidone) hydrogel which is absorbed by the reticuloendothelial system and excreted unchanged in the urine. Polydimethylsiloxane elastomer and polyvinylpyrrolidone have favorable biocompatibility properties. Polydimethylsiloxane is well tolerated by the cellular immune system and is nongenotoxic, non-carcinogenic and non-teratogenic (36). Nowadays, there is still some 
discussion about the minimal particle-size of urethral bulking agents with respect to migration, but authors seem to agree that particles larger than $80 \mu \mathrm{m}$ are not likely to migrate (37). In relevant literature, particle-sizes of polydimethylsiloxane varied between $120-264$ $\mu \mathrm{m}(38,39)$.

Because of its irregular shape and textured surface, agglomeration and host collagen deposition will be enhanced and encouraged. Injected particles will be organized within 6 to 8 weeks in firm nodules with infiltrated collagen and surrounded by a fibrous sheath that is well developed at 9 months $(37,40-42)$. Therefore, the risk of biodegradation and migration of polydimethylsiloxane appear to be non-existing (38). Because of the good bulking characteristics of polydimethylsiloxane mentioned above, probably less material has been required compared to other injectable bulking agents.

The safety of solid polydimethylsiloxane is demonstrated by its long history of successful use in different kinds of biomedical devices, like catheters, etc. There are reports showing an association between silicone gel-containing breast implants and late-onset connective tissue disorders (43-45). However, polydimethylsiloxane is a solid elastomer and not a silicone gel. No evidence has been reported that elastomers are associated with connective tissue disease (46).

Macroplastique ${ }^{\circledR}$, the procedure

The endoscopic injection procedure can be performed under general, regional or local anesthesia. During the transurethral procedure, under direct cystoscopic vision the needle is placed submucosally into the urethra at the six, ten and two o'clock positions 1.5 to $2.0 \mathrm{~cm}$ distal from the bladder neck. The material is slowly injected until a sufficient mucosal bleb is achieved. The procedure is completed if there is a total mucosal apposition together with occlusion of the urethral lumen. The injectable can also be administered periurethrally. This 
procedure is performed under cystoscopic control by inserting a spinal needle percutaneously adjacent to the urethra. After injecting, the cystoscope should not be advanced past injected areas and only small 'in and out' catheters (8-12 Fr) should be inserted because this may result in compression or extrusion of the bulking agent afterwards. To improve and simplify the transurethral implantation technique and to minimize problems associated with endoscopic procedures, the Macroplastique Implantation System (MIS) was developed for the treatment of female stress urinary incontinence. The device seems to allow a constant placement of the implants at predefined depth and angles at the six, ten and two o'clock position of mid-urethra within the same circumferential plane. To identify the site of implantation correctly, the ruler measuring scale on the topside of the device is used. The site of the bladder neck is identified as the position where the water flow from the fluid drainage channel ceases while the tip of the device is slowly withdrawn from the fluid-filled bladder. The standard implantation position is defined by withdrawing the device from the urethra to the appropriate location of the mid-urethra, i.e., 10-15 $\mathrm{mm}$ distance from the level of the bladder neck (Fig. 1).

\section{Materials and methods}

The computerized bibliographic databases from Medline, Excerpta Medica and Cochrane Field in Therapies and Rehabilitation at the University of Maastricht were searched for randomized clinical trials (RCTs), controlled clinical trials (CCTs), and studies with a preexperimental or observational design, published between 1980 and 2002. The keywords incontinence, urinary incontinence, stress urinary incontinence, genuine stress incontinence, urethra, injection, injectable, bulking agent, Macroplastique, silicone microimplants, adult and woman were used. Manual searches for more references of this literature were also 
undertaken. Selection criteria were used for inclusion of studies in this systematic review, and are listed in Table 2.

The methodological quality of the studies was assessed using a modified list of predefined methodological criteria, the Maastricht-Amsterdam Consensus List $(47,48)$, based on generally accepted principles of interventional research $(49,50)$. These criteria assess the internal validity (criteria B, E, F, G, H, I, J, L, N, P), external validity (criteria A, C, D, K, M), and power (criteria O, Q) (see Table 3). Points were given to each fulfilled criterion, and zero if not. The maximum methodological quality score (MQS) was 100 points. Because the two independent reviewers (PhHtM, LCMB) were familiar with most included studies, there was no blinding for authors, journals, and institution during assessment. After assessment, a hierarchical MQS list was generated; a higher MQS indicated that a study had a higher methodological quality. Studies were classified as of 'sufficient' methodological quality (i.e. moderate to high quality studies scoring $\geq 50$ points) or 'low' quality. Low-quality studies provide more limited evidence for efficacy of a treatment, because systematic errors or bias is more likely and more difficult to prevent (51).

\section{Results}

The literature search yielded 13 manuscripts (52-66) and 37 abstracts. Two manuscripts were excluded because they were published in different languages and no version in any of the languages mentioned above was available $(63,64)$. Only two RCTs were found. Because these were published only as an abstract, they had to be excluded $(65,66)$. Five manuscripts were pre-experimental and observational prospective studies $(54,57-59,62)$, the other six were considered to be retrospective $(52,53,55,57,60,61)$. In Table 4 , the 11 studies are presented in a hierarchical order according to the MQS; the median (range) MQS was 26 (21-34) from the 
maximum of 100 points. Of the methodological quality criteria, 14 of the 20 (A1, B1, B2, C, D, E, F, G, H, I, L, N, O, Q) were met by $<60 \%$ of the studies. The main methodological shortcomings of the studies were no random allocation procedure, lack of prestratification on prognostic determinants, no blinding, small sample sizes, and lack of proper description of analysis and presentation of results. Only 5 studies had a description of the inclusion and exclusion criteria $(54,57,60-62)$. None of studies were of sufficient methodological quality to enable valid conclusions to be drawn about polydimethylsiloxane injection for treating stress urinary incontinence due to intrinsic sphincter deficiency or urethral hypermobility in adult women.

The results of the studies are summarized in Table 5. Three different implantation procedures of polydimethylsiloxane were performed; periurethral $(52,56,61,62)$, transurethral $(53-55,58$ 60), or with the use of MIS (57). The indication for implantation was stress urinary incontinence due to intrinsic sphincter deficiency with or without urethral hypermobility. A subgroup analysis was performed in two studies $(58,62)$. In two other studies the type of stress incontinence was not mentioned (52,57). In all studies, most of the patients had undergone previous anti-incontinence or prolapse surgery. The procedure was performed under local, regional, or general anesthesia. The average implantation rate and volume were different between the studies, and varied between 1-1.47 and 2-7 ml, respectively. A second injection after 3 months was performed in some of the patients in an attempt to upgrade the outcome to dry (52-54,56-61). Reported cure and success rates (cured and improved) using polydimethylsiloxane for only intrinsic sphincter deficiency varied between 14 and $66.7 \%$ and between 46 and 80\%, respectively. For intrinsic sphincter deficiency with urethral hypermobility, the cure and success rates varied between 0 and $21.4 \%$ and between 0 and $58.9 \%$, respectively. Follow-up of the studies varied between 3 months and 3 years. Followup showed decreased success rate in 6 studies $(52-56,62)$. Outcome measurements of the 
studies were either subjective or objective, or both. Results were measured subjectively by rating of the investigator or using a patient questionnaire $(53,55-58,60,62)$. In 4 studies the results were also assessed objectively using a stress test or urodynamic studies $(52,54,59,61)$. At 6 and 12 months after polydimethylsiloxane injection, the maximum urethral closure pressure at rest increased significantly in 2 studies $(54,56)$. In another study, urodynamics showed a significant increase in functional urethral length, although no change in maximum urethral closure pressure at 1 month follow-up (58). Most of the failures were associated with vesical descent or bladder neck hypermobiltiy $(53,58,62)$. Before treatment there was no difference between women with or without mild cystocele $(55,56)$. Two studies reported after injection "de novo" idiopathic detrusor overactivity $(52,59)$.

In one study the MIS was described (57). Operator acceptance of this procedure was excellent or acceptable in $95 \%$ after first treatment and $100 \%$ after re-treatment. Urethral insertion was rated as acceptable in $92.5 \%$ of the procedures. In $89 \%$ of the implantation procedures, mild or moderate pain was experienced. All injections were performed under local anesthesia, except for 2 patients who wanted general anesthesia during re-treatment.

None of the studies reported major complications during or after the procedure. Only minor and transient complications, including dysuria, frequency, hematuria, post-operative pain, and urinary retention requiring intermittent catheterisation, have been described.

\section{Discussion}

Because in this systematic review only studies on silicone microimplants (Macroplastique ${ }^{\circledR}$; polydimethylsiloxane) are reviewed, any possible financial support or contribution of the manufacturers to the design or statistical analysis was investigated. It appeared to be that only 
support from the part of the industry was related to the provision of free material in two studies $(52,57)$.

To our knowledge, this is the first published systematic review of silicone microimplants therapy for stress urinary incontinence in adult women that used a list of criteria to assess the methodological quality of included studies. Because of the poor methodological quality and shortcomings and the variability in patient selection and interventional design, comparison between studies was difficult. Therefore, results should be interpreted with caution and no firm conclusions about the efficacy of silicone microimplants were possible. Lack of methodological quality still is a general problem in most studies investigating effects of bulking agents for stress urinary incontinence in adult women. A problem also faced in all other kinds of treatments. Therefore societies like the International Continence Society (ICS), American Urologic Association (AUA) and the World Health Organization (WHO) are developing methodological guidelines for research.

Careful patient selection by optimal diagnostical tools, like history taking including quality of life questionnaires, detailed physical examination, pad test, urodynamic assessment, bladder neck excursion measurements and review of a frequency/volume chart is important for maximal results of urethral bulking agent therapy. Urodynamic evaluation is necessary to demonstrate reduced leak point pressure and to exclude detrusor overactivity and bladder compliance abnormalities.

In general, injection therapy with urethral bulking agents is considered by patients and surgeons as a minimally invasive procedure. Injectables are suggested to offer several potential advantages over other surgical procedures, including lower morbidity, shorter procedure time, shorter inpatient stay and more rapid recovery (67). The procedure is most commonly based on day-case care and use of local or regional anesthesia. 
The mechanism of restoring continence after successful injection therapy is still not clear. Radley et al. reported that firm nodules were realized 6 weeks after polydimethylsiloxane implantation subserosally in the proximal urethra. These findings suggest that the mechanism of action of polydimethylsiloxane is augmentation of pressure transmission to the proximal urethra by producing focal and firm expansion of periurethral tissues (41). In some studies an obstructive component with a decrease in maximum flow and an increase in maximum detrusor pressure has been reported $(30,68,69)$. Other authors have suggested that obstruction is not the mechanism of restoring continence $(29,58,70,71)$. In successfully treated patients, injections result in a cephalad elongation of the urethra with a concomitant increase in pressure transmission ratio in the first quarter of urethral length. These changes are due to adequate injection at the bladder neck or proximal urethra preventing bladder neck opening during stress $(29,58,70,71)$. Therefore, exact placement of the injection material is important to achieve continence. An endoscopic procedure seems to be superior to periurethral application or ultrasound-guided injection for treating incontinence (72). As a procedure, MIS is a more easy procedure to perform than endoscopically guided implantation. The device enables consistent bolus placement at a pre-determined depth and site (57). Radley et al reported in general success to be associated with complete encirclement of the urethra by polydimethylsiloxane (59). If polydimethylsiloxane treatment failed, transvaginal or transurethral ultrasound could be performed to investigate correct placement of polydimethylsiloxane.

In general, optimal patient selection for injection therapy seem to be elderly women, patients with high operative risk, refuse open surgery, those following multiple previous pelvic surgery and radiotherapy, or those with stress incontinence due to intrinsic sphincter deficiency (70). Injection therapy might also be a good option for those women who want pregnancy/delivery. Patients with stress incontinence, caused by a combination of urethral 
hypermobility and intrinsic sphincter deficiency, with failure of suspension, may also benefit from this procedure (70). Bladder neck hypermobility may decrease the success of injection therapy $(53,58,62,73)$. However, some studies have reported a positive outcome of periurethral collagen injections in patients with stress incontinence caused by urethral hypermobility $(30,74)$. In other studies no differences in success between stress urinary incontinence with and without urethral hypermobility could be found $(28,75,76)$. Success seemed to be independent of age, parity, previous pelvic surgery, severity of incontinence, or concomitant a small or mild cystocele $(52,53,55,56)$. However, patients with no previous antiincontinence surgery seemed to have subjectively and objectively superior results in comparison with patients after previous anti-incontinence surgery (59). It is likely, that preexistent and 'de novo' idiopathic detrusor overactivity are negative prognostic factors for success. Patients with gross pelvic organ prolapse are not suitable for injection therapy (77). A leak point pressure increase of $10 \mathrm{~cm} \mathrm{H} 2 \mathrm{O}$ or more may predict success of therapy, providing indication of restoring continence and the required amount of injection material (78). Patients with a maximum urethral closure pressure of $20-50 \mathrm{~cm} \mathrm{H} 2 \mathrm{O}$ at rest had a better outcome than patients with a maximum urethral closure pressure lower than $20 \mathrm{~cm} \mathrm{H} 2 \mathrm{O}(79)$. As previous polydimethylsiloxane implantation does not appear to compromise future surgical outcome, patients who do not respond to injection therapy may still be treated using open surgical techniques (80).

Further research is mandatory to improve patient selection for treatment with urethral bulking agents. Treatment needs to be cost-effective since only limited resources are available for general healthcare. 


\section{Conclusions}

Because of the low methodological quality of included studies, results should be interpreted with caution and no firm conclusions about the efficacy of silicone microimplants were possible. Randomized controlled clinical trials, using valid and reliable subjective and objective measurements, are necessary to establish the efficacy of silicone microimplants therapy in treating stress urinary incontinence in adult women.

\section{References}

1. Urinary incontinence-ACOG Technical Bulletin, No.213, October 1995 (Replaces No. 100, January 1987). Int J Gynecol Obstet 1996;52:75-86.

2. Resnick N, Subbaro Y, Laurino E. Pathofysiology in urinary incontinence amongst institutionalized elderly persons. N Engl J Med 1989;320:1-7.

3. Ouslander J, Staskin D, Raz S, Su HL, Hepps K. Clinical versus urodynamic diagnosis in an incontinent geriatric female population. J Urol 1987;137:68-71.

4. Haab F, Zimmern PE, Leach GE. Female stress urinary incontinence due to intrinsic sphincter deficiency: recognition and management. J Urol 1996;156:3-17.

5. Murless BC. The injection treatment of stress incontinence. J Obstet Gynaecol Br Emp $1938 ; 45: 67-71$.

6. Quackels R. Deux incontinences après adenomectomie gueries par injection de parrafine dans le perinee. Acta Urol Belg 1955;23:259-262.

7. Sachse S. Treatment of urinary incontinence with sclerosing agent solutions: Indication, results, complications. Urol Int 1963;15:225-244.

8. Berg S. Polytef augmentation urethroplasty correction of surgically incurable incontinence by injection technique. Arch Surg 1973;107:379-381. 
9. Politano AV. Periurethral polytetrafluoroethylene injection for urinary incontinence. $\mathrm{J}$ Urol 1982;127:439-442.

10. Shortliffe LMD, Freiha FS, Kessler R, Stamey TA, Constantinou CE. Treatment of urinary incontinence by periurethral implantation of glutaraldehyde cross-linked collagen. J Urol 1989;141:538-541.

11. Gonzales de Garibay S, Jimeno C, York M, Gomez P, Borruell S. Endoscopic autotransplantation of fat tissue in the treatment of urinary incontinence in the female. $\mathrm{J}$ d'Urol 1989;95:363-366.

12. Mittleman RE, Marracchini JV. Pulmonary Teflon granuloma following periurethral Teflon injection for urinary incontinence. Arch Pathol Lab Med 1983;107:611-618.

13. Boykin W, Rodriquez FR, Brizzolara J, Thompson IM, Zeidman EJ. Complete urinary obstruction following periurethral polytetrafluoroethylene injection for urinary incontinence. J Urol 1989:1199-1200.

14. Malizia AA, Reiman HM, Myers RP, Sande JR, Barham SS, Benson RC, Dewanjee MK, Utz WJ. Migration and granulomatous reaction after periurethral injection of polytef (Teflon). JAMA 1984;251:3277-3281.

15. Aaronson IA, Rames RA, Green WB, Walsh LG, Hasal UA, Garen PD. Endoscopic treatment of reflux: migration of teflon to the lungs and brain. Eur Urol 1993;23:394-399.

16. Kiilholma PJ, Chancellor MB, Makinen J, Hirsch IH, Klemi PJ. Complications of Teflon injection for stress urinary incontinence. Neurourol Urodyn 1993;12:131-137.

17. Hakky M, Kolbusz R, Reyes CV. Chondrosarcoma of the larynx. ENTJ 1989;68:60-62.

18. Lewy RB. Experience with vocal cord injection. Ann Otol 1976;85:440-450.

19. Appell RA. Collagen injection therapy for urinary incontinence. Urol Clin North Am 1994;21:177-182. 
20. Stothers L, Goldenberg SL, Leone EF. Complications of periurethral collagen injection for stress urinary incontinence. J Urol 1998;159:806-807.

21. Wainstein MA, Klutke CG. Periurethral pseudocyst following cystoscopic collagen injection. Urology 1998;51(5):835-836.

22. Harris RL, Cundiff GW, Coates KW, Addison WA, Bump RC. Urethral prolapse after collagen injection. Am J Obstet Gynecol 1998;178(3):614-615.

23. Matthews K, Govier FE. Osteitis pubis after periurethral collagen injection. Urology 1997;49(2):237-238.

24. Tschopp PJ, Wesley-James T, Spekkens A, Lohfeld L. Collagen injections for urinary stress incontinence in a small urban urology practice: time to failure analysis of 89 cases. J Urol 1999;162:779-783.

25. Winters JC, Chiverton A. Scapero HM, Prats LJ. Collagen injection therapy in elderly women: long-term results and patient satisfaction. Urology 1999;55(6):856-861.

26. Gorton E, Stanton S, Monga A, Wiskind AK, Lentz GM, Bland DR. Periurethral collagen injection: a long-term follow-up study. BJU Int 1999;84:966-971.

27. Kim YH, Kattan MW, Boone TB. Correlation of urodynamic results and urethral coaptation with succes after transurethral collagen injection. Urology 1997;50(6):941948.

28. Herschorn S, Radomski SB. Collagen injections for genuine stress urinary incontinence: Patient selection and durability. Int Urogynecol 1997;8:18-24.

29. Khullar V, Cardozo LD, Abbott D, Anders K. GAX collagen in the treatment of urinary incontinence in elderly women: a two year follow up. Br J Obst Gynaecol 1997;104:9699.

30. Monga AK, Robinson D, Stanton SL. Periurethral collagen injections for genuine stress incontinence: A 2-year follow-up. Br J Urol 1995;76:156-160. 
31. Santarosa RP, Blaivas GJ. Periurethral injection of autologous fat for the treatment of sphincteric incontinence. J Urol 1994;151:607-611.

32. Currie L, Drutz HP, Oxorn D. Adipose tissue and lipid drop embolism following periurethral injection of autologous fat: case report and review of the literature. Int Urogynecol J Pelvic Floor Dysfunct 1997;8:923-926.

33. Palma PC, Riccetto CL, Netto Jr NR. Urethral pseudolipoma: a complication of periurethral lipo-injection for stress urinary incontinence in a women. J Urol 1996;155(2):646.

34. Su TH, Hsu CY, Chen JC. Injection therapy for stress incontinence in women. Int Urogynecol J 1999;10:200-206.

35. Dmochowski RR, Appell RA. Injectable agents in the treatment of stress urinary incontinence in women: where are we now? Urology 2000;56(supplement 6A):32-40.

36. Personal communication. Technical Overview: Macroplastique Implants for the treatment of stress urinary incontinence and vesicoureteral reflux. Uroplasty BV, Geleen, the Netherlands. 11/98:0334-4030 Rev. D.

37. Henly DR, Barrett DM, Weiland TL, O’Connor MK, Malizia AA, Wein AJ. Particulate silicone for use in periurethral injections: local tissue effects and search for migration. $\mathrm{J}$ Urol 1995;153:2039-2043.

38. Schulman CC. "Biocompatibility of Injected Materials in Urology" in Implanted and Injected Materials in Urology, Buzelin JM (Editor), ISIS Medical Media, Oxford, United Kingdom: 1995, Chapter 1 and 2.

39. Solomon LZ, Birch BR, Cooper AJ, Davies CL, Holmes SAV. Nonhomologous bioinjectable materials in urology: 'size matters'?. BJU Int 2000;85:641-645.

40. Smith DP, Kaplan WE, Oyasu R. Evaluation of polydimethylsiloxane as an alternative in the endoscopic treatment of vesicoureteral reflux. J Urol 1994:152:1221-1224. 
41. Radley SC, Chapple CR, Lee JA. Transurethral implantation of silicone polymer for stress incontinence: evaluation of a porcine model and mechanism of action in vivo. BJU Int 2000;85:646-650.

42. Allen O. Response to subdermal implantation of textured microimplants in humans. Aesth Plast Surg 1992;16:227-230.

43. Spiera H. Scleroderma after silicone augmentation mammoplasty. JAMA 1986;260:236238.

44. Varga J, Schumacher HR, Jiminez SA. Systemic sclerosis after augmentation mammoplasty with silicone implants. Ann Intern Med 1989;111:377-383.

45. Silver RM, Sahn EE, Allen JA, Sahn S, Greene W, Maize JC, Garen PD. Demonstration of silicone in sites of connective tissue disease in patients with silicone-gel breast implants. Arch Dermatol 1993;129:63-68.

46. Tinkler JB, Campbell HJ, Senior JM, Ludgate SM. Evidence for an association between the implantation of silicones and connective tissue disease. Medical Device Directorate (UK Department of Health) Report 1993; MDD/92/42:1-65.

47. Tulder Mw van, Assendelft WJJ, Koes BW, Bouter LM. Editorial board of the Cochrane Collaboration Back Review Group. Method guidelines for systematic reviews in the Cochrane Collaboration Back Review Group for spinal disorders. Spine 1997;22:22232230.

48. Rutjes AWS, Rossum E van, Verhagen AP, Berghmans LCM, Bie RA de. Effectivity of electrostimulation as treatment for motor urge incontinence in adult women: a systematic review. Ned T Fysiother 2001;111(1):2-12. Dutch.

49. Feinstein AR. Clinical epidemiology: the architecture of clinical research. Philadelphia: WB Saunders, 1985. 
50. Meinert CL. Clinical trials: design, conduct and analysis. New York: Oxford University Press, 1986.

51. Verhagen AP, Vet HCW de, Bie RA de, Kessels AGH, Boers M, Knipschild PG. Taking baths: the efficacy of balneotherapy in patients with arthritis. A systematic review. J Rheumatol 1997;24:1964-1971.

52. Harriss DR, Iacovou JW, Lemberger RJ. Periurethral silicone microimplants (Macroplastique) for the treatment of genuine stress incontinence. Br J Urol 1996;78:722728.

53. Sheriff MKM, Foley S, Mcfarlane J, Nauth-Misir R, Shah PJR. Endoscopic correction of intractable stress incontinence with silicone micro-implants. Eur Urol 1997;32:284-288.

54. Koelbl H, Saz V, Doerfler D, Haeusler G, Sam C, Hanzal E. Transurethral injection of silicone microimplants for intrinsic urethral sphincter deficiency. Obstet Gynecol $1998 ; 92: 332-336$.

55. Usman F, Henalla S. A single transurethral macroplastique injection as primary treatment for stress incontinence in women. J Obstet Gynecol 1998;18:56-60.

56. Hidar S, Attyaoui F, de Leval J. Injection périurétrale de microparticules de silicone dans le traitement de l'incontinence urinaire par insuffisance sphinctérienne. Prog Urol 2000;10:219-223.

57. Henalla SM, Hall V, Duckett JRA, Link C, Usman F, Tromans PM, van Veggel L. A multicentre evaluation of a new surgical technique for urethral bulking in the treatment of genuine stress incontinence. Br J Obstet Gynecol 2000;107:1035-1039.

58. Barranger E, Fritel X, Kadoch, Liou Y, Pigné A. Results of transurethral injection of silicone microimplants for women with intrinsic sphincter deficiency. J Urol 2000;164:1619-1622. 
59. Radley SC, Chapple CR, Mitsogiannis IC, Glass KS. Transurethral implantation of macroplastique for the treatment of female stress urinary incontinence secondary to urethral sphincter deficiency. Eur Urol 2001;39:383-389.

60. Soliman S, Evans C. Endoscopic macroplastique injection for the treatment of female stress incontinence: role and efficacy. African J Urol 2001;7(2):45-50.

61. Peeker R, Edlund C, Wennberg AL, Fall M. The treatment of sphincter incontinence with periurethral silicone implants (macroplastique). Scand J Urol Nephrol 2002;36:194-198.

62. Gürdal M, Tekin A, Erdoğan K, Şengőr F. Endoscopic silicone injection for female stress urinary incontinence due to intrinsic sphincter deficiency: impact of coexisting urethral mobility on treatment outcome. Urology 2002;60:1016-1019.

63. Tamanini JTN, D’Acona CAL, Netto Jr NR. Tratamento da incontinência urinária de esforco com MIS - "Macroplastique Implantation System”- resultados preliminares. Urodinamica 2001;4(2):44-52.

64. Franceschetti GP, Baghani F, Marchetti S, Vicini D. Minimally invasive treatment of female urinary incontinence due to sphincter incompetence. Chir Ital 1998:50(1):17-24.

65. Anders K, Khullar V, Cardozo L, Bidmead J, Athanasiou S, Toozs-Hobson P, Robinson D. Contigen or Macroplastique? A five year follow-up. Abstract from the International Society Meeting, Heidelberg, Germany, 2002.

66. Link C. Henalla SM. Macroplastique implantation in women with stress urinary incontinenc using a new transurethral implantation technique. Abstract from the International Continence Society meeting, Seoul, South-Korea, 2001

67. Shah J. Injectables and stress urinary incontinence. Urol News 1997;2:7-11.

68. Kieswater H, Fischer M, Wober L, Flamm J. Endoscopic implantation of collagen (GAX) for the treatment of urinary incontinence. Br J Urol 1992;69:22-25. 
69. O’Connell HE, McGuire EJ, Aboseif S, Usui A. Transurethral collagen therapy in women. J Urol 1995;154:1463-1465.

70. Benshushan A, Brezezinski A, Shoshani O, Rojansky N. Periurethral injection for the treatment of urinary incontinence. Obstet Gynecol Surv 1998;53(6):383-388.

71. Monga AK, Stanton SL. Urodynamics: prediction, outcome and analysis of mechanism for cure of stress incontinence by periurethral collagen. Br J Obstet Gynaecol $1997 ; 104: 158-162$

72. Gottfried HW, Maier S, Gschwend J, Brändle E, Hautmann RE. Minimally invasive treatment of stress urinary incontinence by collagen administration. Comparison between endosonography controlled and transurethral submucous collagen injection. Urologe A 1996;35:6-10.

73. Herschorn S, Radomski SB, Steele DJ. Early experience with intraurethral collagen injections for urinary incontinence. J Urol 1992;148:1797-1800.

74. Bent AE, Foote JE, Siegel S, Faerber G, Chao R, Gormley EA. Collagen implant in treating stress urinary incontinence in women with urethral hypermobility. J Urol 2001;164(4):1354-1357.

75. Steele AC, Kohli N, Karram MM. Periurethral collagen injection for stress incontinence with and without urethral hypermobility. Obstet Gynecol 2000;95:327-331.

76. Herschorn S, Steele DJ, Radomski S. Followup of intraurethral collagen for female stress urinary incontinence. J Urol 1996;156:1305-1309.

77. Buckley J, Lingham K, Scott R. Early experience with a new injectable material for female stress incontinence. Abstract from the Institute of Urology and Nephrology, University College, London, UK, 1995, Jun; and the British Association of Urological Surgeons (BAUS) Annual Meeting, Brighton, UK, 1995, Jun. 
78. Foley SJ, Kashif KM, Holmes SAV. Periurethral injection: prediction of outcome.

Abstract from the Annual Meeting of the British Association of Urological Surgeons, Harrogate, UK, 1998, June.

79. Fischer M. The role of injection therapy in female stress urinary incontinence. Abstract from the 23th Biennial Congres of Urological Association of South Africa, Urban, RSA, 2000.

80. Fischer M, Dimou G. Endoscopic implantation of Macroparticulate silicone for the treatment of female urinary incontinence. Abstract from the International Continence Society Meeting, Yokohama, Japan, September, 1997.

Fig. 1. The Macroplastique Implantation Device (MID)
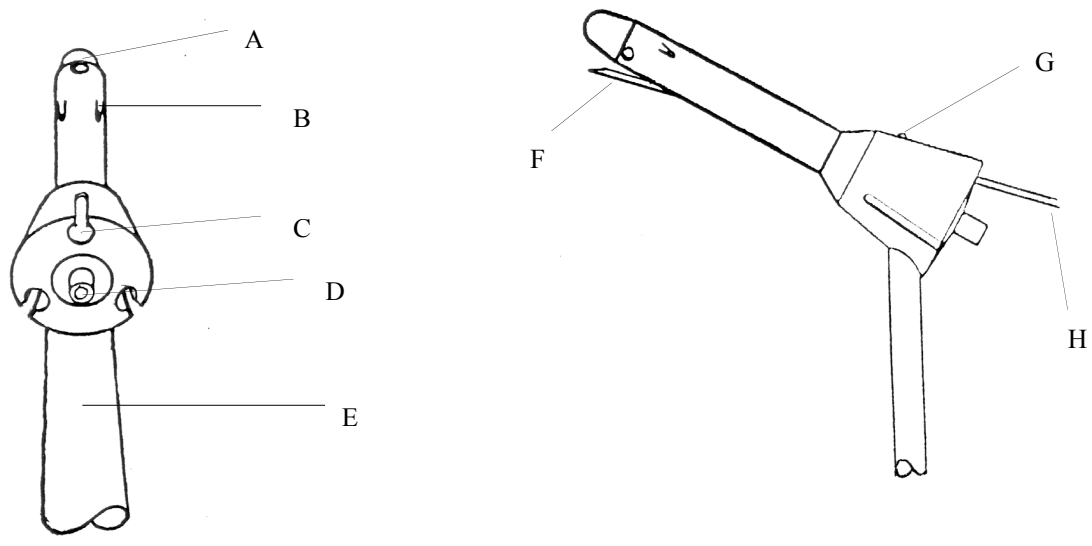

$\begin{array}{ll}\text { A } & \text { Drainage Port } \\ \text { B } & \text { Needle Exit Port } \\ \text { C } & \text { Needle Locator Guide } \\ \text { D } & \text { Drainage Channel } \\ \text { E } & \text { Handle } \\ \text { F } & \text { Needle Tip } \\ \text { G } & \text { Locator Peg } \\ \text { H } & \text { Needle Shaft }\end{array}$




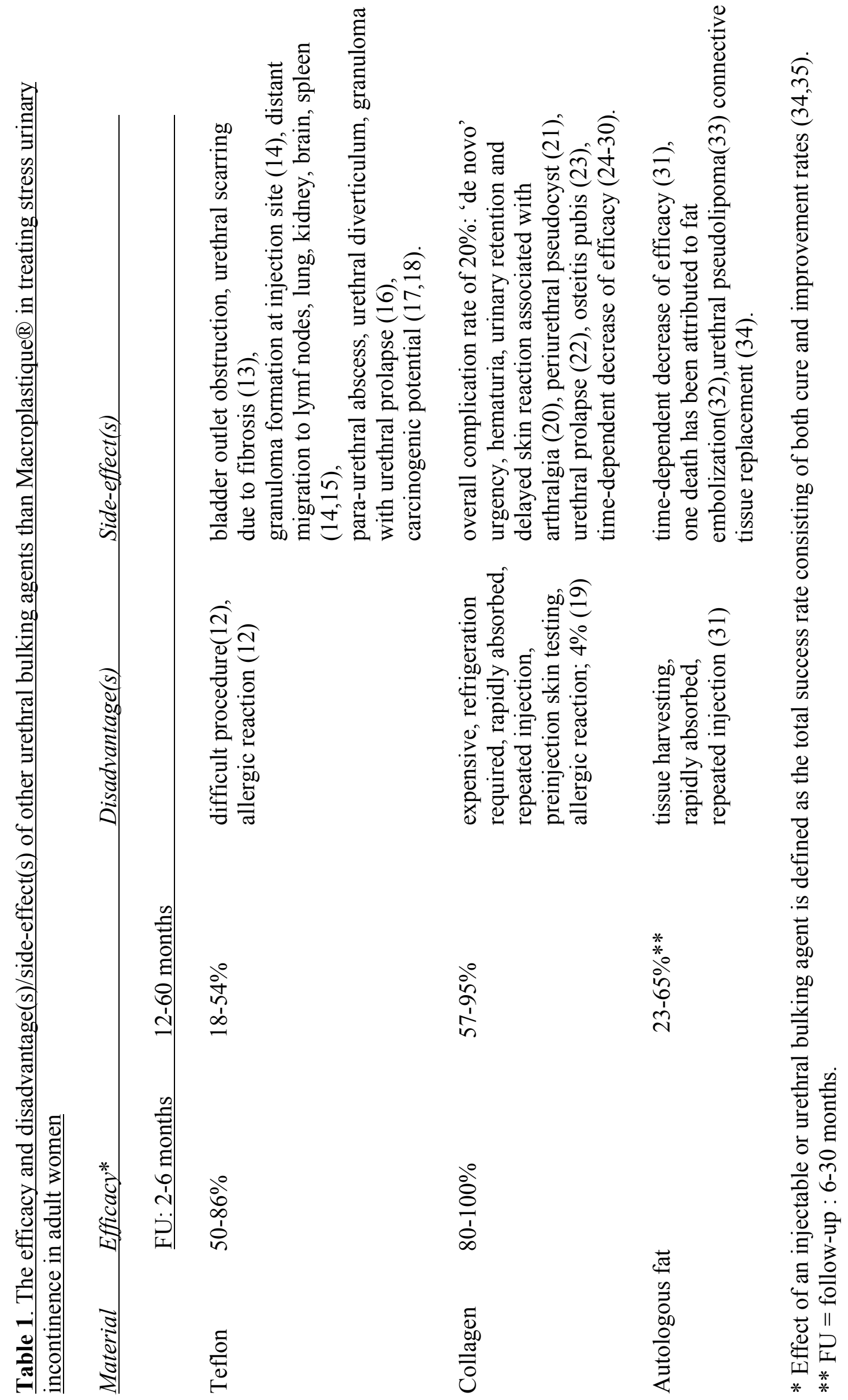


Table 2. Selection criteria for inclusion of studies in this systematic review.

1. The design was either a RCT, or a CCT, or a study with a pre-experimental or observational design.

2. Adult women with stress urinary incontinence due to intrinsic sphincter deficiency or urethral hypermobility, or both.

3. The treatment of stress urinary incontinence was transurethral or periurethral Macroplastique injection.

4. The study was published in English, German, French, or Dutch.

5. Abstracts and unpublished studies were excluded.

Table 3. Criteria for assessing methods in studies of the efficacy of Macroplastique ${ }^{\circledR}$ for stress urinary incontinence in adult women using the Maastricht-Amsterdam Consensus List $(47,48)$. points

Patient selection

A. About the specification of the eligibility criteria:

1 Were the inclusion and exclusion criteria described?

Yes/No/Don't know 2

2 Is the diagnostic procedure described?

Yes/No/Don't know 4

B. Treatment allocation

1 Was a method of randomization performed?

Yes/No/Don't know 10

2 Was the treatment allocation concealed?

Yes/No/Don't know 5

C. Were the groups similar at baseline regarding the

Yes/No/Don't know 6 most important prognostic indicators?

\section{Interventions}


D. Were the index and control interventions explicitly $\quad$ Yes/No/Don't know 10 described?

E. Was the care provider blinded to the intervention? Yes/No/Don't know 4

F. Were co-interventions avoided or comparable? $\quad$ Yes/No/Don't know 4

G. Was the compliance acceptable in all groups? $\quad$ Yes/No/Don't know 4

H. Was the patient blinded to the interventions? $\quad$ Yes/No/Don't know 4

\section{Outcome measurement}

I. Was the outcome assessor blinded to the intervention? Yes/No/Don't know 4

$\begin{array}{ll}\text { J. Were the outcome measures relevant? } & \text { Yes/No/Don't know } 8\end{array}$

$\begin{array}{ll}\text { K. Were adverse effects described? } & \text { Yes/No/Don't know } 1\end{array}$

L. Was the withdrawal/dropout rate described and $\quad$ Yes/No/Don't know 8 acceptable?

M. Timing of follow-up measurements

1. Was a short term follow-up measurement performed? Yes/No/Don't know 3

2. Was a long term follow-up measurement performed? Yes/No/Don't know 2

N. Was the timing of the outcome assessment in both $\quad$ Yes/No/Don't know 4 groups comparable?

\section{Statistics}

O. Was the sample size for each group described and $\quad$ Yes/No/Don't know 11 adequate?

P. Did the analysis include an intention-to-treat analysis? Yes/No/Don't know 4

Q. Were point estimates and measures of variability $\quad$ Yes/No/Don't know 2 presented for the primary outcome measures? 


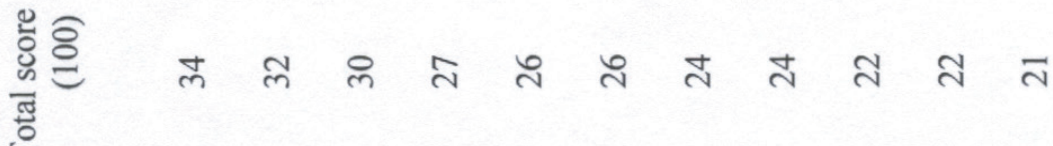$$
\stackrel{0}{\circ}
$$

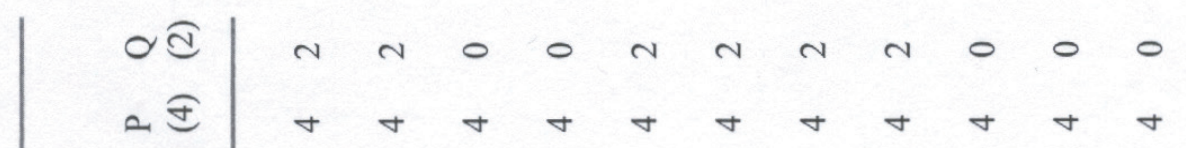

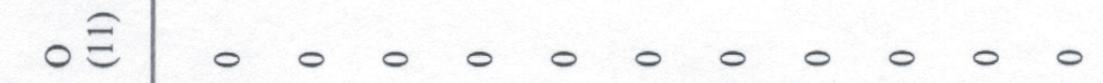

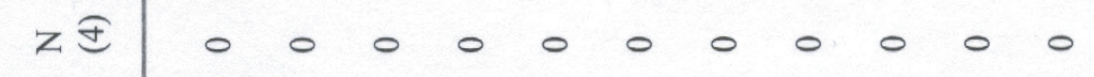

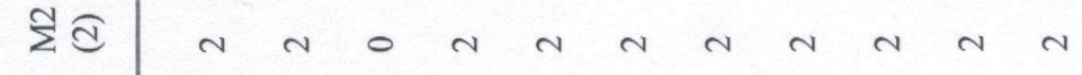
$\bar{\Sigma} \hat{C} m m m m m m m m$ $\sim\left[\begin{array}{llllllllllll} & \infty & \infty & \infty & \infty & 0 & 0 & 0 & 0 & 0 & 0 & 0\end{array}\right.$ $\forall \doteq----,--,--$

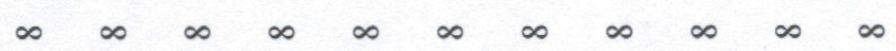
-

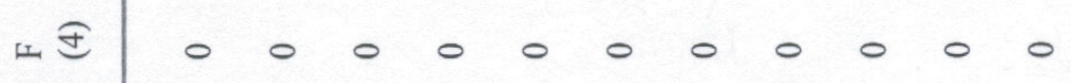

000000000000

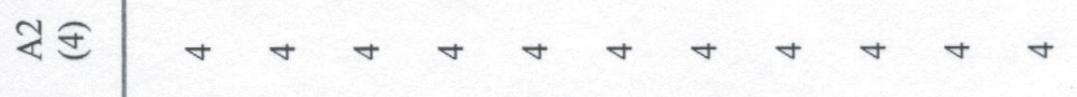




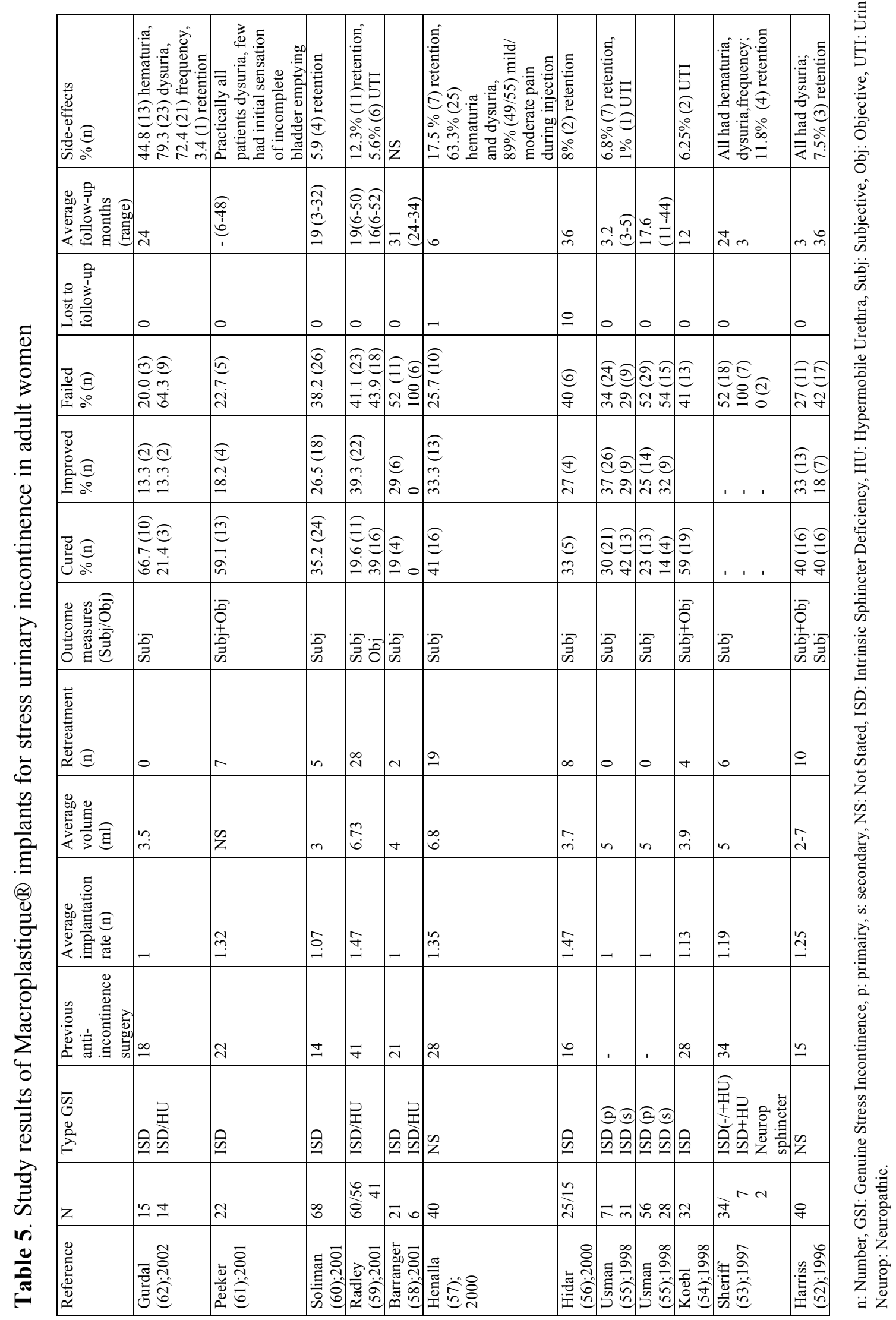




\section{Chapter 7}

\section{Effects of Macroplastique ${ }^{\circledR}$ implantation system for stress urinary incontinence and urethral hypermobility in women}

Ph.H. ter Meulen (MD) *, L.C.M. Berghmans (PhD, MSc, RPt) **, F.H.M. Nieman $(\mathrm{PhD})^{* * *}$, Ph.E.V.A. van Kerrebroeck (PhD, MD) *

* Department of Urology, University Hospital Maastricht, Maastricht, the Netherlands

** Pelvic care Center Maastricht, University Hospital Maastricht, Maastricht, the Netherlands

*** Department of Clinical Epidemiology \& Medical Technology Assessment, University Hospital Maastricht, Maastricht, the Netherlands

Journal: Int Urogynecol J 2009;20:177-183. 


\begin{abstract}
A study was carried out to evaluate efficacy of Macroplastique ${ }^{\circledR}$ (MPQ) Implantation System (MIS), in women with urodynamic stress urinary incontinence (SUI) and urethral hypermobility after an unsuccessful conservative treatment. This is a prospective randomized controlled trial in women without previous incontinence surgery. Twenty-four women received MPQ. Twenty-one controls underwent a pelvic floor muscle exercises home program. Follow-up was at 3 months and the MPQ group also at 12 months. At 3 months, pad usage decreased significantly more in the MPQ group than in the control group $(\mathrm{p}=0.015)$. According to physician and patient self-assessment, respectively, $71 \%$ and $63 \%$ women in the MPQ group were considered cured or markedly improved. This was significantly higher compared to controls. There was a significant higher increase of Incontinence Quality-of-Life questionnaire score in the MPQ group compared to controls $(p=0.017)$. Improvements in MPQ group at 3 months are sustained to 12 months. Adverse events were mild and transient. MIS is an acceptable option for women with SUI and urethral hypermobility.
\end{abstract}

Key words: Hypermobility, Macroplastique ${ }^{\circledR}$ Implantation System, Polydimethylsiloxane, Quality of life, Randomized clinical trial, Stress urinary incontinence.

Macroplastique $^{\circledR}$ and Macroplastique ${ }^{\circledR}$ Implantation System are trademarks of Uroplasty, Geleen, the Netherlands. 


\section{Introduction}

For the treatment of stress urinary incontinence (SUI) in adult women there is a broad variety of therapies nowadays. They range from physiotherapy to surgical interventions. Injection therapy with urethral bulking agents is generally considered as a minimally invasive procedure for SUI (1). However "minimally invasive" is a relative term and can be viewed as minimally invasive from the surgeon's perspective or the patient's. Acceptance for injection therapy as the least invasive of all surgical procedures is progressing $(2,3)$.

Injection therapy can be used for all types of SUI. Urethral hypermobility is thought to decrease the success of treatment with injectables (4). However, published results of periurethral collagen injections for SUI caused by hypermobility indicate positive outcome (5). No differences in success rates with and without hypermobility were reported (6).

Macroplastique $^{\circledR}$ is a urethral bulking agent that has been used in the treatment of urodynamic stress incontinence (USI) in adult women for approximately 9 years $(2,7,8)$. In studies success rates vary from $58 \%$ (long term) to $73 \%$ (short term) (9). Macroplastique ${ }^{\circledR}$ is a bulking agent that consists of solid polydimethylsiloxane particles with a mean maximum diameter of 209 $\mu \mathrm{m}$ (10). After injection, these particles seem to be non-migratory and will be organized within 6 to 8 weeks in firm nodules with infiltrated collagen and surrounded by a fibrous sheath that is well developed at 9 months (11-14).

The aim of this study is to evaluate the efficacy and the quality of life in women using the Macroplastique $^{\circledR}$ Implantation System (MIS), a novel guiding instrument for transurethral injection of Macroplastique ${ }^{\circledR}$, as a minimally invasive procedure in adult women with USI and urethral hypermobility after an unsuccessful conservative treatment (i.e., no improvement of SUI after pelvic floor muscle exercises (PFME)). 


\section{Materials and methods}

The study was approved by the Medical Ethical Committee of the University Hospital Maastricht, the Netherlands. Data out of this study and the informed consent forms were obtained complying with the applicable regulatory requirements, adhering to Good Clinical Practice and to the ethical principles that have their origin in the Declaration of Helsinki (15). The study is designed to comply with the CONSORT statement and follows the CONSORT checklist registration study (www.consort-statement.org).

Forty-seven adult women with USI and urethral hypermobility after an unsuccessful conservative treatment and no history of previous incontinence surgery were included in this prospective, randomized controlled and single center clinical trial between April 2002 and May 2007. Prior to participation of this study each woman completed dipstick urinalysis, a Quality of Life Questionnaire (QoL), Patient Questionnaire including Stamey incontinence rating (16). Stamey rating is as follows. Grade 0: The patient is continent (dry). Grade 1: The patient will lose urine with sudden increases in abdominal pressure (stressful activities such as lifting weights, coughing or sneezing) but never in bed at night. Grade 2: The patient's incontinence worsens with lesser degrees of stress such as walking, standing erect from a sitting position or sitting up in bed. Grade 3: The patient has total incontinence and urine is lost with any activity, irrespective of position. Also a

Frequency-volume chart (FVC) and 1-hour International Continence Society pad test (17) in addition to routine urogynecological work-up including detailed physical examination with assessment of bladder neck excursion measurement and pelvic organ prolapse (18), urodynamic assessment were performed. The Incontinence Quality-of-Life (I-QoL) Questionnaire was used in this study for the assessment of QoL (19). The Dutch-translated and validated version is a reliable instrument for the assessment of QoL in women with urinary incontinence. The mean score lies theoretically between 1 and 5 and the higher the 
score is, the more satisfied patients are about their continence condition. The $22 \mathrm{I}-\mathrm{QoL}$ item scores can be divided in three domains: "avoidance and limiting behavior", "psychosocial impacts", and "social embarrassment". Measurement of bladder neck mobility was assessed by the Q-tip test (20). Independently, Valsalva leak point pressure was measured. This measurement provides a validated tool to assess urethral function allowing an estimation of the relative contributions of intrinsic sphincter deficiency and urethral hypermobility (21). Women, who met the primary inclusion and exclusion criteria (Table 1), were considered candidates for randomization. Written informed consent was obtained from all women. The women were randomized for Macroplastique ${ }^{\circledR}$ injection utilizing the Macroplastique ${ }^{\circledR}$ Implantation Device (MID) or a control PFME home training program. Randomization process was performed using sealed envelopes containing the treatment assignment. A table of random numbers was used, all 0-4 were assigned to MPQ and all 5-9 were assigned to control PFME home training program. The control group was offered written instruction material for the maintenance of the PFME home training program.

The transurethral injection was performed using the MIS. The MIS consists of a set of two syringes of Macroplastique ${ }^{\circledR}$ (2.5 ml. each), the implantation device (MID) and two special needles. The MID is used to standardize the location of periurethral injection, as described by Henalla et al (22). The initial injection was placed $10 \mathrm{~mm}$ from the bladder neck. The procedure was performed under sterile conditions and was carried out under local anesthesia in day case setting. Although only women with negative urinalysis and urine culture were allowed to undergo the intervention, post-operatively, $250 \mathrm{mg}$ ciproxin twice daily was given for 5 days as prophylaxis. If the patient was unable to pass urine spontaneously up to 3 or 4 hours following the procedure, "in and out catheterization" with a catheter Ch12 was performed to relieve any symptoms of urinary retention. If residuals of more than $100 \mathrm{ml}$ 
were detected the patient was instructed to perform clean intermittent selfcatheterization (CISC) with a catheter Ch12.

Both patient groups were followed up to 3 months from the moment of injection and the Macroplastique ${ }^{\circledR}$ group also up to 12 months after treatment. The 3- and 12-month follow-up visit included an FVC, I-QoL Questionnaire, Patient Questionnaire and a pad test. A further Macroplastique ${ }^{\circledR}$ implantation procedure was scheduled after the 3-month follow-up, if clinically indicated or requested by the patient. A re-implantation was performed at a new level, in the mid-urethral position as defined by location with the MID. After repeat Macroplastique ${ }^{\circledR}$ implantation, women were again followed up at 3 and 12 months. Objective assessments of treatment outcome are the results of pad testing and FVC. Subjective assessments of treatment outcome are the results of I-QoL Questionnaire with Stamey incontinence rating, side effects and complications, investigator Stamey incontinence rating, and subjective investigator stress incontinence cure rating. Treatment success and failure are defined as follows: success is "cured" (dry) or "markedly improved" (no further incontinence treatment needed), and failure is "slightly improved" (requires further incontinence treatment) or "unchanged" (requires further incontinence treatment).

\section{Statistical analysis}

The sample size was determined using the following power calculation. Given $\mathrm{p} 1=30 \%$ (success rate of control), $\mathrm{p} 2=75 \%$ (success rate of Macroplastique), $\alpha=0.05, \beta=0.05$, results in a value of 25.5 for $n$. The number of patients of each group should be a least 26. Metric variables are first inspected for normality of statistical distribution by the KolmogorovSmirnov test. If normally distributed, means and standard deviations are given for univariate variables, if not; medians and ranges are also provided. Categorical data are represented by frequencies and percentages (or proportions). Patient demographical characteristics and 
clinical data are broken down for the randomization arm: Macroplastique ${ }^{\circledR}$ group or control group. For normally distributed variables, Student $t$ test is used to verify similarity of means for baseline characteristics; for non-normally distributed variables the Mann-Whitney test is used. For categorical data, the log-likelihood chi-squared test is applied. For the pad test on the data a $10-\log$ transformation is also done to ensure normality of distribution for the performance of Student $t$ test. The analysis of I-QOL data is performed at two levels: first, a general total scale is calculated on all 22 items and next the three subscales (the avoidance and limiting behavior, psychosocial impacts and social embarrassment items) are constructed. To test changes in I-QoL data at 3 months after baseline measurements, repeated-measures analysis of variance is done and to control these changes for baseline factors or variables repeated-measures analysis of covariance is performed. To control for baseline measurements (and other confounding variables or factors) in non-normally distributed changes in outcome variables measured at 3 months, a Mann-Whitney test is performed on the Studentized residuals of these outcomes found in regression analysis.

According to intention-to-treat principles in data analysis, missing values are imputed by general mean substitution. A p value of less than 0.05 is considered to be statistically significant. All data were analyzed with SPSS-pc, version 15.0 (23).

\section{Results}

The MPQ group contained 24 women and the control group 21. Two patients had to be excluded because they did not fulfill inclusion criteria (one was accidentally included twice and one had mainly frequency and urgency complaints). Mean age was 55 years (range 4076). Baseline characteristics of both groups were similar as shown in Table 1. The injected volume of MPQ was $5 \mathrm{ml}$ in all women. An additional injection of $5 \mathrm{ml}$ MPQ was performed in two women after the 3-month follow-up. The treatment was well tolerated according to the 
women treated, and considered acceptable and easy to perform by the physician. The following adverse events of 26 transurethral Macroplastique ${ }^{\circledR}$ injection using Macroplastique ${ }^{\circledR}$ Injection System in 24 women were reported; retention $19(73.1 \%)^{*}$, mild pain $2(7.7 \%)$, hematuria $2(7.7 \%)$, dysuria $12(46.2 \%)$, leakage implant $2(7.7 \%)$, infection $0(0 \%)$. Duration of retention $(>100 \mathrm{ml})$ and dyuria complaints were 1-2 days, except in one woman with persistent retentions because of a "de novo" prolapse of the anterior vagina wall. The women experienced these events as acceptable and mild. Product-related side effects were not seen. There were no dropouts at the 3-month follow-up (Figure 1).

The mean pad test at baseline showed a 19.6-g (median 7.5, range 0-115) and 24.9-g (median 13.8, range 2-84) urinary loss in the control group and MPQ group, respectively. After 3 months, the mean pad test showed an 11.9-g (median 4, range 0-66.6) and 15.1-g (median 3, range 0-133) urinary loss in the control group and MPQ group, respectively. This improvement was not statistically significant between the two groups $(p=0.328)$.

The mean number of pads used per day at baseline was 2.7 (median 3, range 0-6) and 3.4 (median 3, range 0-6) in the control group and MPQ group, respectively. After 3 months, the mean number of pads were 2.5 (median 2, range 0-6) and 1.9 (median 1, range 0-11) in the control group and MPQ group, respectively. The number of pads used at 3 months in the MPQ group decreased statistically significantly compared the number used in the control group $(\mathrm{p}=0.015)$.

After the 3-month follow-up, five women in the MPQ group received other continence treatment because of treatment failure. The incontinence condition of women was rated by Stamey rating. At baseline and 3-month follow-up the frequencies in grading for both groups as well as the 12-month follow-up of the MPQ group are shown in Table 3. At 3-month follow-up the Stamey grading showed a statistically significant difference compared to baseline scores $(\mathrm{p}=0.020)$. 
The physician's global impression of the incontinence condition of women was rated by the final surgeon incontinence rating (Table 4$)$. The number of women $(17 ; 70.8 \%)$ that was "cured" or "markedly improved" at three months was statistically significantly higher than that in the control group $(6 ; 28.5 \% ; \mathrm{p}=0.029)$.

The subject's global impression of the incontinence condition was rated by patient selfassessment of the incontinence problem and is presented in Table 4. There was a statistically significant difference in the number of women $(15 ; 62.5 \%)$ "cured" or "markedly improved" at 3 months in the MPQ group compared to that in the control group $(4 ; 19.0 \% ; \mathrm{p}=0.002)$.

The Dutch-validated overall 22-item I-QoL showed a mean total score at baseline for the control group and MPQ group of $2.96(\mathrm{SD}=0.62)$ and $2.59(\mathrm{SD}=0.61)$, respectively, and at 3 months this mean total score was $3.03(\mathrm{SD}=0.66)$ and $3.20(\mathrm{SD}=0.73)$, respectively (Table 5A). The increase in the MPQ group was significantly higher compared to the control group ( $\mathrm{F}$ ratio $=9.83: 1$ and $43 d f, \mathrm{p}=0.003$ ). When the I-QoL scores are corrected for baseline values the difference remained statistically significant ( $\mathrm{F}$ ratio $=6.15: 1$ and $42 d f, \mathrm{p}=0.017)$. The mean scores and standard deviations of the domain scales are also shown in Table 5. In all three scales and controlled for their respective baseline measurements, there was a statistically significant improvement in the means of the MPQ group compared to the ones of the control group $(\mathrm{F}=4.57: 1$ and $42 d f, \mathrm{p}=0.038, \mathrm{~F}=4.85: 1$ and $42 d f, \mathrm{p}=0.033, \mathrm{~F}=7.99: 1$ and $42 d f$, $\mathrm{p}=0.007$, respectively). The increase in mean scores was the highest on the "social embarrassment" subscale after correction for possible differences in baseline values between the control and MPQ group. In contrast to the control group, the I-QoL for the MPQ group was again measured at 12 months after treatment. If - outside the trial data analysis - a cohort trend analysis for just these 18 patients who had a successful MPQ treatment at 3 months is done, the improved mean overall and subscale scores in I-QoL at 3 months turn out to be sustained to the 1-year follow-up. The overall score and the subscale score social 
embarrassment seem even to improve statistically significant compared to the 3 -month scores $(\mathrm{F}=4.87: 1$ and $17 d f, \mathrm{p}=0.041, \mathrm{~F}=7.77: 1$ and $17 d f, \mathrm{p}=0.013$, respectively; Table 5).

At 12 months, physician and patient self-assessment "cure" and "markedly improved" rate was $88.9 \%(16 / 18)$ and $82.4 \%(14 / 17)$ in the MPQ group, respectively (Table 4). After treatment, five women presented with symptoms of de novo urgency but only one needed medical treatment.

\section{Discussion}

To our knowledge, this is the first randomized clinical trial comparing transurethral Macroplastique $^{\circledR}$ injection with a control pelvic floor muscle exercises home training program in adult women with urodynamic SUI and urethral hypermobility after an unsuccessful conservative treatment. The enrollment time was long ( 5 years); this could be due to the strict inclusion and exclusion criteria. Also in this period of time the suburethral slings became popular and could have been of influence on the patient's choice of treatment.

The exact mechanism of achieving continence with urethral bulking agents is unknown. It is commonly thought that they increase urethral resistance at the level of the bladder neck by adding "bulk" or provide internal support to the urethral mucosa and creating urethral coaptation when injected submucosally (14).

At 3 months, results of the pad test results showed improvement, although no significant difference between the two groups could be shown. We have used the 1-h pad test as recommended by the International Continence Society (17). However, a number of studies have reported poor reproducibility for the 1- and 24-h pad test (24-27). In a study by Simons et al, the test-retest reliability of the 1-h pad test was shown to be inadequate, with the first and second tests differing by -44 to $+66 \mathrm{~g}$, despite the women having similar bladder volumes (27). Lower anxiety levels at the second test may account for this finding. The 1-h pad test is 
a useful baseline measure of incontinence, but the poor repeatability suggests that is not an optimal measure of post-treatment.

More clearly, the decrease in number of pads used in the MPQ group at 3 months was significantly different from the control group. Also, the subjective parameters were significantly better in the MPQ group compared to the control group. The "cure" and "markedly improved" rates were sustained in the MPQ group at 12 months. These results of MPQ treatment of SUI in patients with urethral hypermobility are in line with data from literature in patients without hypermobility (28). Comparing the results with other more invasive surgical treatments the MPQ shows a slightly lower success rate, however with a lower risk of complications (29). In this study the retention rate seems rather high. This can be explained by strict control of women after the procedure. The duration of retention was 1 to 2 days and treated by CISC, except in one woman with a body mass index of $40 \mathrm{~kg} / \mathrm{m}^{2}$, who had persistent retention because of a "de novo" prolapse of the anterior vagina wall unrelated to the procedure. Surgical correction of this prolapse was necessary. CISC may influence the results of injection therapy by possible dislocation and/or loss of the bulking agent. However, a small-sized catheter ( $\mathrm{Ch}$ 12) was used to minimalize this risk as much as possible. The improvement in the quality of life is in the same range as with surgical interventions and confirms the trend in patient's preference to have a procedure with a lower risk of complications (30). In a recent study of Robinson et al, the majority of women have realistic expectations regarding outcome hoping for improvement so that their quality of life increases. In general, they are able to tolerate the inconvenience of minor lower urinary tract symptoms. Women would appear to prefer a minor procedure with a lower risk of complications and are content to accept a lower success rate (30).

An advantage of Macroplastique $^{\circledR}$ implantation using the MID is that it is performed following an out-patient treatment protocol requiring local anesthesia only. Also, the 
instrument is easy to handle in comparison to the cystoscope, with predetermined and consistent depth of needle penetration, and consistent implant placement at three predetermined locations.

\section{Conclusions}

In the treatment algorithm of stress urinary incontinence, the bulking agent Macroplastique ${ }^{\circledR}$ using MPQ Implantation Device seems to be a suitable option as a first-line surgical treatment. The procedure is easy to perform, safe and well accepted by women and physician. The success rates are satisfactory and the patient's quality of life increases significantly. The results appear to be sustained at least for 1 year postoperatively.

Acknowledgment This study was funded by an unrestricted grant of Uroplasty BV.

Conflicts of interest None.

\section{References}

1. Shah J (1997) Injectables and stress urinary incontinence. Urol News 2:7-11.

2. Chapple CR, Wein AJ, Brubaker L, Dmochowski R, Espuna Pons M, Haab F, Hill S.1. Stress incontinence injection therapy: What is the best for our patients? Eur Urol 2005; 48: 552-565.

3. Tamanini JT, D'Ancona CA, Netto NR. Macroplastique Implantation System for female stress urinary incontinence: long term follow-up. J Endourol 2006;20(12):826.

4. Herschorn S, Radomski SB, Steele DJ (1992) Early experience with intraurethral collagen injections for urinary incontinence. J Urol 148:1797-1800. 
5. Bent AE, Foote JE, Siegel S, Faerber G, Chao R, Gormley EA (2001) Collagen implant in treating stress urinary incontinence in women with urethral hypermobility. J Urol 164(4):1354-7.

6. Steele AC, Kohli N, Karram MM (2000) Periurethral collagen injection for stress incontinence with and without urethral hypermobility. Obstet Gynecol 95:327-31.

7. Harriss DR, Iacovou JW, Lemberger RJ (1996) Periurethral silicone microimplants (Macroplastique) for the treatment of genuine stress incontinence. Br J Urol 78:7228.

8. Koelbl H, Saz V, Doerfler D, Haeusler G, Sam Ch, Hanzal E (1998). Transurethral injection of silicone microimplants for intrinsic urethral sphincter deficiency. Obstet Gynecol 92:332-6.

9. ter Meulen PhH, Berghmans LCM, van Kerrebroeck PhEVA (2003) Systematic review: Efficacy of silicone microimplants (Macroplastique $\left.{ }^{\circledR}\right)$ Therapy for stress urinary incontinence in adult women. Eur Urol 44:573-82.

10. Solomon LZ, Birch BR, Cooper AJ, Davies CL, Holmes SAV (2000) Nonhomologous bioinjectable materials in urology: 'size matters'?. BJU Int 85:641645.

11. Allen O (1992) Response to subdermal implantation of textured microimplants in humans. Aesth Plast Surg 16:227-230.

12. Smith DP, Kaplan WE, Oyasu R (1994) Evaluation of polydimethylsiloxane as an alternative in the endoscopic treatment of vesicoureteral reflux. J Urol 152:12211224.

13. Henly DR, Barrett DM, Weiland TL, O’Connor MK, Malizia AA, Wein AJ (1995) Particulate silicone for use in periurethral injections: local tissue effects and search for migration. J Urol 153:2039-2043. 
14. Radley SC, Chapple CR, Lee JA (2000) Transurethral implantation of silicone polymer for stress incontinence: evaluation of a porcine model and mechanism of action in vivo. BJU Int 85:646-50.

15. Declaration of Helsinki (Document 17.C), World Medical Association, Note on Paragraph 29, 6.10.2002.

16. Stamey (1979) Urinary Incontinence in the female. Campbell's Urology Fourth Edition W B Saunders Company pp 2272-2293.

17. Abrams P, Blaivas JG, Stanton SL, Anderson JT (1988) The standardization of terminology of lower urinary tract function. The International Continence Society Committee on Standardization of Terminology. Scand J Urol Nephrol 114(suppl):519.

18. Bump RC, Mattiasson A, Bo K,Brubaker LP, Delancey JOL, Klarskov P, et al. (1996) The standardization of terminology of female organ prolapse and pelvic floor dysfunction. Am J Obstet Gynecol 175:10-17.

19. Patrick DL, Martin ML, Buschnell DM, Yalcin I, Wagner TH, Buesching DP (1999) Quality of life of women with urinary incontinence: further development of the incontinence quality of life instrument (I-QOL). Urology 53:71-76.

20. Crystle CD, Charme LS, Copeland WE. Q-tip test in stress urinary incontinence. Obstet Gynecol 1971; 38: 313-15.

21. Cummings J M (1997) Leakpoint pressures in female stress urinary incontinence. Int Urogynaecol_J 8:153-155.

22. Henalla SM, Hall V, Duckett JRA, Link C, Usman F, Tromans PM, et al. (2000) A multicentre evaluation of a new surgical technique for urethral bulking in the treatment of genuine stress incontinence. Br J Obstet Gynecol 107:1035-9.

23. SPSS 15.0 for Windows. SPSS Inc. Chicago, IL, USA. 
24. Jorgensen L, Steen A, Bagger PV, Fisher-Rasmussen W. (1985) The one-hour padweighing test for assessment of the result of female incontinence surgery. In: Proceedings of the $15^{\text {th }}$ Annual Meeting of the International Incontinence Society; London pp.392-3.

25. Lose G, Gammelgaard J, Jorgensen TJ (1986) The one-hour-hour pad weighing test: reproducibility and the correlation between the best result, the start volume in the bladder and the diuresis. Neurourol Urodyn 5:17-21.

26. Lose G, Jorgensen L, Thunedborg P. (1989) 24-hour home pad weighing test versus 1-hour ward test in the assessment of mild stress incontinence. Acta Obstet Gynecol Scand 68:211-5.

27. Simons AM, Yoong WC, Buckland S, Moore KH (2001) Inadequate repeatability of the one-hour pad test: the need for a new incontinence outcome measure. Br J Obstet Gynecol 108:315-9.

28. ter Meulen PhH, van Kerrebroeck PhEVA (2004) Injection therapy for stress urinary incontinence in adult women. Expert Rev Med Devices 1:89-97.

29. Costantini E, Lazzeri M, Porena M (2007) Managing complications after midurethral sling for stress urinary incontinence. Eur Urol Update Series 5; 232-240.

30. Robinson D, Anders K, Cardozo L, Bidmead J, Dixon A, Balmforth J, et al. (2003) What do women want? Interpretation of the concept of cure. J Pelvic Med Surg 9:273-7.

\section{Table 1. Inclusion and exclusion criteria}

Inclusion

-Female and at least 18 years of age

-Urodynamic stress urinary incontinence and urethral hypermobility

-Urodynamic assessment of SUI and VLPP > 60-cm water 
-SUI not shown defined improvement after PFME therapy

-No more than stage 0,1 or 2 pelvic organ prolapse (Bump classification)

-Negative dipstick urinalysis

-Post-void residual urine $\leq 100 \mathrm{ml}$

-Not pregnant or within 12 months postpartum

-Understanding of the Dutch language

-Written informed consent document

\section{$\underline{\text { Exclusion }}$}

-Any prior solid particle UBA treatment or any surgical anti-incontinence procedure

-A form of urinary incontinence other than SUI contributing substantially to their symptoms

-A neurogenic bladder

-Urinary incontinence due to an anatomical defect, fibrotic urethral mucosa (preventing Macroplastique ${ }^{\circledR}$ bolus formation), tissue damage due to injury, pelvic radiotherapy or other therapy affecting the bladder neck and/or urethral tissues

-A history of intermittent or long-term use of intraurethral continence devices

-Voiding difficulties

-A history of unexplained haematuria

-Cystitis, urethritis or evidence of possible infection, which would preclude safe penetration of the urethral wall with the implantation needle

-An incurable malignant disease or other form of disease that is advancing rapidly and causing deterioration of the patient's physical condition

-Any condition that could lead to serious postoperative complications (e.g. current infection or uncontrolled diabetes)

-Lactating, within 12 months postpartum or planning to become pregnant in the next 12 months 
-Morbidly obese (i.e., Body Mass Index; BMI $>40$ kg/m²)

-Unable or unwilling to perform clean intermittent self-catheterization if the need arises (e.g., lack of manual dexterity, arthritic hands, dementia, etc.)

Table 2. Patient's characteristics

\begin{tabular}{|c|c|c|c|}
\hline & MPQ group $(n=24)$ & Control group $(n=21)$ & $\mathrm{p}$ value \\
\hline Mean age, years (SD; range) & $54.7(8.9 ; 41-76)$ & $55.6(8.9 ; 40-73)$ & 0.73 \\
\hline Mean BMI, $\mathrm{kg} / \mathrm{m}^{2}$ (SD; range) & $26.6(4.3 ; 20-40)$ & $28.3(8.3 ; 19-38)$ & 0.41 \\
\hline Menstrual cycle (normal/perimeno/meno) & $6 / 3 / 15$ & $7 / 2 / 12$ & $0.81^{\mathrm{a}}$ \\
\hline Parities (median) & 2 & 2 & $0.23^{\mathrm{a}}$ \\
\hline Duration of incontinence, months (range) & $142(36-360)$ & $118(36-360)$ & 0.35 \\
\hline VLPP, cm water (SD; range) & $102(28 ; 70-172)$ & $93(21 ; 63-136)$ & 0.28 \\
\hline
\end{tabular}

$S D=$ standard deviation

a =log-likelihood chi-squares test (other $p$ values: Student's $t$ test)

Table 3. Stamey rating frequencies ( $n$ ) for the control and the MPQ group at baseline and at 3-month follow-up and at 12 months for the successful part of the MPQ group only

\begin{tabular}{|l|l|c|c|c|c|c|}
\hline Grade & & 0 & I & II & III & p value \\
\hline Baseline & Control (n=21) & 0 & 14 & 7 & 0 & \\
\cline { 2 - 7 } & MPQ (n=24) & 1 & 15 & 8 & 0 & \\
\hline 3 months & Control (n=21) & 1 & 16 & 4 & 0 & \\
\cline { 2 - 7 } & MPQ (n=24) & 8 & 15 & 1 & 0 & 0.020 \\
\hline 12 months & MPQ (n=18) & 10 & 7 & 1 & 0 & \\
\hline
\end{tabular}


Table 4. Final surgeon's subjective cure rating and the patient self-assessment of patient's incontinence condition (n) for the control and the MPQ group at 3-month follow-up and at 12 months for the successful part of the MPQ group only

\begin{tabular}{|c|c|c|c|c|c|c|c|c|c|c|c|c|}
\hline & \multicolumn{6}{|c|}{ Final surgeon's subjective cure rating } & \multicolumn{6}{|c|}{ patient self-assessment } \\
\hline & $n$ & 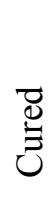 & 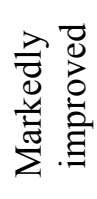 & 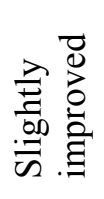 & $\begin{array}{l}\vec{\Xi} \\
\infty \\
\bar{\Xi} \\
\bar{ত} \\
\Xi\end{array}$ & $\begin{array}{l}\stackrel{0}{\Xi} \\
\stackrel{\pi}{\pi} \\
2 \\
2\end{array}$ & $n$ & Ü & 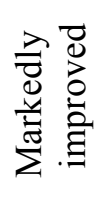 & 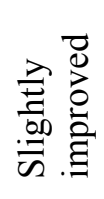 & $\begin{array}{l}\vec{D} \\
\infty \\
\text { ज्ञ } \\
\bar{U} \\
\Xi\end{array}$ & $\begin{array}{l}\stackrel{0}{\Xi} \\
\stackrel{0}{\pi} \\
2 \\
2\end{array}$ \\
\hline $\begin{array}{c}\text { Control } 3 \\
\text { months }\end{array}$ & 21 & 2 & 4 & 4 & 11 & & 21 & 0 & 4 & 3 & 14 & \\
\hline $\begin{array}{c}\text { MPQ } \\
3 \text { months }\end{array}$ & 24 & 8 & 9 & 1 & 6 & 0.029 & 24 & 7 & 8 & 2 & 7 & 0.002 \\
\hline $\begin{array}{c}M P Q \\
12 \text { months }\end{array}$ & 18 & 9 & 7 & 1 & 1 & & $17^{\mathrm{a}}$ & 6 & 8 & 2 & 1 & \\
\hline
\end{tabular}

${ }^{a}$ One missing data 
Table 5. A] mean (sub)scale scores and standard deviations (sd) of the I-QoL at baseline and 3 months for both treatment groups (overall mean imputed data; $n=45)$. Scores will lie between 1.00 (worst possible QoL) and 5.00 (best possible QoL). B] mean (sub)scale scores and standard deviations (sd) of the I-Qol at baseline, three and twelve months for patients who had a successful MPQ treatment after 3 months $(n=18)$. Scores will lie between 1.00 (worst possible QoL) and 5.00 (best possible QoL)

$\mathbf{A}$

\begin{tabular}{|c|c|l|l|l|l|c|}
\hline Subscale & treatment & $n$ & baseline & 3 months & $p$ value & $\begin{array}{l}p \text { value } \\
\text { controlled for } \\
\text { baseline values }\end{array}$ \\
\hline \multirow{2}{*}{ Overall } & control & 21 & $2.96(0.62)$ & $3.03(0.66)$ & & \\
\cline { 2 - 7 } & MPQ & 24 & $2.59(0.61)$ & $3.20(0.73)$ & $0.003^{\mathrm{a}}$ & $0.017^{\mathrm{c}}$ \\
\hline $\begin{array}{c}\text { Avoidance \& limiting } \\
\text { behavior }\end{array}$ & control & 21 & $2.86(0.72)$ & $2.99(0.71)$ & & \\
\cline { 2 - 7 } & MPQ & 24 & $2.55(0.65)$ & $3.26(0.86)$ & $0.012^{\mathrm{a}}$ & $0.038^{\mathrm{c}}$ \\
\hline \multirow{2}{*}{$\begin{array}{c}\text { Psycho-social impacts } \\
\text { Control }\end{array}$} & 21 & $3.27(0.66)$ & $3.31(0.65)$ & & \\
\cline { 2 - 7 } & MPQ & 24 & $2.76(0.70)$ & $3.37(0.74)$ & $0.003^{\mathrm{a}}$ & $0.033^{\mathrm{c}}$ \\
\hline \multirow{2}{*}{ Social embarrassment } & control & 21 & $2.53(0.66)$ & $2.59(0.87)$ & & \\
\cline { 2 - 7 } & MPQ & 24 & $2.31(0.68)$ & $2.95(0.81)$ & $0.004^{\mathrm{a}}$ & $0.007^{\mathrm{c}}$ \\
\hline
\end{tabular}

${ }^{\text {a }}$ ANOVA results (time * group) effects

${ }^{c}$ ANCOVA results (time * group) effects

B

\begin{tabular}{|c|c|c|c|c|c|c|}
\hline Subscale & $n$ & Baseline & 3 months & 12 months & $p$ value & $p$ value \\
\hline Overall & 18 & $2.58(0.64)$ & $3.38(0.70)$ & $3.85(0.81)$ & $0.041^{\mathrm{b}}$ & $0.006^{\mathrm{d}}$ \\
\hline Avoidance \& limiting behavior & 18 & $2.47(0.58)$ & $3.37(0.80)$ & $3.65(0.73)$ & $0.185^{\mathrm{b}}$ & $0.093^{\mathrm{d}}$ \\
\hline Psychosocial impacts & 18 & $2.76(0.77)$ & $3.60(0.66)$ & $3.94(0.78)$ & $0.157^{\mathrm{b}}$ & $0.058^{\mathrm{d}}$ \\
\hline Social embarrassment & 18 & $2.35(0.71)$ & $3.13(0.73)$ & $3.77(0.97)$ & $0.013^{\mathrm{b}}$ & $0.008^{\mathrm{d}}$ \\
\hline
\end{tabular}

${ }^{\mathrm{b}}$ Paired $\mathrm{t}$ test

${ }^{\mathrm{d}}$ Wilcoxon paired test 
Figure 1. Flow diagram of study

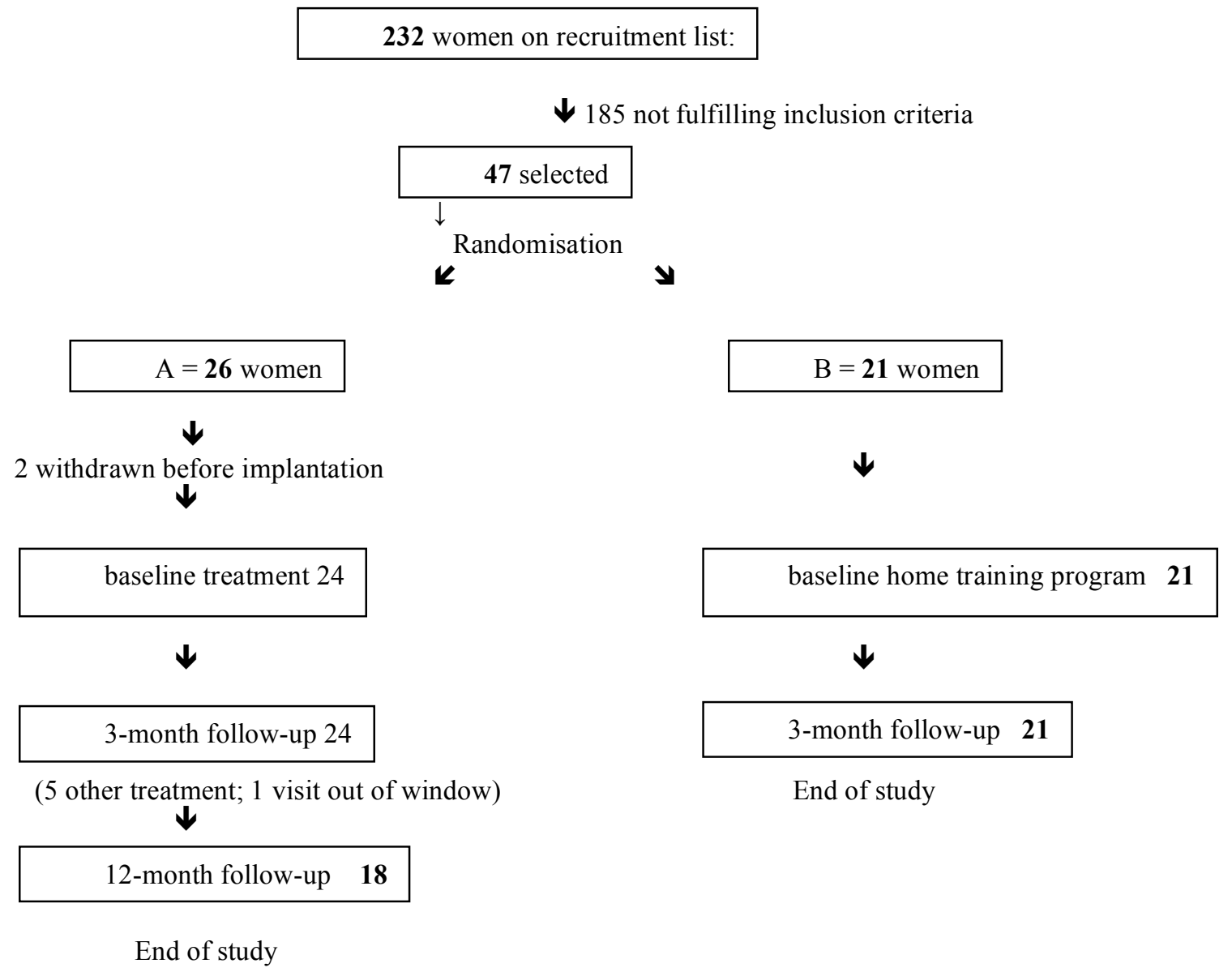




\section{Chapter 8}

\section{Discussion and conclusions}

This thesis focuses on the efficacy, safety and durability of urethral bulking agents (UBA's) using new techniques of transurethral injection as a minimally invasive procedure in adult women with stress urinary incontinence (SUI). Based on these results, the place of these techniques in the treatment algorithm of SUI is established.

SUI in adult women is an important health problem with high impact on Quality of Life (QoL) and there is a clear need for treatment (1). The PURE (Prospective Urinary Incontinence REsearch) study provides insight into patient characteristics, associated bother and treatment patterns of SUI symptoms in clinical practice $(2,3)$. The majority of patients (42\%) had symptoms of moderate severity, $30 \%$ of the patients had severe symptoms and $17 \%$ had very severe symptoms. Quality of life (QoL) decreased with increasing symptom severity. Despite the negative impact of SUI on QoL, women often fail or delay seeking treatment. This study showed that nearly half of the patients (48\%) suffered from their symptoms for less than 2 years before consulting a physician; $28 \%$ delayed seeking treatment for $3-5$ years, with $13 \%$ waiting for $6-10$ years and the remaining $11 \%$ waiting for 11 or more years. Several reasons may explain this delay, including the misconception that the condition is a normal consequence of childbirth and aging, the embarrassment about discussing SUI with a physician and the lack of knowledge about available therapy $(4,5)$. Of the incontinent women, $20-45 \%$ had received conservative treatment (mainly pelvic muscle floor therapy; PFMT), 25-41\% had received medication, and only $2-4 \%$ had undergone surgery.

An initial conservative approach of pelvic muscle floor therapy (PFMT) in association with lifestyle modifications is essential before embarking on more invasive treatment modalities. PFMT is considered as better than no treatment by the Cochrane Collaboration and is recommended as first-line treatment for SUI by the $3^{\text {rd }}$ International Consultation on 
Incontinence (ICI; 6,7). Long-term success of PFMT is much dependent of patient motivation and compliance. However, a significant number of patients have persistent symptoms after PFMT. PFMT improve the extrinsic supporting mechanism. In cases of a (concurrent) dysfunction of the intrinsic urethral closing mechanism, the object of PFMT is to compensate this mechanism as far as possible by improving the functionality of the pelvic floor muscles (8). So, it is not likely that these patients will recover completely. This patient group would be candidate for minor invasive procedures as injection therapy with UBA's. Also surgical intervention can be proposed. The choice between these two treatment options must be made on the basis of efficacy, safety (and the efficacy/safety balance), and cost aspects. Surgical intervention is widely considered as the most effective option for SUI, although it is not suitable for all patients. Injection therapy is generally associated with a lower objective cure rate compared to surgery (9). However with reduced invasiveness comes the potential for improved tolerability, decreased morbidity and, therefore, similar improvements in overall QoL (9). Two studies comparing injection therapy and surgery found superior objective efficacy with surgery, but no significant differences in QoL improvements $(10,11)$. In recent years several suburethral tapes seem to result in high cure rates $(84-95 \%)$ that remain stable over time, with a reported $85 \%$ of patients cured and $11 \%$ with significant improvements after 5 years (12-14). However, the adverse events of tapes are still substantial and can have a serious impact on quality of life, as described in chapter one. A survey (2003) of patients with SUI showed that most patients prefer less invasive therapy with a lower risk of complications, even if the chance of cure may be lower than with major (more invasive) procedures (15). Therefore, a focus on patient's wishes and expectations with respect to success and risks is required. From the patient perspective it could be speculated that the lower cure rate may be of less importance when weighted against the potential complications (9). With this information injection therapy could have an important place in a treatment algorithm of SUI. 
Many different UBA's have been used as described in chapter two, although the ideal one remains to be discovered. In general, injection therapy was offered to frail elderly women, obese individuals, previously operated patients and patients unwilling or unfit to undergo more invasive surgery. UBA's were usually used for intrinsic sphincter deficiency (ISD) related SUI, although there is good evidence that women with (concomitant) urethral hypermobility respond similarly (16). Nowadays, more and more we are leaving the simple concept of a dichotomy between ISD and urethral hypermobility as causes for or associations with SUI. In the standardization of terminology report by the ICS (17) and the more recently published consultation of the ICI 2004 meeting the description was changed into a variable combination of these factors. Long-term outcome studies of correction of hypermobility point in the direction that there may be more urethral weakness among patients with urethral hypermobility than had been previously considered. Most studies of UBA's were designed for ISD related SUI. If there was concurrent urethral hypermobility this could be a reason for exclusion in such a study. The safety and durability of various UBA's remain a concern (18). No differences in UBA's from an efficacy point of view have been found. Different injection techniques of UBA's, endoscopic and non-endoscopic administration (blind injection using a guiding instrument), have been used. The recent development of two devices for blind injection has increased the speed and convenience of urethral injection, removing the need for surgical facilities (9). The devices are the Implacer ${ }^{\circledR}$ device for blind administration of NASHA/Dx copolymer (non-animal stabilized hyaluronic acid/dextranomer; Zuidex ${ }^{\mathrm{TM}}$ ) and the Macroplastique ${ }^{\circledR}$ Implantation System (MIS) for blind administration of polydimethylsiloxane/silicone microimplants (Macroplastique $\left.{ }^{\circledR}\right)$. Before starting our randomised clinical trial (RCT) of silicone microimplants (Macroplastique ${ }^{\circledR}$ ) described in chapter seven, the literature of injection therapy with UBA's for treating SUI in adult women was of rather poor quality, and therefore difficult to compare 
because of several factors, such as different patient selection, materials, techniques, definition of success, number of treatments, and follow-up period. In chapter six, a systematic review about the efficacy of silicone microimplants showed a low methodological quality of included studies (19). Therefore, at that time results should be interpreted with caution and no firm conclusions about the efficacy of this UBA were possible.

Injection therapy can achieve significant improvement of symptoms in up to $73 \%$ of patients with a cure rate of $24-36 \%$ in the short term (18). Many short-term studies have been performed, although long-term evidence confirming the durability of treatment effects needs to be strengthened (9). In a pilot study (open, prospective, multicenter study) of 42 invasive therapy-naive women with stress urinary incontinence (ISD and/or urethral hypermobility) treated with NASHA/Dx copolymer using the Implacer ${ }^{\mathrm{TM}}$ device, $76 \%$ of women showed improvement of leakage at 3 and 12 months post treatment (20). Statistically significant reductions in median urine leakage and in the median number of incontinence episodes in 24 hours were observed. Between 12 and 36 months little deterioration in these efficacy parameters were observed (21). Significant improvements of QoL measurements were observed in 7 of ten King's Health Questionnaire (KHQ) domains at 12 months, and 6 of ten at 36 months $(21,22)$. This study has its limitations, as the primary endpoint, change from baseline in cough-induced leak point pressure (CILPP), could not be obtained. CILPP was not measured consistently among the centers, values proved difficult to verify, and a large number of values were missing. Only a small number $(\mathrm{N}=17)$ of women were available at 36 months. Nevertheless, this study showed statistically significant improvement in subjective and objective measurements and sustained for at least 36 months. In chapter 7, the first RCT has been described comparing Macroplastique ${ }^{\text {injection(s) }}$ utilizing the Macroplastique ${ }^{\circledR}$ Implantation Device with a control pelvic floor muscle exercises home training program in adult women with urodynamic SUI and urethral 
hypermobility after non-successful conservative treatment. All subjective (I-QoL

Questionnaire with Stamey incontinence rating, investigator Stamey incontinence rating, and subjective investigator stress incontinence cure rating) and objective measurements (frequency/volume chart and one-hour ICS pad test) showed a more pronounced statistically significant improvement in the Macroplastique group. Only the results of the pad test were not statistically significant between groups at 3 months, although the pad test showed improvement in both groups. The number of women $(\mathrm{N}=17 ; 70.8 \%)$ that was cured or markedly improved at three months was statistically significantly higher than in the control group $(\mathrm{N}=6 ; 28.5 \%)$. The increase of the overall score and subscale scores of I-Qol in the Macroplastique group was significantly higher compared to the control group. The subjective and objective improvements in Macroplastique group at 3 months are sustained at 12 months (23). The number of participants of this RCT was rather limited (Macroplastique group contained 24 women and the control group 21) and the enrolment time was long (5 years). This could be due to the strict in- and exclusion criteria of this study and also to the fact that in this period of time the suburethral tapes became popular and have influenced the patient's choice of treatment.

The efficacy and safety of UBA's depends on the material used, the technique applied and the experience of the physician (18). The overall safety of these two UBA's, NASHA/Dx copolymer and silicone microimplants, was acceptable in these studies. There are some safety concerns with non-biodegradable agents, such as polydimethylsiloxane/silicone. There are reports showing an association between silicone gel-containing breast implants and late-onset connective tissue disorders (24-26). However, polydimethylsiloxane is a solid elastomer and not a silicone gel. No evidence has been reported that elastomers are associated with connective tissue disease (27). Particle migration has been only observed with silicone in dogs 
(28). NASHA/Dx copolymer, a biodegradable agent, shows no safety concern up to 7 years after treatment of SUI (29).

The two transurethral injection systems studied, the Zuidex ${ }^{\mathrm{TM}}$ system and the Macroplastique ${ }^{\circledR}$ Implantation System (MIS), were well tolerated by the female patients treated as minimal invasive procedure. NASHA/Dx copolymer was administered under local or general anaesthesia and silicone microimplants only under local anaesthesia $(20,23)$. Both systems were easy to use by the operator. Adverse events were usually mild and uncommon, often self-limiting and easily managed. In one patient a pseudocyst developed after NASHA/Dx copolymer injection and could be resolved with simple fluid aspiration (21). A cost-effectiveness study was not done. Data on this subject are limited in the literature and do not allow a final conclusion (30,31).

The current data indicate that physicians should look beyond objective efficacy rates when considering treatment options for SUI (9). Despite superior cure rates with suburethral tapes, women may experience similar subjective benefits after injection therapy vs. surgery. Maybe QoL aspects (subjective parameters) are more important than leakage outcomes (objective parameters). The choice of therapy needs to take many factors (e.g. personal goals and expectations, success rates/complications/procedure of a treatment) into account and should involve considered discussion between patient and physician, with a comprehensive review of the available treatment options for SUI.

Our studies with NASHA/Dx copolymer and silicone microimplants make it evident that injection therapy can be proposed to any adult women with SUI. However, many clinicians would feel uncomfortable administering injection therapy to the very young individuals (18). Another possible new indication for injectables is recurrent stress urinary incontinence after surgery with any of the new suburethral tapes (32). 
Patient's interest will continue drive us away from surgery into minimally invasive therapies to restore functionality to diseased areas of the urologic system. The development of new UBA's is on-going and progressing, such as the use of muscle-derived stem cells which may lead to sphincter regeneration. Strasser et al (2008) suggested that SUI can be treated effectively with autologous myoblasts and fibroblasts injected into the rhabdosphincter and urethral submucosa by transurethral ultrasound guidance, respectively. At the moment the results seem durable $(33,34)$. However, recently these results have been questioned $(35)$. Concerns about the ethical study approval and conduct of this study were observed. The study was conducted neither according to Austrian law nor according to the standards of the International Conference on Harmonisation of Good Clinical Practice. Therefore, this article has been withdrawn by The Lancet (36). In theory, the perfect injectable could be the optimal alternative for suburethral tapes.

\section{Conclusions}

According to results of these studies, injection therapy using these new delivery systems with NASHA/Dx copolymer (Zuidex ${ }^{\mathrm{TM}}$ system) and silicone microimplants (Macroplastique ${ }^{\circledR}$ Implantation System; MIS) showed a satisfactory efficacy, a good safety profile, an acceptable long term durability, and an improvement of QoL aspects for treating SUI in adult women. A possible main advantage of injection therapy is the good risk/benefit ratio. Therefore, injection therapy should have a place between pelvic floor muscle therapy and (more invasive) surgical interventions in an algorithm for treatment of SUI in adult women. 


\section{References}

1. Temml C, Haidinger G, Schmidbauer J, Schatzl G, Madersbacher S. Urinary incontinence in both sexes: prevalence rates and impact on quality of life and sexual life. Neurourol Urodyn 2000;19:259-71.

2. Monz B, Pons ME, Hampel C, Hunskaar S, Quail D, Samsioe G, Sykes D, Wagg A, Papanicolaou S. Patient-reported impact of urinary incontinence--results from treatment seeking women in 14 European countries. Maturitas 2005;52(suppl 2):S2434.

3. Sykes D, Castro R, Pons ME, Hampel C, Hunskaar S, Papanicolaou S, Quail D, Samsioe G, Voss S, Wagg A, Monz B. Characteristics of female outpatients with urinary incontinence participating in a 6-month observational study in 14 European countries. Maturitas 2005;52(suppl 2):S13-23.

4. Norton PA, MacDonald LD, Sedgwick PM, Stanton SL. Distress and delay associated with urinary incontinence, frequency, and urgency in women. BMJ 1988;297(6657):1187-9.

5. Hägglund D, Walker-Engström ML, Larsson G, Leppert J. Reasons why women with long-term urinary incontinence do not seek professional help: a cross-sectional population-based cohort study. Int Urogynecol J Pelvic Floor Dysfunct 2003;14:296304.

6. Hay-Smith EJ, Dumoulin C. Pelvic floor muscle training versus no treatment, or inactive control treatments, for urinary incontinence in women. Cochrane Database Sits Rev 2006 Jan 25;(1):CD005654).

7. Wilson PD, Berghmans B, Hagen S, Hay-Smith J, Moore K, Nygaard I, Sinclair L, Yamanishi T, Wyman J, Dorey G. Adult conservative management. In: Abrams P, 
Cardozo L, Khoury S, Wein A, editors. Incontinence, $3^{\text {rd }}$ ed. Paris, France: Health Publications Ltd; 2005:855-964.

8. Berghmans LCM, Bernards ATM, Hendriks HJM, Bø K, Grupping MHM. Guidelines for the physiotherapeutic management of genuine stress incontinence. Physical Therapy Reviews 1998;3:133-147.

9. Chapple CR, Brubaker L, Haab F, van Kerrebroeck P, Robinson D. Patient-perceived outcomes in the treatment of stress urinary incontinence: focus on urethral injection therapy. Int Urogynecol J 2006, DOI 10.1007/s00192-006-0148-0.

10. Corcos J, Collet JP, Shapiro S, Herschorn S, Radomski SB, Schick E, Gajewski JB, Benedetti A, Macramallah E, and Hyams B. Multicenter randomized clinical trial comparing surgery and collagen injections for treatment of female stress urinary incontinence. J Urol 2005;65:898-904.

11. Maher CF, O’Reilly BA, Dwyer PL, Carey MP, Cornish A, Schluter P. Pubovaginal sling versus transurethral Macroplastique for stress urinary incontinence and intrinsic sphincter deficiency: a prospective randomised controlled trial. BJOG 2005;112:797801.

12. Meschia M, Pifarotti P, Bernasconi F, Guercio E, Maffiolini M, Magatti F. Spreafico L. Tension-free vaginal tape: analysis of outcomes and complications in 404 stress incontinent women. Int Urogynecol J Pelvic Floor Dysfunct 2001;12(Suppl 2):S24-7.

13. Olsson I, Kroon U. A three-year postoperative evaluation of tension-free vaginal tape. Gynecol Obstet Invest 1999;48:267-9.

14. Nilsson CG, Kuuva N, Falconer G, Rezapour M, Ulmsten U. Long-term results of the tension-free vaginal tape (TVT) procedure for surgical treatment of female stress urinary incontinence. Int Urogynecol J Pelvic Floor Dysfunct 2001;12(sppl 2):S5-8. 
15. Robinson D, Anders K, Cardozo L, et al. What do women want? Interpretation of the concept of cure. J Pelvic Surg Med 2003;9:273-7.

16. Herschorn S. Current role of injectable agents for female stress urinary incontinence. Can J Urol 2006;13 suppl 1:5-12.

17. Abrams P, Cardozo L, Fall M, Griffiths D, Rosier P, Ulmsten U, van Kerrebroeck P, Victor A, and Wein A. The standardization of terminology of lower urinary tract function. Neurourol Urodyn 2002;21:167-78.

18. Chapple CR, Wein AJ, Brubaker L, Dmochowski R, Espuna Pons M, Haab F, Hill S. Stress incontinence injection therapy: what is best for our patients? Eur Urol 2005;48:552-65

19. Ter Meulen PhH, Berghmans LCM, van Kerrebroeck PhEVA. Systematic review: Efficacy of silicone microimplants (Macroplastique ${ }^{\circledR}$ ) Therapy for stress urinary incontinence in adult women. Eur Urol 2003;44:573-82.

20. Van Kerrebroeck P, ter Meulen F, Larsson G, Farrelly E, Edwall L and FianuJonasson A. Efficacy and safety of a novel system (NASHA/Dx copolymer via the Implacer device) for the treatment of SUI. Urology. 64: 276-81, 2004.

21. Van Kerrebroeck P, ter Meulen F, Larsson G, Farrelly E, Edwall L and FianuJonasson A. NASHA/Dx gel (Zuidex ${ }^{\mathrm{TM}}$ ) for the treatment of stress urinary incontinence: results up to three years of follow-up. Submitted.

22. Van Kerrebroeck P, ter Meulen F, Larsson G, Farrelly E, Edwall L and FianuJonasson. A Treatment of stress urinary incontinence using a copolymer system: impact on quality of life. BJU 2004;94:1040-1043.

23. Ter Meulen PhH, Berghmans LCM, Nieman FHM, van Kerrebroeck PhEVA. Effects of Macroplastique ${ }^{\circledR}$ Implantation System for stress urinary incontinence and urethral hypermobility in women.Int Urogynecol J 2009;20:177-183. 
24. Spiera H. Scleroderma after silicone augmentation mammoplasty. JAMA 1986;260:236-238.

25. Varga J, Schumacher HR, Jiminez SA. Systemic sclerosis after augmentation mammoplasty with silicone implants. Ann Intern Med 1989;111:377-383.

26. Silver RM, Sahn EE, Allen JA, Sahn S, Greene W, Maize JC, Garen PD. Demonstration of silicone in sites of connective tissue disease in patients with silicone-gel breast implants. Arch Dermatol 1993;129:63-68.

27. Tinkler JB, Campbell HJ, Senior JM, Ludgate SM. Evidence for an association between the implantation of silicones and connective tissue disease. Medical Device Directorate (UK Department of Health) Report 1993; MDD/92/42:1-65.

28. Henly DR, Barrett DM, Weiland TL, O’Connor MK, Malizia AA, Wein AJ. Particulate silicone for use in periurethral injections: local tissue effects and search for migration. J Urol 1995;153:2039-2043.

29. Stenberg AM, Larsson G, Johnson P. Urethral injection for stress urinary incontinence: long-term results with dextranomer/hyaluronic acid copolymer. Int Urogynecol J Pelvic Floor Dysfunct 2003;14:335-338.

30. Berman CJ, Kreder KJ. Comparative cost analysis of collagen injection and fascia lata sling cystourethropexy for the treatment of type 3 incontinence in women. J Urol $1997 ; 157: 122-4$.

31. Oremus M, Collet J, Shapiro S, Penrod J, Corcos J. Surgery versus collagen for female stress urinary incontinence economic assessment in Ontario and Quebec. Can J Urol 2003;10:1934-44.

32. Van Kerrebroeck PhEVA, Corcos J. The motion: injectables are justified as a first option for stress urinary incontinence. Eur Urol 2006;50:857-860. 
33. Mitterberger M, Pinggera GM, Marksteiner R, Margreiter E, Fussenegger M, Frauscher F, Ulmer H, Hering S, Bartsch G, Strasser H. Adult stem cell therapy of female stress urinary incontinence. Eur Urol 2008;53:169-175.

34. Strasser H, Marksteiner R, Margreiter E, Pinggera GM, Mitterberger M, Frauscher F, Ulmer H, Fussenegger M, Kofler K, Bratsch G. Autologuos myoblasts and fibroblasts versus collagen for treatment of stress urinary incontinence in women: a randomised controlled trial. Lancet 2007;369:2179-2186.

35. Expression of concern - Autologuos myoblasts and fibroblasts versus collagen for treatment of stress urinary incontinence in women: a randomised controlled trial. The Editors of the Lancet. Lancet 2008;371:1490.

36. Retraction - Autologuos myoblasts and fibroblasts versus collagen for treatment of stress urinary incontinence in women: a randomised controlled trial. Kleinert S, Horton R. Lancet 2008;372:789-790. 


\section{Chapter 9}

\section{Summary}

This thesis focuses on the efficacy, safety, and durability of urethral bulking agents (UBA's) using new techniques of transurethral injection as a minimally invasive procedure to treat stress urinary incontinence (SUI) in adult women and to assess its place in a treatment algorithm of SUI including quality of life aspects.

SUI is prevalent in adult women and has a considerable impact on quality of life. However, it often remains undiagnosed and therefore untreated. Treatment options for SUI are lifestyle modifications (losing weight, quitting smoking, regulating fluid intake), pelvic floor muscle training (PFMT), minimally invasive devices, pharmacotherapy, urethral injection and surgery. In a treatment algorithm of SUI, PFMT in association with lifestyle modifications is the first choice before further interventions for SUI. If PFMT fails or has unsatisfactory result, invasive treatment modalities can be proposed. Surgical intervention is widely considered as the most effective option for SUI, although it is not suitable for all patients. Another option is injection therapy with UBA's but this is generally associated with a lower objective cure rate compared to surgery. Although Quality of life (QoL) improvements are similar for both treatments. Most patients with SUI prefer less invasive therapy with a lower risk of complications, even if the chance of cure may be lower than with more invasive procedures. Therefore, a focus on patient's wishes and expectations with respect to success and risks is required. From the patient perspective it could be speculated that the lower cure rate may be of less importance when weighted against the potential complications. With this information injection therapy can have an important place in a treatment algorithm of SUI.

After an introduction in chapter 1, chapter 2 presents a general review of injection therapy with different UBA's for SUI in adult women. Many different UBA's have been used, although the ideal one remains to be discovered. In general, injection therapy was offered to 
frail elderly women, obese individuals, previously operated patients and patients unwilling or unfit to undergo more invasive surgery. UBA's were usually used for intrinsic sphincter deficiency (ISD) related SUI, although there is good evidence that women with (concomitant) urethral hypermobility respond similarly. Nowadays, more and more we are leaving the simple concept of a dichotomy between ISD and urethral hypermobility as causes for or associations with SUI. The safety and durability of various UBA's remain a concern. No differences in UBA's from an efficacy point of view have been found. Different injection techniques of UBA's, endoscopic and non-endoscopic administration (blind injection using a guiding instrument), have been used. The recent development of two devices for blind injection (the Implacer ${ }^{\mathrm{TM}}$ and Macroplastique ${ }^{\circledR}$ Implantation Device) has increased the speed and convenience of urethral injection, removing the need for surgical facilities.

Chapter 3, 4 and 5 show the efficacy, safety, durability and QoL data of non-animal stabilized hyaluronic acid/dextranomer (NASHA/Dx; Zuidex ${ }^{\mathrm{TM}}$ ) copolymer used for transurethral injection with a new guiding instrument (the Implacer ${ }^{\mathrm{TM}}$ ) for stress urinary incontinence (ISD and/or urethral hypermobility) in adult women. $76 \%$ of forty-two invasive therapy-naive women showed improvement of leakage at 3 and 12 months post treatment. Statistically significant reductions in median urine leakage and in the median number of incontinence episodes in 24 hours were observed. Between 12 and 36 months little deterioration in these efficacy parameters were observed. Significant improvements of QoL measurements were observed in 7 of ten King's Health Questionnaire (KHQ) domains at 12 months, and 6 of ten at 36 months. This study showed statistically significant improvement in subjective and objective measurements and sustained for at least 36 months.

Before we started with our randomised clinical trial (RCT) of another UBA, silicone microimplants (Macroplastique ${ }^{\circledR}$ ), we performed a systematic review about the efficacy of this UBA for SUI in adult women described in chapter six. Only two RCTs, only published as 
an abstract, were found. Eleven pre-experimental or observational studies were identified. Overall, the methodological quality of included studied was low. The main methodological shortcomings of the studies were no random allocation procedure, lack of prestratification on prognostic determinants, no blinding, small sample sizes, and lack of proper analysis and presentation of results. There was variability in the indication for implantation, implantation procedure, rate and volume of silicone microimplants. The use of different outcome measures in most of the trials made comparison between studies difficult. Therefore, at that time results should be interpreted with caution and no firm conclusions about the efficacy of this UBA were possible. Lack of methodological quality still is a general problem in most studies investigating effects of UBA's for SUI in adult women. RCT's, using valid and reliable subjective and objective measurements, are necessary to establish the efficacy of injection therapy with UBA's in treating SUI in adult women.

In chapter 7 we describe the first RCT comparing Macroplastique ${ }^{\circledR}$ injection(s) utilizing the Macroplastique ${ }^{\circledR}$ Implantation Device with a control pelvic floor muscle exercises home training program in adult women with urodynamic SUI and urethral hypermobility after nonsuccessful conservative treatment. All subjective and objective measurements showed a more pronounced statistically significant improvement in the Macroplastique group. Only the results of the pad test were not statistically significant between groups at 3 months, although the pad test showed improvement in both groups. The number of women that was cured or markedly improved in the Macroplastique group at three months $(\mathrm{N}=17 ; 70.8 \%)$ was statistically significantly higher than in the control group $(\mathrm{N}=6 ; 28.5 \%)$. The increase of the overall score and subscale scores of I-Qol in the Macroplastique group was significantly higher compared to the control group. The subjective and objective improvements in Macroplastique group at 3 months are sustained at 12 months. 
The overall safety of these two UBA's, NASHA/Dx copolymer and silicone microimplants, was acceptable in these studies. Both systems, the Zuidex ${ }^{\mathrm{TM}}$ system and the Macroplastique ${ }^{\circledR}$ Implantation System (MIS), were well tolerated by the female patients treated as minimal invasive procedure and were easy to use by the operator. NASHA/Dx copolymer was administered under local or general anaesthesia and silicone microimplants only under local anesthesia. Adverse events were usually mild and uncommon, often self-limiting and easily managed. In one patient a pseudocyst developed after NASHA/Dx copolymer injection and could be resolved with simple fluid aspiration.

According to results of these studies, injection therapy using these new delivery systems with NASHA/Dx copolymer (Zuidex ${ }^{\mathrm{TM}}$ system) and silicone microimplants (Macroplastique ${ }^{\circledR}$ Implantation System; MIS) showed a satisfactory efficacy, a good safety profile, an acceptable long term durability, and an improvement of QoL aspects for treating SUI in adult women. A possible main advantage of injection therapy is the good risk/benefit ratio. Therefore, injection therapy should have a place between pelvic floor muscle therapy and (more invasive) surgical interventions in an algorithm for treatment of SUI in adult women. 


\section{Chapter 10}

\section{Nederlandse samenvatting}

Dit proefschrift gaat over de effectiviteit, veiligheid en duurzaamheid van 'urethral bulking agents' (UBA's) waarbij nieuwe transurethrale injectietechnieken werden gebruikt als een minimaal invasieve procedure voor de behandeling van stress urine incontinentie (SUI) bij volwassen vrouwen. Verder werd ook gekeken naar de invloed van deze behandeling op 'kwaliteit van leven' aspecten en wat de plaats van deze behandeling is in het behandelalgoritme van SUI.

SUI komt veel voor bij volwassen vrouwen en heeft een aanzienlijke invloed op de kwaliteit van leven. Vaak gaan vrouwen met SUI niet naar de dokter omdat ze het in veel gevallen beschouwen als een onontkoombaar element van het ouder worden, omdat ze zich ervoor schamen, en/of omdat ze het idee hebben dat het onbehandelbaar is. Een mogelijke behandeling blijft hierdoor vaak achterwege. Behandelopties voor SUI zijn aanpassingen van de levensstijl (gewichtsreductie, stoppen met roken, gereguleerde vochtiname), bekkenbodemspieroefeningen, farmacotherapie, transurethrale injectie, en chirurgie. In het behandelalgoritme van SUI zijn bekkenbodemspieroefeningen in combinatie met aanpassingen van de levensstijl de eerste keuze. Als bekkenbodemspieroefeningen geen succes of onvoldoende resultaat hebben, kunnen invasieve behandelmogelijkheden worden voorgesteld. Chirurgie wordt gezien als de meest effectieve behandeling voor SUI, maar is niet geschikt voor alle vrouwen. Een andere mogelijkheid is injectietherapie met UBA's maar deze behandeling wordt over het algemeen geassocieerd met een lager objectief genezingspercentage in vergelijking met chirurgie. Toch laat de verbetering van 'kwaliteit van leven' aspecten gelijkwaardige resultaten zien voor beide behandelingen. De meeste vrouwen met SUI geven de voorkeur aan een minder invasieve behandeling met een lager risico op complicaties, ook al is de kans op genezing lager in vergelijking met meer invasieve 
behandelingen. Daarom is het belangrijk dat er wordt gekeken naar de wensen en verwachtingen van vrouwen ten aanzien van succes- en complicatiepercentages van de verschillende behandelmogelijkheden. Het lijkt er op dat vrouwen eerder een behandeling accepteren met een lager genezingspercentage en minder complicaties dan het omgekeerde. Op basis hiervan kan injectietherapie een belangrijke plaats in het behandelalgoritme van SUI innemen.

$\mathrm{Na}$ een introductie in hoofdstuk 1, laat hoofdstuk 2 een algemeen overzicht van injectietherapie met verschillende UBA's voor SUI bij vrouwen zien. Verschillende UBA's zijn al in gebruik zonder dat de ideale UBA reeds geïdentificeerd is. In het algemeen werd injectietherapie toegepast bij oudere of obese vrouwen, of bij vrouwen die reeds eerder voor SUI geopereerd werden. Andere doelgroepen waren vrouwen die geen chirurgie wilden ondergaan of niet gezond genoeg waren voor meer invasieve chirurgie. Verder was injectietherapie met UBA's doorgaans geïndiceerd voor SUI gerelateerd aan intrinsieke sphincter deficiëntie (ISD). Uit recentere literatuur blijkt echter dat vrouwen met SUI veroorzaakt door een (gelijktijdig) bestaande urethrale hypermobiliteit even goed reageerden. Tegenwoordig wordt meer en meer het concept van een dichotomie tussen ISD en urethrale hypermobiliteit als oorzaak voor of associaties met SUI verlaten.

Veiligheid en duurzaamheid van UBA's blijven een punt van zorg. Tot nu toe is geen verschil in effectiviteit tussen de verschillende UBA's gebleken. Verschillende injectietechnieken van UBA's, endoscopische en niet-endoscopische toediening (blinde injectie met gebruik van een speciaal daarvoor ontwikkeld instrument), worden gebruikt. Recent zijn twee apparaten voor blinde injectie op de markt gekomen (de Implacer ${ }^{\mathrm{TM}}$ en Macroplastique ${ }^{\circledR}$ Implantation Device). De procedures met deze apparaten kunnen sneller en makkelijker worden toegepast zonder noodzaak van chirurgische faciliteiten. 
De hoofdstukken 3,4 en 5 geven de resultaten van effectiviteit, veiligheid, duurzaamheid en 'kwaliteit van leven' bij gebruik van 'non-animal stabilized hyaluronic acid/dextranomer (NASHA/Dx; Zuidex ${ }^{\mathrm{TM}}$ ) copolymer' voor transurethrale injectie gebruikmakend van de Implacer ${ }^{\mathrm{TM}}$ voor ISD en/of urethrale hypermobiliteit gerelateerde SUI bij volwassen vrouwen. $76 \%$ van de 42 niet eerder invasief behandelde vrouwen laten een verbetering van de urinelekkage op 3 en 12 maanden na behandeling zien. Er was een statistisch significante reductie van de mediane urinelekkage en het mediane aantal incontinentie episodes per 24 uur. Er was slechts een kleine vermindering van de effectiviteit tussen 12 en 36 maanden. Ook werden statistisch significante verbeteringen van 'kwaliteit van leven' metingen in 7 van de 10 King's Health Questionnaire (KHQ) domeinen na 12 maanden, en 6 van de 10 na 36 maanden gezien. Er was dus sprake van een statistisch significante verbetering van zowel subjectieve als objectieve metingen persisterend voor tenminste 36 maanden. Voor aanvang met de gerandomiseerde klinische trial (RCT) met betrekking tot Macroplastique ${ }^{\circledR}$, een ander UBA van siliconen elastomeren, werd een systematische review over de effectiviteit van deze UBA voor SUI bij vrouwen verricht. Deze review is beschreven in hoofdstuk 6. Slechts twee RCT's, gepubliceerd als abstract, en elf pre-experimentele of observationele studies werden gevonden. Over het geheel was de methodologische kwaliteit van de geïncludeerde studies laag. De belangrijkste methodologische beperkingen van deze studies waren: geen randomisatie procedure, ontoereikende prestratificatie op prognostische determinanten, geen blindering, kleine aantallen, en ontoereikende analyse en presentatie van resultaten. Verder was sprake van variatie in de indicatie voor implantatie, de implantatie procedure en het aantal en volume van siliconen micro-implantaten. Het gebruik van verschillende uitkomstmetingen in de meeste van deze studies maken vergelijking tussen de studies moeilijk. Ten tijde van publicatie van de review werd geconcludeerd de resultaten met 
voorzichtigheid te interpreteren en vooralsnog geen harde conclusies te trekken over de effectiviteit van deze UBA.

Überhaupt is de gebrekkige methodologische kwaliteit nog steeds een probleem in de meeste studies over effecten van UBA's voor SUI bij vrouwen. Uit de review bleek de noodzaak voor RCT's, waarbij gebruik wordt gemaakt van valide en betrouwbare subjectieve en objectieve metingen, om de effectiviteit van injectietherapie met UBA's als behandeling van SUI bij vrouwen vast te stellen.

In hoofdstuk 7 wordt een RCT beschreven waarbij voor het eerst een groep vrouwen met urodynamische SUI en urethrale hypermobiliteit, na een niet-succesvolle conservatieve behandeling behandeld met Macroplastique ${ }^{\circledR}$ injectie(s) gebruikmakend van de Macroplastique ${ }^{\circledR}$ Implantation Device, vergeleken wordt met een controlegroep die alleen maar bekkenbodemspieroefeningen voor thuis deden. Alle subjectieve en objectieve metingen lieten een meer uitgesproken statistisch significante verbetering zien in de Macroplastique groep. Alleen de resultaten van de pad test waren niet statistisch significant tussen de twee groepen na 3 maanden, terwijl de test wel een significante verbetering in beide groepen liet zien. Het aantal vrouwen dat genezen of duidelijke verbeterd was in de Macroplastique groep $(\mathrm{N}=17 ; 70.8 \%)$ bleek statistisch significant hoger dan in de controlegroep $(\mathrm{N}=6 ; 28.5 \%)$ na 3 maanden. De toename van de totaal score en afgeleide scores van de incontinentie-' $k$ waliteit van leven' vragen (I-Qol questionnaire) in de Macroplastique groep was significant hoger dan in de controlegroep. De subjectieve en objectieve verbeteringen in de Macroplastique groep na 3 maanden persisteren ook na 12 maanden.

Veiligheid van de twee bestudeerde UBA's, NASHA/Dx copolymer en siliconen microimplantaten, was acceptabel. Het Zuidex ${ }^{\mathrm{TM}}$ systeem en het Macroplastique ${ }^{\circledR}$ Implantatie Systeem werden als minimaal invasieve systemen goed verdragen door de deelnemende vrouwen en waren makkelijk te gebruiken door de operateur. NASHA/Dx copolymer werd 
toegediend onder locale of algemene anesthesie en siliconen micro-implantaten alleen onder locale anesthesie. Bijwerkingen waren over het algemeen mild, vaak zelflimiterend en makkelijk behandelbaar. Bij één vrouw ontstond een pseudo-cyste na NASHA/Dx copolymer injectie. Deze werd eenvoudig behandeld met behulp van vloeistofaspiratie.

Volgens de resultaten van beide studies laat injectietherapie met de genoemde systemen als behandeling voor SUI bij volwassen vrouwen een redelijke effectiviteit, een goed veiligheidsprofiel, een acceptabele lange termijn duurzaamheid, en een verbetering in 'kwaliteit van leven' aspecten zien. Een mogelijk belangrijk voordeel van injectietherapie is de goede verhouding tussen succes en risico van de behandeling. Daarmee dient injectietherapie een plaats te hebben tussen bekkenbodemspieroefeningen en (meer invasieve) chirurgische interventies in het behandelalgoritme voor SUI bij volwassen vrouwen. 


\section{Dankwoord}

Zonder de hulp van vele mensen was dit proefschrift niet tot stand gekomen. Een aantal van hen wil ik in het bijzonder noemen en bedanken.

Allereerst wil ik de vrouwen bedanken die aan het onderzoek hebben willen meewerken.

Prof.dr.Ph.E.V.A. van Kerrebroeck. Beste Philip, bedankt voor de "injectie" die geleid heeft tot interesse in de bekkenbodem problematiek, met als direct gevolg de mogelijkheid van het kunnen doen van dit onderzoek. Verder veel dank voor de begeleiding. Het heeft lang geduurd, maar het is ons gelukt.

Dr.L.C.M. Berghmans. Beste Bary, onze besprekingen waren enerverend en confronterend. Dit heeft belangrijk bijgedragen in het verdere proces van dit onderzoek en ook in het schrijven van dit proefschrift. Je energie, enthousiasme en gedrevenheid zijn van wezenlijke invloed geweest. Bedankt.

Dr.F.H.M. Nieman. Dank voor uw hulp en geven van inzicht in de medische statistiek. Marieke Dormans van Uroplasty en de medewerkers van Q-Med wil ik bedanken voor de prettige samenwerking. Ook de voormalige assistenten urologie in het AZM, inmiddels urologen: Bas Sebregts, Wout Scheepers, Otto Stroosma, Enrico Dassen, en Dries Sonneveld (was al uroloog), wil ik bedanken voor de prettige samenwerking. Het personeel van de polikliniek, de behandelkamer en het secretariaat urologie in het AZM wil ik danken voor de noodzakelijke hulp. Verder dank ik Cindy Botty voor de hulp in het formele proces tot promotie.

Nogmaals bedankt, ook diegenen die ik niet genoemd heb. 


\section{Curriculum Vitae}

Flip (Philip Hendrik) ter Meulen werd geboren in Delft op 30 maart 1964. In 1983 behaalde hij het Atheneum B diploma aan het Atheneum "De Munnik" in Utrecht. Na het vervullen van zijn militaire dienstplicht, begon hij in 1986 met de studie geneeskunde aan de Erasmus Universiteit in Rotterdam. Op 20 november 1992 behaalde hij het artsexamen. Vervolgens was hij werkzaam als agnio chirurgie en urologie in het Ruwaard van Putten ziekenhuis in Spijkenisse, het De Wever ziekenhuis in Heerlen en het academisch ziekenhuis in Maastricht. In 1998 startte hij met de vooropleiding chirurgie bij dr. W.J. Prakken in het Diaconessenhuis in Eindhoven en in het jaar 2000, startte hij met de opleiding urologie bij dr.K.P.J. Delaere in het Atrium Medisch Centrum in Heerlen. Vervolgens werden de drie academische jaren voortgezet bij prof.dr.Ph.E.V.A. van Kerrebroeck in het academisch ziekenhuis Maastricht.

Op 1-1-2004 werd hij geregistreerd als uroloog in het MRSC. Sinds die datum is hij werkzaam als uroloog in het Orbis Medisch Centrum (voorheen Maasland ziekenhuis) in Sittard-Geleen.

Hij is getrouwd met Gaby Reuvers en heeft 3 kinderen. 